\title{
Herramientas Didácticas para la Formación Agroforestal
}

\section{Volumen 5}

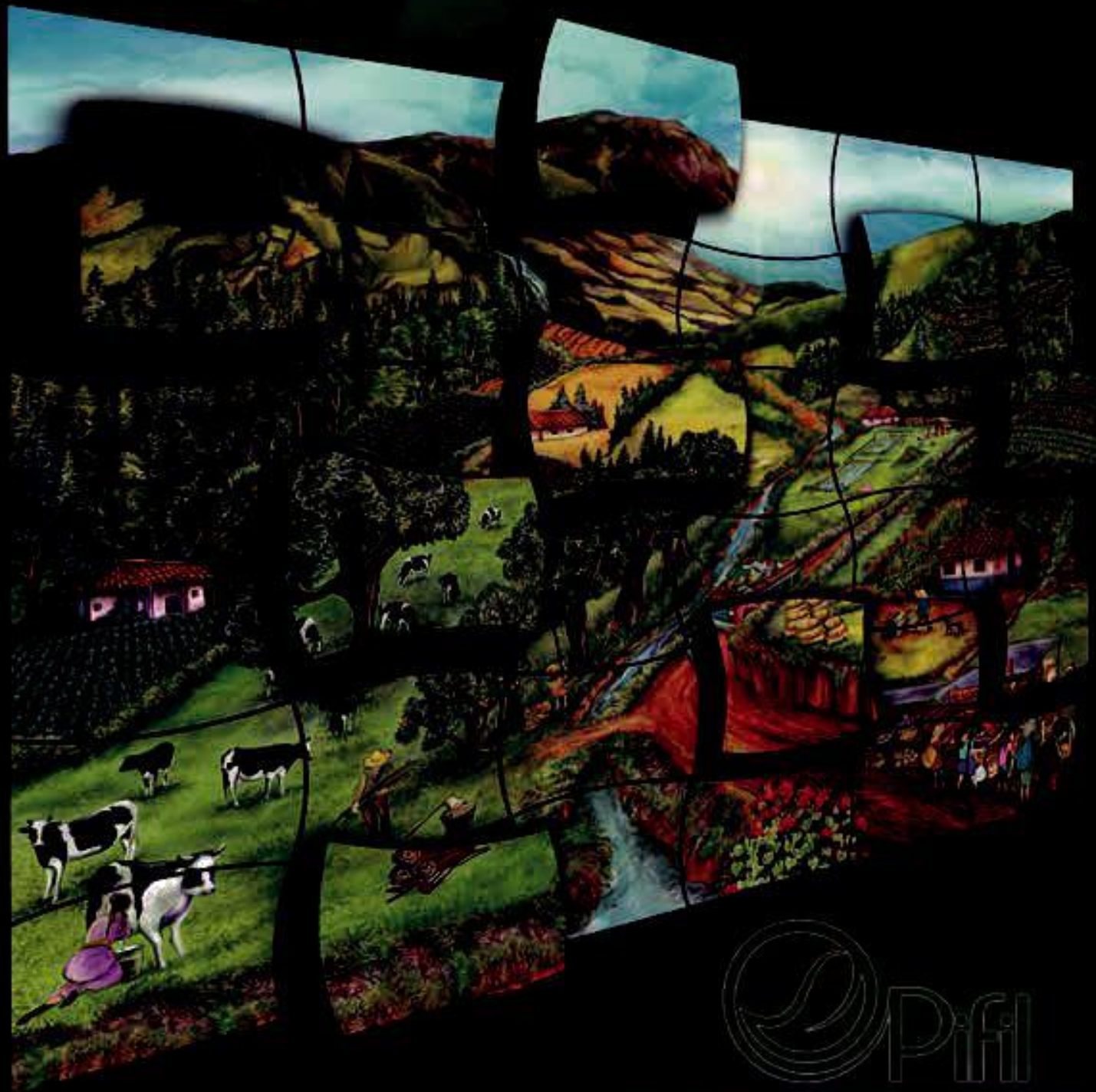

PI AN DI INVISIKGACION PAKA II. IORLAIICIMIISIO

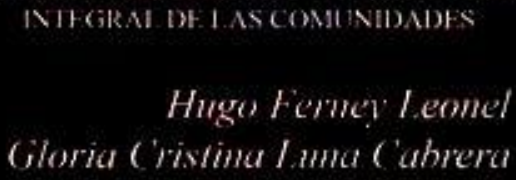

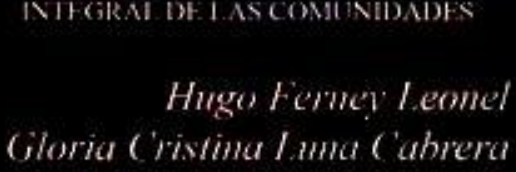

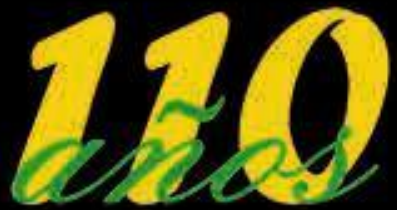





\section{SERIE DE LIBROS:}

\section{“Producción Investigativa UdeNar" Volúmen 5}

La serie de libros sobre "Producción Investigativa UdeNar" tiene como propósito la divulgación de los resultados de la investigación de todas las áreas del conocimiento, realizada por los profesores investigadores de la Universidad de Nariño pertenecientes a grupos de investigación escalafonados por COLCIENCIAS. Las investigaciones deben haberse termi-nado en los últimos cinco (5) años, previos a la convocatoria anual realizada por el Comité de Investigaciones.

Las convocatorias iniciadas en el mes de Agosto de 2014, emitidas con motivo de la celebración de los 110 años de fundación de la Universidad de Nariño y oficializadas mediante Acuerdo No. 035 de Agosto 4 de 2014 del Comité de Investigaciones, reconocen y divulgan la calidad investigativa de un máximo de 10 libros o libros conformados por capítulos, que cumplen con los requisitos establecidos en cada convocatoria y que además cuentan con dos evaluaciones positivas de pares académicos externos.

\section{VOLUMENES PUBLICADOS EN ESTA SERIE}

1. Bastidas A, Jesús Alirio. (2016). La educación inicial de los profesores de lenguas extranjeras, un proyecto basado en lineamientos del currículo. Pasto, Col.: Editorial Universidad de Nariño. ISBN: 978-958-8609-97-3.

2.

Isabel Goyes Moreno - Mónica Hidalgo Oviedo (2016) Docentes investigadoras Universidad de Nariño, directora e integrante del grupo de investigación “Derecho, Justicia y Región”..Principios y Riesgos Laborales Pasto, Col.: Editorial Universidad de Nariño. ISBN: 978-958-8958-07-1.

3. Gema Lucía Zambrano Burbano - Yohana Melissa Eraso Cabrera - William Orlando Burgos Paz - Carlos Eugenio Solarte Portilla - Iván Fernando Caviedes Castro - Carol Yovanna Rosero Galindo - Paula Andrea Escobar Zambrano Diana Milena David Martínez - Jackeline Recalde Morillo - Álvaro Javier Burgos Arcos (2016). Hacia el Bovino Lechero del Trópico Alto de Nariño: un enfoque desde el mejoramiento genético animal. Pasto, Col.: Editorial Universidad de Nariño. ISBN: 978-958-8958-08-8

4. Ricardo Timarán Pereira, Ph.D.(2016) Detección de Patrones de Muertes por causa externa con técnicas de minería de datos en el Observatorio del Delito del Municipio de Pasto.

Pasto, Col.: Editorial Universidad de Nariño. ISBN: 978-958-8958-00-2

5. Hugo Ferney Leonel, PhD. Gloria Cristina Luna Cabrera, M.Sc.(2016) Herramientas Didácticas para la Formación Agroforestal.

Pasto, Col.: Editorial Universidad de Nariño. ISBN: 978-958-8958-11-8
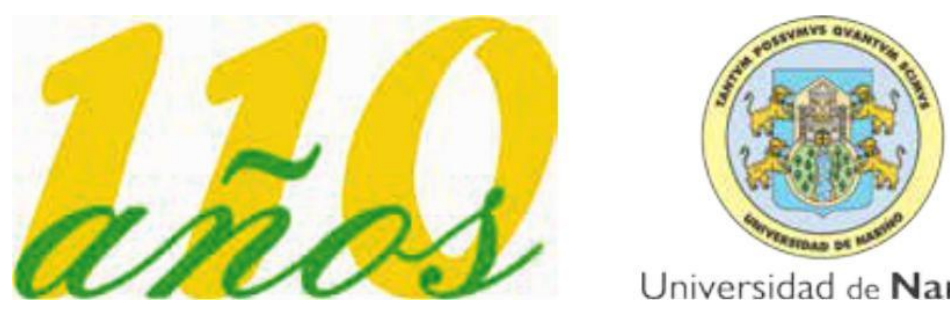



\section{Herramientas Didácticas Formación Agroforestal}





\title{
Herramientas Didácticas Formación Agroforestal
}

\author{
Hugo Ferney Leonel PhD. \\ Gloria Cristina Luna Cabrera M.Sc
}

Facultad de Ciencias Agrícolas

Universidad de Nariño

(Colombia) San Juán de Pasto

2016 


\section{Leonel, Hugo Ferney}

Herramientas didácticas para la formación agroforestal / Hugo Ferney Leonel y Gloria Cristina Luna Cabrera / San Juan de Pasto: $1^{\text {a }}$. Ed.- Editorial Universitaria - Universidad de Nariño - Grupo de Investigación PIFIL, Departamento de Recursos Naturales y Sistemas Agroforestales, 2016

124 pág.- il.- Serie Producción Investigativa

"UdeNar". v. 5.- Incluye Bibliografía.-

ISBN: 978-958-8958-11-8

1. Agroforestaría - Herramientas Didácticas. 2. Desarrollo Agroforestal Procesos Participativos. 3. Sistemas Agroforestales - Investigaciones.

\subsection{L583}

SCDD- Ed. 21

Biblioteca Alberto Quijano Guerrero

Departamento de Recursos Naturales y Sistemas Agroforestales

Universidad de Nariño (Colombia)

CEditorial Universitaria - Universidad de Nariño

Autores: HUGO FERNEY LEONEL, GLORIA CRISTINA LUNA CABRERA

ISBN Impreso: 978-958-8958-11-8

ISBN Digital: 978-958-8958-19-4

Número de edición: 1a Edición

Diseño de cubierta:Angie Lagos

Corrección de estilo:Miguel Angel Viveros

Indización:Viñeta Publicidad

Diagramación, impresión y terminación:Viñeta Publicidad

Impreso y hecho en Colombia / Printed and made in Colombia

Prohibida la reproducción total o parcial, por cualquier medio o con cualquier propósito, sin la autorización escrita de sus autores: HUGO FERNEY LEONEL, GLORIA CRISTINA LUNA CABRERA 


\title{
AGRADECIMIENTOS
}

\author{
Universidad de Nariño \\ Vicerrectoría de Investigaciones, Posgrados y Relaciones \\ Internacionales - VIPRI \\ Facultad de Ciencias Agrícolas \\ Departamento de Recursos Naturales \\ y Sistemas Agroforestales \\ Investigadores colaboradores \\ Hernán Rivas, Ángela León, Angela Molina, \\ Sandra Timaná, Alvaro Cadena, Iván Delgado
Diseño gráfico
Diego Mejía
Angie Lagos
Harold Ocaña \\ Licenciados en informática \\ Darío Fernando Bolaños \\ Sandra Carolina Timaná \\ Johny Alexander Carlosama

\section{Comunidad educativa} \\ Institución Educativa Municipal Mocondino \\ Institución Educativa Municipal Cabrera

\section{Comunidad rural} \\ Veredas Marqueza Alta y San Felipe, \\ Departamento de Nariño
}





\section{PRÓLOGO}

"Una verdad incómoda", es el nombre de una película documental acerca de la campaña del ex vicepresidente de los Estado Unidos Al Gore para educar a los ciudadanos sobre el calentamiento global. Su objetivo es sensibilizar a la población del daño causado a la capa de ozono por la contaminación y su incidencia en el cambio climático que trae como consecuencia una serie de desastres naturales como descongelamiento que podrían ocasionar la desa-parición de muchas ciudades costeras del mundo y disminución de las reservas de agua dulce, entre otras.

En Colombia el Sistema de Monitoreo de Bosques y Carbono del Instituto de Hidrología, Meteorología y Estudios Ambientales (IDEAM) y el Minis-terio de Ambiente y Desarrollo Sostenible, reportan que la deforestación se sigue concentrando en la Amazonia, con el 45\% del total nacional, y la región Andina, con el 24\%. De continuar así, en el año 2040, el aumento promedio anual de la temperatura será de $1,4^{\circ} \mathrm{C}$ y podría haber un descenso de un $20 \%$ en la precipitación media anual, situación que repercutiría fuertemente en la producción agrícola. Un total de 140.356 hectáreas deforestadas fueron registradas en 2014 como consecuencia de la minería y la tala ilegal, la conversión de bosques en pastizales para ganadería y agricultura, los incendios forestales y los cultivos ilícitos. Se presentó un incremento del $16 \%$ en comparación con 2013, cuando se registraron 120.934 hectáreas deforestadas.

Por lo expuesto anteriormente es perentorio tomar medidas ambientales para disminuir el calentamiento global y tomar la iniciativa de no contaminar el planeta tierra. Ante la creciente probabilidad de cambio climático severo, es necesario la adopción de enfoques proactivos hacia el desarrollo sostenible, en este sentido la Agroforestería al combinar especies vegetales perennes multipropósitos con el componente agrícola y/o pecuario se constituye como una adecuada alternativa para la conservación de recursos naturales. Sin embargo, es necesario aumentar el conocimiento y la difusión de experiencias relacionadas con este tema, con el fin de que los encargados de diseñar la política de conservación de recursos naturales los contemplen en sus planes, programas y proyectos y contribuir con su promoción y adopción.

En consecuencia con lo anterior, la Universidad de Nariño por intermedio de los docentes Hugo Ferney Leonel y Gloria Cristina Luna Cabrera pertene- 
cientes al grupo de investigación PIFIL, dan a conocer mediante el presente libro "Herramientas didácticas para la formación agroforestal" el resultado de un número considerable de sus investigaciones sobre proyección comunitaria y que permitieron idear una metodología totalmente práctica basada en la lúdica y cuyos productos se plasman en el software educativo "Mundo Agroforestal" y el " Material Didáctico de Agroforestería". stas herramientas deben ser tema de consulta prioritaria por los docentes que tienen a su cargo la enseñanza de la Agroforestería, entre otras áreas del conocimiento relacionadas con el manejo agrícola y ambiental; además, de otros agentes de extensión del sector agropecuario.

De esta manera los autores contribuyen a la generación de estrategias de solución de unos de los mayores problemas de la humanidad relacionada con la degradación de los recursos naturales con las consecuencias que esto acarrea a la población.

Jairo Muñoz Hoyos

Exrector Universidad de Nariño

Fundador grupo de investigación PIFIL

Abril de 2016 


\section{RESEÑA}

Como resultado de los trabajos de investigación por más de diez años del grupo Plan de Investigación para el Fortalecimiento Integral de las Comunidades - PIFIL, en el libro "Herramientas didácticas para la formación agroforestal", se evidencian las lecciones aprendidas en el diseño y uso de herramientas didácticas para la formación de comu-nidades rurales; destacándose el material didáctico manual y digital agroforestal, como innovadores en la implementación de las tecnologías de la información y la comunicación - TIC que facilitan los procesos de enseñanza - aprendizaje para la aprehensión del conocimiento, consolidación del tejido social; fortalecimiento de la cohesión y cogestión que coadyuvan con el mejoramiento de los medios de vida y uso sustentable de los recursos naturales. 



\section{CONTENIDO}

INTRODUCCIÓN

1 CARACTERÍSTICAS RELEVANTES PARA EL 19 DESARROLLO DE HERRAMIENTAS DIDÁCTICAS

1.1 Características de los procesos de enseñanza aprendizaje $\quad 19$

1.2 Características de los procesos participativos 25

1.3 Características de los procesos investigativos 28

2. DISEÑO DE MATERIAL DIDÁCTICO MANUAL 31

$\begin{array}{lll}2.1 & \text { Generalidades } & 31\end{array}$

2.2 Metodología 32

2.2.1 Área de estudio y características generales de la población participante 32

2.2.2 Método 32

2.3 Resultados $\quad 35$

2.3.1 Fase 1: Identificación de características relevantes para 35 el desarrollo de herramientas didácticas

2.3.2 Fase 2. Diseño y elaboración del material didáctico manual 42

3. DISEÑO DE MATERIAL DIDÁCTICO DIGITAL 83

$\begin{array}{lll}3.1 & \text { Generalidades } & 83\end{array}$

3.2 Metodología 90

3.2.1 Área de estudio y características generales de la población participante 90

3.2.2 Métodos 91

$\begin{array}{lll}3.3 & \text { Resultados } & 94\end{array}$

3.3.1 Evaluación de conocimientos previos $\quad 94$

(Diagnóstico del conocimiento agroforestal)

3.3.2 Capacitación a los estudiantes sobre agroforestería 98

3.3.3 Diseño del Software educativo 99

4. LECCIONES APRENDIDAS 107

$\begin{array}{ll}\text { BIBLIOGRAFÍA } & 109\end{array}$

$\begin{array}{ll}\text { GLOSARIO } & 123\end{array}$ 


\section{LISTA DE FIGURAS}

1.1 Características relevantes para el diseño de 21 herramientas didácticas

1.2 Recorridos de campo que permiten la caracterización 22 biofísica y socioeconómica del área de estudio.

1.3 Ilustración de vivienda rural 23

1.4 Ilustración de personaje de la zona 24

1.5 Ruta Interdisciplinar para el diseño de material didáctico. 27

2.1 Ruta del proceso de investigación para el 33 material didáctico manual

2.2 Análisis de clúster. $\quad 40$

2.3 Diseño de logos $\quad 42$

2.4 Logo definitivo del material didáctico manual 43

2.5 Componentes del juego "Sendero del conocimiento" 46

2.6 Componentes del juego "Riqueza Ambiental" 53

2.7 Componentes del juego "ClasiSAF"

2.8 Componentes del juego "Arreglotón" 61

2.9 Componentes del juego "Planificando Ando" 68

2.10 Aplicación del material $\quad 82$

3.1 Relación de número de estudiantes por $\quad 90$ institución educativa y grado

3.2 Ruta metodológica para el diseño de $\quad 91$ Software Educativo Agroforestal

3.3 Elementos constitutivos en la estructuración del Software 92 Educativo Agroforestal-SEA

3.4 Participación y conocimientos, importancia del árbol en 94 sistemas productivos

3.5 Ele mentos integradores del conocimiento agroforestal 95

3.6 Menú principal del Software Educativo "Mundo Agroforestal" 102

3.7 Ventana diccionario del software educativo "Mundo Agroforestal" 102

3.8 Ventana agroforestería del software educativo 103

"Mundo Agroforestal"

3.9 Ventana juegos del software educativo "Mundo Agroforestal” 104

\section{LISTA DE TABLAS}




\section{INTRODUCCIÓN}

Hoy en día, el uso de las tecnologías de información y la comunicación TIC, juegan papel importante en los procesos de investigación, enseñan-zaaprendizaje, mejoramiento de los sistemas productivos, difusión de información; que al convertirse en medios de comunicación, brindan conocimientos técnicos y de identidad territorial; como herramientas didácticas eficaces para la formación de jóvenes y adultos.

Considerando que existen dificultades en la transferencia de conocimiento y adopción de sistemas agroforestales, así como limitadas herramientas que coadyuven con estos objetivos; los integrantes del grupo de investigación Plan de Investigación para el Fortalecimiento Integral de las Comunidades PIFIL, ha comprobado que el uso de las TIC, se convierten en un eje fundamental para los procesos de extensión rural, enseñanza-aprendizaje, innovación y transferencia de tecnología.

Mediante el diseño del software educativo "Mundo agroforestal" y el material didáctico de "Agroforestería", se han generado soluciones innovadoras y creativas con criterios técnicos de diseñadores profesionales, sociales y del sector agropecuario desde un enfoque interdisciplinar para el fortalecimiento, que contribuyen en desarrollo rural, a través de la aprehensión del conoci-miento agroforestal y en un futuro la adopción de estos sistemas de produc-ción sustentable.

Por ello, en el presente documento se evidencian los apartes más significativos del proceso de investigación adelantado con la financiación de la Vicerrectoría de Investigaciones, Postgrados y Relaciones Internacionales VIPRI de la Universidad de Nariño y ejecutada por el grupo de investigación PIFIL, adscrito a la Facultad de Ciencias Agrícolas - FACIA.

Con esta investigación, se ha logrado aunar esfuerzos, fortalecimiento de procesos comunicativos, participativos e interdisciplinares; articulación universidad-comunidad rural-instituciones del Estado y empresa mixta. Así mis-mo, se considera que este material didáctico, se convierte en un gran aporte a la Agroforestería y en especial a sus extensionistas; por cuanto, podría contri-buir en la apropiación social del conocimiento. 
El documento está organizado en cuatro capítulos: el primero está orientado a identificar las características relevantes para el desarrollo de herramientas didácticas; entre las que se destacan: el trabajo interdisciplinario; participación de diferentes actores, para este caso, comunidades rurales; procesos investigativos que permitan dar lectura de contexto y su articulación con los contenidos, gustos y preferencias (identidad territorial); así mismo, considera de importancia los procesos de sensibilización, que tienen que ver con los elementos motivacionales del ser; los lazos comunitarios o de consolidación del tejido social; y los procesos de enseñanza-aprendizaje orientados desde lo cognitivo y procedimental.

El segundo capítulo, aborda los elementos constitutivos para el diseño de material didáctico manual; en donde para la identidad del producto, se hace una descripción de la localización del área de estudio y de las características más relevantes de los habitantes de la vereda Marqueza Alta, ubicada en la microcuenca Miraflores, municipios de Tangua y Pasto; así mismo se explica metodológicamente como se logra el diseño a través de la categorización, selección de variables y la consolidación de cluster; factores relevantes para el diseño del logo del material, integrando los componentes fundamentales como cultivos, árboles y animales.

Para el diseño de los juegos, se describen dos aspectos fundamentales: los aportes realizados por el panel de expertos en agroforestería (grupo de profesionales de amplia experiencia y trayectoria en el tema); y el diagnóstico de percepción sobre gustos, preferencias de juegos y uso del tiempo libre. Por otra parte, se hace alusión al contenido del material didáctico manual, que contempla cinco juegos: Sendero del conocimiento, Riqueza Ambiental, ClasiSAF, Arreglotón, y Planificando Ando.

Como contribución al conocimiento sobre la Ciencia Agroforestal, en este capítulo se dan algunos elementos teóricos y resultados de investigaciones en el campo de la agroforestería, que contribuyeron con el diseño de los cinco juegos; en tanto, permita que los extensionistas tengan claridad en las temáti-cas a tratar y puedan aprovechar de diferentes maneras el material didáctico; teniendo en cuenta, que este libro producto de investigación no tiene la pre-tensión de convertirse en un manual; sino por el contrario, en una herramienta que genere reflexión, incentive la creatividad y con ello lleve al lector a la innovación y desarrollo de nuevas TIC. 
En el capítulo tercero, se describe el diseño del software educativo "Mundo agroforestal" como una herramienta que brinda soluciones innovadoras, creativas, a partir de construcciones colectivas e intercambio de saberes y contextualizadas con una realidad rural desde lo natural, productivo, económico y sociocultural; transformada a la identidad del software educativo; con criterios técnicos desde un enfoque multidisciplinar y proceso investigativo, basado en el conocimiento agroforestal, gustos y preferencias de los jóvenes de las Instituciones Educativas Municipales de Mocondino y Cabrera, Pasto, Nariño.

En el último aparte se relacionan las principales lecciones aprendidas durante la experiencia del desarrollo de herramientas didácticas, resaltando aquellos aprendizajes significativos, orientadores, para adelantar procesos de formación de comunidades rurales, así como también, aquellos que marcan una clara directriz para los técnicos- extensionistas que deben asumir el rol de facilitadores de procesos de cambio en el sector rural.

Se agradece por la colaboración, apoyo y participación a los habitantes de la vereda Marqueza Alta; comunidad educativa de las instituciones municipales de Mocondino y Cabrera, Pasto, Nariño; equipo técnico, expertos en el tema agroforestal e investigadores del grupo PIFIL; y a la Vicerrectoría de Investi-gaciones, Postgrados y Relaciones Internacionales VIPRI de la Universidad de Nariño. 



\section{CARACTERÍSTICAS RELEVANTES PARA EL DESARROLLO DE HERRAMIENTAS DIDÁCTICAS}

\subsection{Características de los procesos de enseñanza aprendizaje}

Hoy en día, los procesos de enseñanza- aprendizaje se han mejorado con el uso de las Tecnologías de la Información y Comunicación (TIC). Costa y Dorrío (2010:462), plantean que las TIC, "juegan un papel importante en cualquier proceso de aprendizaje o investigación". Los niveles de calidad y efectividad en la educación científica no podrán ser llevados a cabo, sin un cambio en la forma en que tradicionalmente se orienta o direcciona el apren-dizaje (European Commision, 2007, citado por Costa y Dorrio, 2010).

En el sector educativo, se aprecia la necesidad de entender la capacidad de transformación y mejora de la educación a través de las TIC, en función de los usos efectivos que se hagan de éstas, de acuerdo a los propósitos y contextos específicos (Bustos y Román, 2011). La evaluación de proyectos de integración de TIC, está directamente relacionada con las metas propuestas en cada proyecto, los contextos de la población objetivo; los aspectos no previstos y además por la visión que los distintos actores (promotores, tutores, entes gubernamentales y docentes) poseen acerca de la relación pedago-gía-educación-tecnología (Moreno, et al., 2014).

Badia, et al. (2013), plantean cinco factores que influyen en el uso educativo de las TIC:

\footnotetext{
- $\quad$ Utilidad y entorno educativo de las TIC

- $\quad$ Apoyo docente en el uso de las TIC

- $\quad$ Experiencia auto-percibida del maestro en el uso educativo de las TIC

- $\quad$ Disponibilidad y acceso a las TIC en el aula

- $\quad$ Acceso a las TIC fuera del aula
}

Desde el enfoque antropológico, la discusión, va más allá del acceso y del uso de las TIC y se vincula con la vital importancia de tener claro, cómo es que lo sociocultural va incursionando en los procesos tecnológicos y qué factores, aspectos y actores influyen en ello; por ello, la aproximación teórica a estos cambios se ha dado desde enfoques planteados en los estudios de ciencia, tecnología- sociedad, sociedad - antropología (Acosta, 2014). Por otra parte, Escobar (2005:22), infiere que la tecnología no es sólo el resultado de una "nueva cuadrícula de control en el planeta" sino que también bosqueja un conjunto de "nuevas posibilidades para articulaciones potenciales entre los seres humanos la naturaleza y las máquinas". 
En este sentido, los docentes (orientadores) e investigadores, tienen la tarea de buscar procesos que conlleven a la construcción y aprehensión de conocimiento; por ello, las herramientas didácticas se convierten en una de las alternativas pedagógicas que permiten la motivación e interés de los diferentes actores, desde el punto de vista del contexto social, antropológico, tecno-lógico y natural. Por otra parte, el paradigma constructivista del aprendizaje, sugiere que el alumnado puede aprender mejor cuando está activamente implicado y realizando razonamientos y tareas próximas a las que realizan los científicos, guiados u orientados por el profesorado (Hodson, 1992; Gatt, 2003), en ese orden de ideas, la educación no debe centrarse únicamente en lo cognitivo, sino también, en proporcionar herramientas para que los estudiantes construyan su propio aprendizaje (Ruiz, et al., 2005 citado por Muñoz, et al., 2007), en donde los aspectos afectivo y emocional juegan un papel primordial.

Para asegurar el éxito de un aprendizaje valioso y de calidad, además de las herramientas didácticas, es necesario contar con aspectos afectivos y de acción (Leonel, et al., 2011); el cambio afectivo está relacionado con la con-ciencia sensorial, entendida como aquella que nos acerca a la experiencia de la realidad; por ello, la dimensión cognitiva no es suficiente para el cam-bio de valores y conductas, porque lo cognitivo es sólo una parte de la per-sonalidad humana (Fernández y López, 2008). La construcción intelectual, constituye un proceso umbral necesario para el aprendizaje, pero insuficiente para un cambio duradero. Goleman (2008), plantea que un cambio profundo requiere de la estructuración de los hábitos intelectuales, emocionales y de conductas más arraigados.

Los planteamientos anteriores y como estrategia metodológica para el diseño del software educativo "Mundo agroforestal" y material didáctico manual "Agroforestería", se consideraron aspectos cognitivos, afectivos y motiva-cionales (Figura 1.1); que permiten una mayor participación de la comunidad en cada una de las etapas del desarrollo de estos, mejorando los procesos de aprendizajes significativos y de autogestión. 
Figura 1. 1 Características relevantes para el diseño de herramientas

didácticas Fuente: Este estudio

\section{PARTICIPACIÓN COMUNIDADES RURALES}

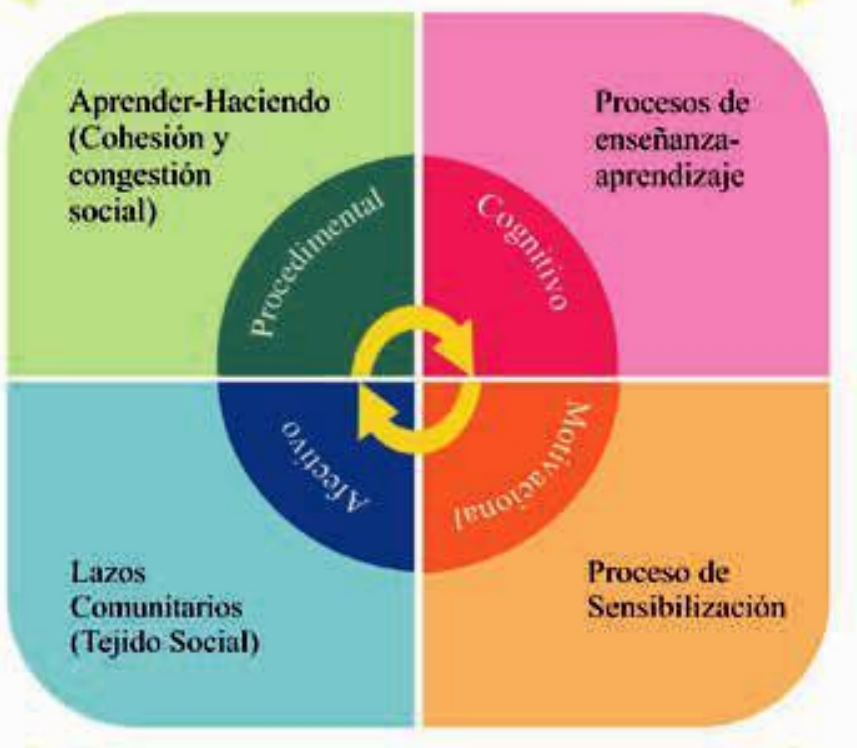

PROCESO INVESTIGATIVO

Como se observa en la Figura 1.1, la característica "Motivacional" se relaciona directamente con los procesos de sensibilización, lo que permitió la generación de confianza entre los investigadores del grupo "Plan de Investi-gación para el Fortalecimiento Integral de Comunidades - PIFIL) y la comu-nidad (jóvenes y adultos rurales); así como el conocer los objetivos previstos en la investigación y el planteamiento de estrategias y roles de participación en las diferentes etapas para el diseño y evaluación de las herramientas di-dácticas.

El componente "Cognitivo", se relaciona directamente con los procesos de enseñanza - aprendizaje; donde el investigador cumplió el rol de orientador y facilitador de los aprendizajes significativos; por ello, el uso de herramientas participativas (talleres, encuestas, juegos, ollas comunitarias y recorridos de campo), se convirtieron en una de las mejores alternativas para la identificación de los contenidos, colores, tamaño de letras e imágenes, entre otros, usados en creación - diseño - evaluación del material didáctico. 
La característica "Afectiva", se explora a partir de la apropiación del territorio; así como la consolidación de lazos sociales que conllevan al fortalecimiento del tejido social, en articulación con la característica "Procedimental", que permite rescatar procesos sociales de cogestiónautogestión (trabajo en equipo) y cohesión (grado de consenso).

Los recorridos de campo, entrevistas y el análisis grupal del contexto de vida en aspectos de vivienda, sistemas productivos y prácticas tradicionales permiten la caracterización de la zona de estudio; información sistematizada en archivos fotográficos y audiovisuales (Figura 1.2).

Figura 1. 2 Recorridos de campo que permiten la caracterización biofísica y socioeconómica del área de estudio. Fuente: Este estudio

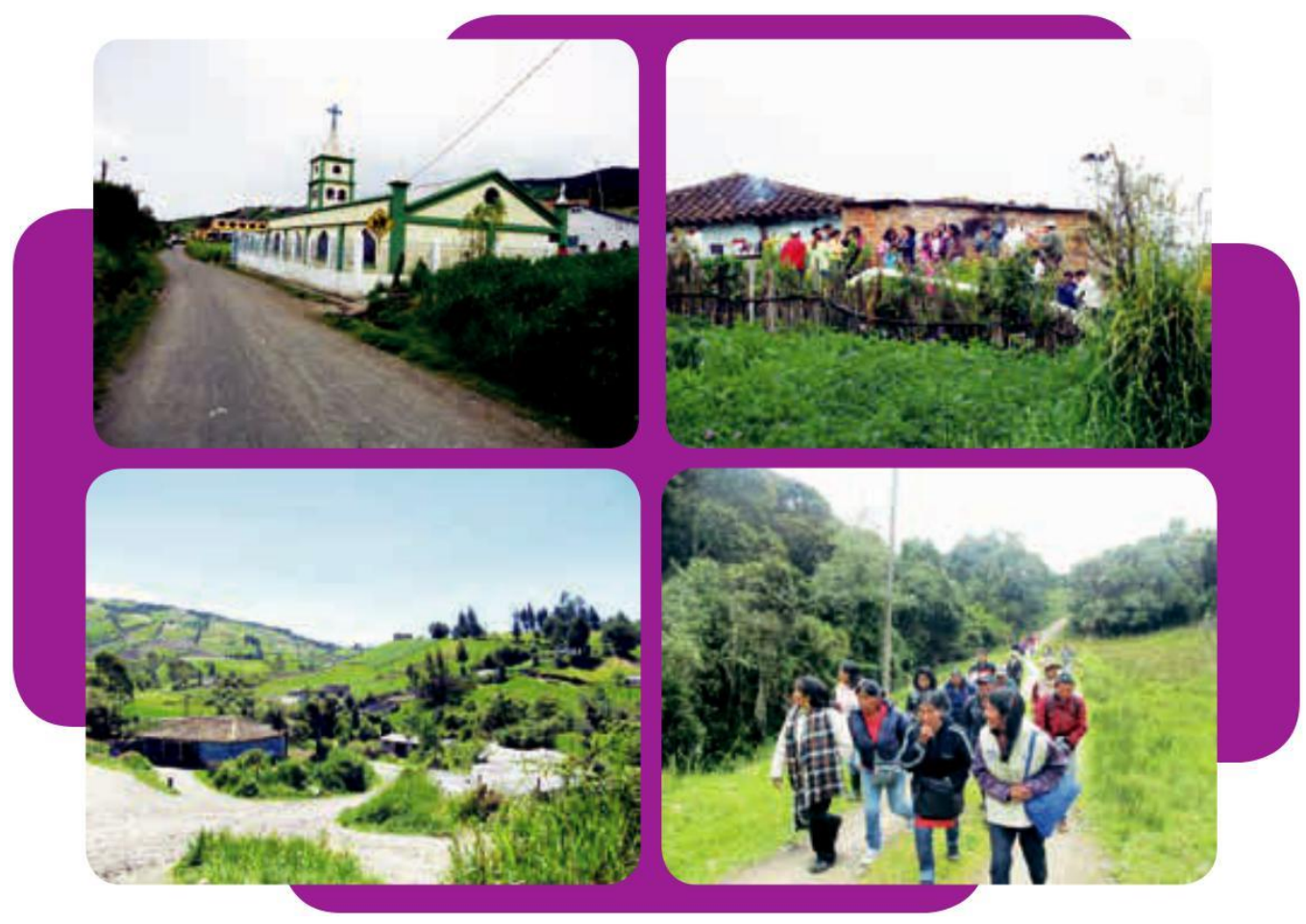

Por otra parte, el desarrollo y análisis del contenido visual, confiabilidad y validez, se adelantó, a partir de una revisión documental. Galeano (2008), plantea que las fuentes primarias y secundarias contribuyen a soportar la vera-cidad de la información. 
Así mismo, la reconstrucción paisajística ilustrada, permite fortalecer la característica "Afectiva", se considera que se reconocen los principales aspectos que determinan los medios de vida, visualizar prácticas productivas similares a las suyas, que tienen por objeto, motivar la planificación agroforestal. Con las ilustraciones se generan espacios de reconocimiento, empoderamiento social e identificación de los personajes de las herramientas didácticas (Figura 1.3 y 1.4).

Figura 1. 3 Ilustración de vivienda rural

Fuente: Este estudio

Vivienda Rural

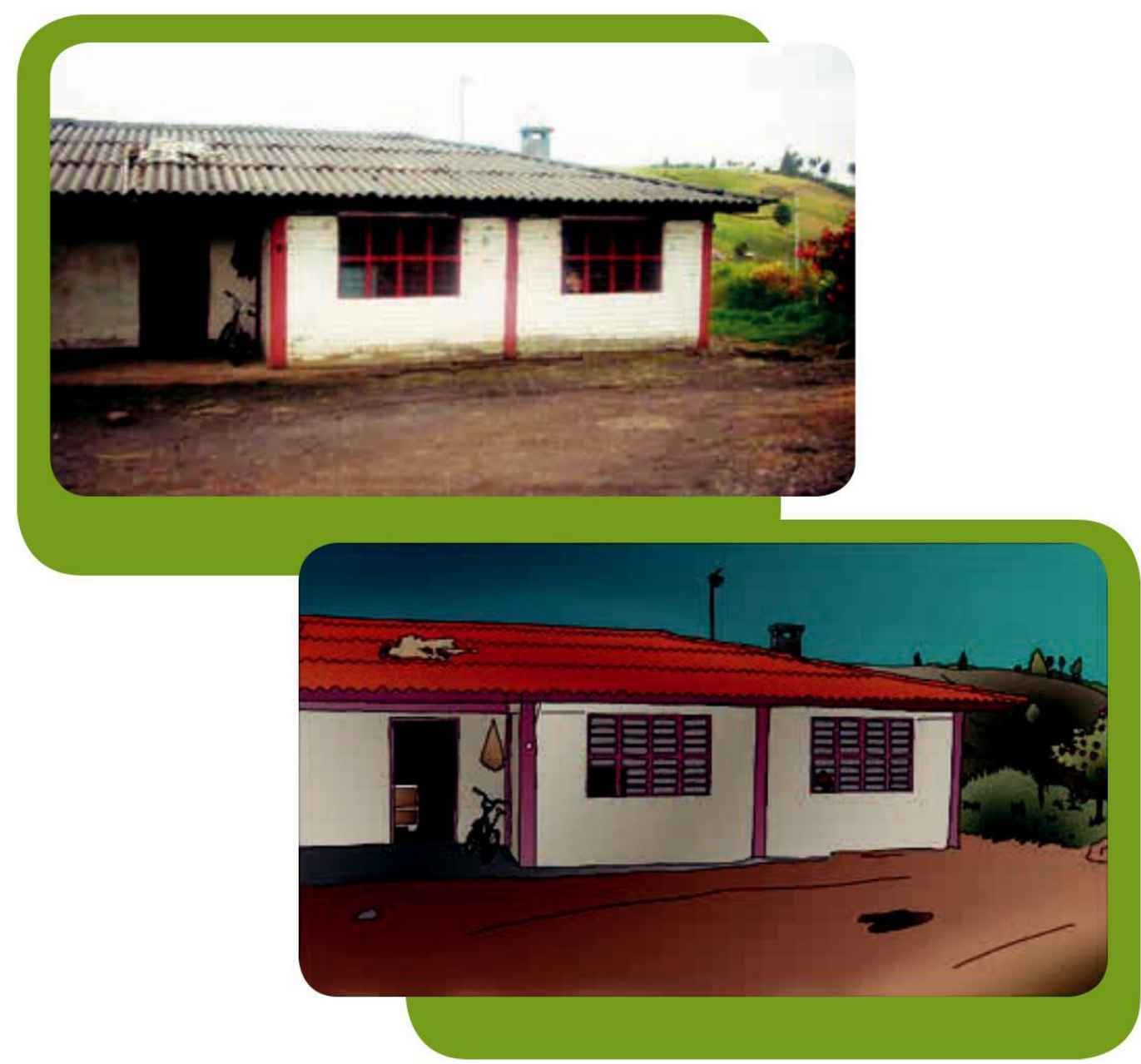

Vivienda rural ilustrada 
Figura 1. 4 Ilustración de personaje de la zona

Fuente: Este estudio

Niño del sector rural

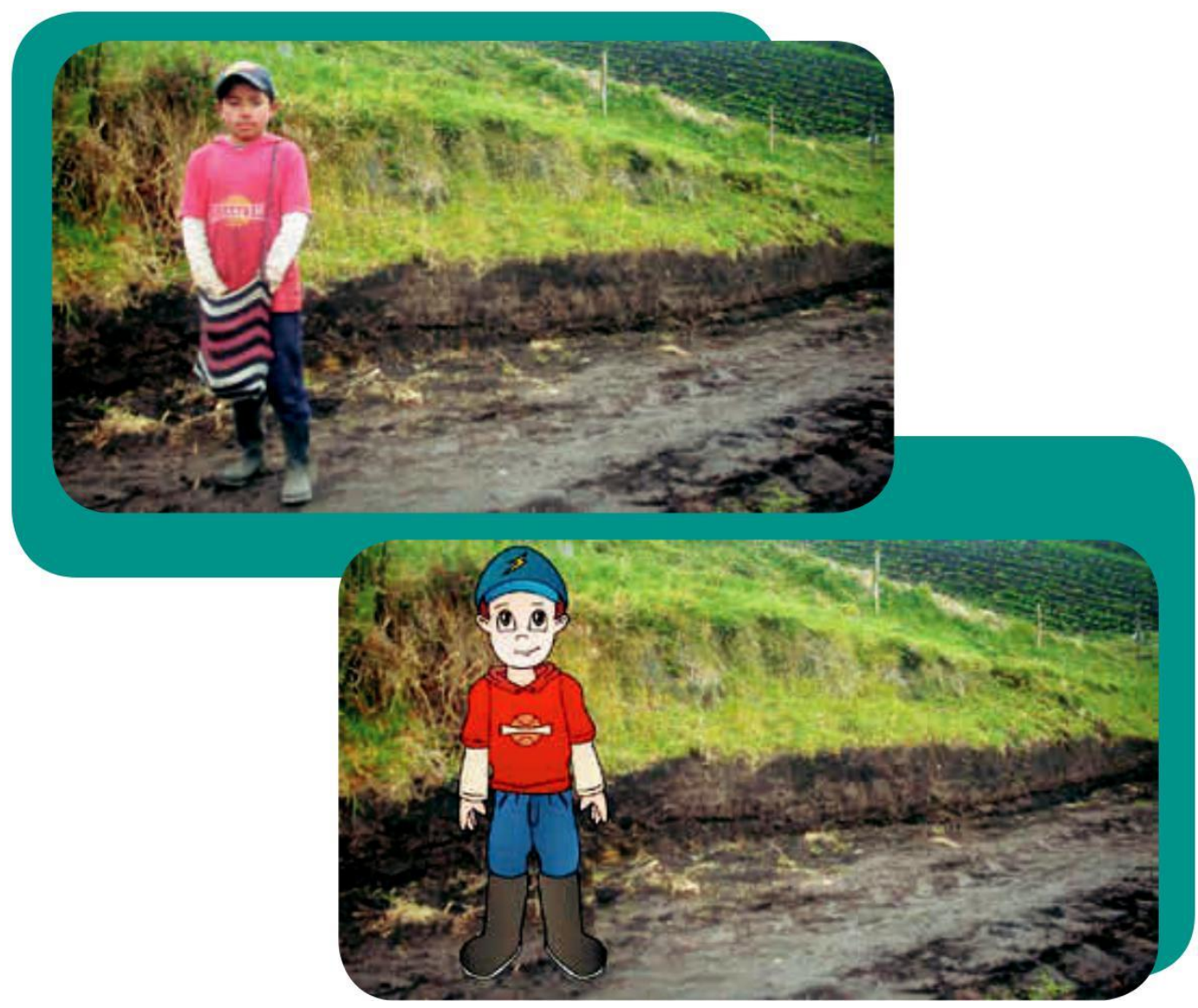

Personaje ilustrado

Uno de los aspectos a considerar en el proceso del diseño de las herramientas didácticas, es la importancia de conocer profundamente a las comunidades, ya que es una de las características relevantes para el diseño y estructu-ración de la "Identidad", que se reflejan en la creación de piezas gráficas innovadoras y auténticas de la zona andina.

El diseño de herramientas didácticas tiene en cuenta los postulados de Freire (1969), quien plantea "El facilitador-educador que no conoce el mundo del campesino no puede tratar de cambiar la actitud de este último"; destaca los principios y fundamentos de una educación que fomenta la práctica de la libertad, la cual no se reduce a un simple apoyo técnico, sino que incluye un 
esfuerzo personal de descifrarse a sí mismo para acercase a descifrar al otro, por medio de técnicas aplicables a todos los niveles de la enseñanza formal y no formal, tal como se plateó para la zona de trabajo del departamento de Nariño, donde se empleó grupos de estudio y de acción, mesas redondas, debates y tarjetas temáticas, entre otros.

\subsection{Características de los procesos participativos}

Para el diseño de las herramientas didácticas (Digitales y material manual) el componente participativo juega un papel relevante, para lo cual, fue de importancia considerar las características propuestas por Leonel (2011).

-La participación es un proceso, es decir, no puede ser resultado de acciones discretas, aisladas, puntuales o coyunturales; por el contrario, obedece a diferentes acciones planificadas, continúas y sostenidas en el tiempo que llevan al logro de los objetivos por los cuales se decide participar.

-Debe ser un acto voluntario, lo que implica tener claridad en el ¿para qué? se va a participar. Aquí juega un papel importante el conocimien-to que se tenga del problema a solucionar, así como la experiencia de quien participa.

-Las decisiones que se toman son colectivas o en conjunto y no de ma-nera individual, ya sea que un individuo en su doble condición de "representante" (autonombrado o elegido) de una colectividad o por el simple hecho de ser un "ser social"; es decir, ser "portador de rela-ciones sociales" en el sentido marxista del término-; en tanto, se par-ticipa por el interés y bienestar común; lo que significa el respeto por los otros, el fortalecimiento de la comunicación y de la redistribución del poder (compartir).

-Debe ser capaz de influir en los tomadores de decisiones; es decir, la participación no sólo se debe limitar a los niveles más bajos de la participación (información, consulta) sino que, además, debe formar parte del poder para lograr con ello la autogestión; en tanto se construya socialmente el problema, se legitime y se actué para la solución del mismo (proyectos) hasta la evaluación y seguimiento de los procesos. 
-La participación al influir en los tomadores de decisiones conlleva al control de la gestión pública y a la construcción de modelos de desarro-llo colectivos.

-Debe ser organizada, planificada, autónoma y mantener el control de las acciones o decisiones, lo que conlleva a una mayor responsabili-dad.

-La participación debe ser capaz de permitir pasar de un proceso de toma de decisión excluyente y autoritaria "voluntariamente a fuerzas" a un proceso de participación "libre”.

-La participación promueve la igualdad y la libertad en género, sexo, raza o etnia, entre otros.

-Debe suscitar a la transparencia

En este sentido, la participación, tiene que ver con la construcción social de una realidad que conlleva a acciones de diálogos, decisiones, consensos (Leonel, et al., 2010); para ello, es fundamental la PLANIFICACIÓN; es decir no puede ser el resultado de acciones improvisadas; sino de aquellas que conduzcan al logro de los objetivos.

Otra de las características de importancia en el diseño de las herramientas didácticas, es el trabajo "Interdisciplinar"; por ello, la vinculación de distintos profesionales sobre la temática a tratar es fundamental para direccionar y organizar la estrategia comunicacional, considerando los contenidos y expresiones técnicas a utilizar; para el caso los profesionales de diseño industrial y gráfico, contribuyen con la identidad de los materiales, manejo del color, textos e imágenes de acuerdo a los diferentes contenidos; licencia-dos en informática e ingenieros de sistemas, encargados de las orientaciones formativas desde la didáctica y de las animaciones digitales; los ingenieros forestales, agroforestales y agrónomos, quienes dirigen los procesos investigativos orientados a la caracterización socio-económica y biofísica del área de estudio, analizados desde los principios del enfoque de medios de vida sostenibles planteado por (Gottret, 2011); y la comunidad considerada protagonista de su propio desarrollo, quienes a partir del aporte desde su conocimiento local, permiten afianzar los contenidos y relacionarlos con 
gustos y preferencias de su vida cotidiana. De esta manera todos los aportes conducen a la producción de los materiales didácticos que en la práctica agroforestal son herramientas didácticas de gran utilidad. La interdisciplinariedad, convierte el trabajo de diseño, en una construcción colectiva, en un proceso de enseñanza-aprendizaje para los profesionales involucrados, quienes adquirieren conocimiento de otras disciplinas; y se facilita la comprensión y diálogo técnico-social entre ellos.

En este sentido, el trabajo interdisciplinario, consiste en la unidad de relaciones y de acciones recíprocas, de interpretaciones entre diferentes disciplinas; manteniendo los límites propios de cada una de ellas, se buscan factores de unidad en lo que toca al objeto, al método o al lenguaje (Bernal, 2000).

En la figura 1.5. Se visualiza la ruta interdisciplinar utilizada como proceso participativo de los diferentes actores.

Figura 1. 5 Ruta Interdisciplinar para el diseño de material didáctico. Fuente: Este estudio

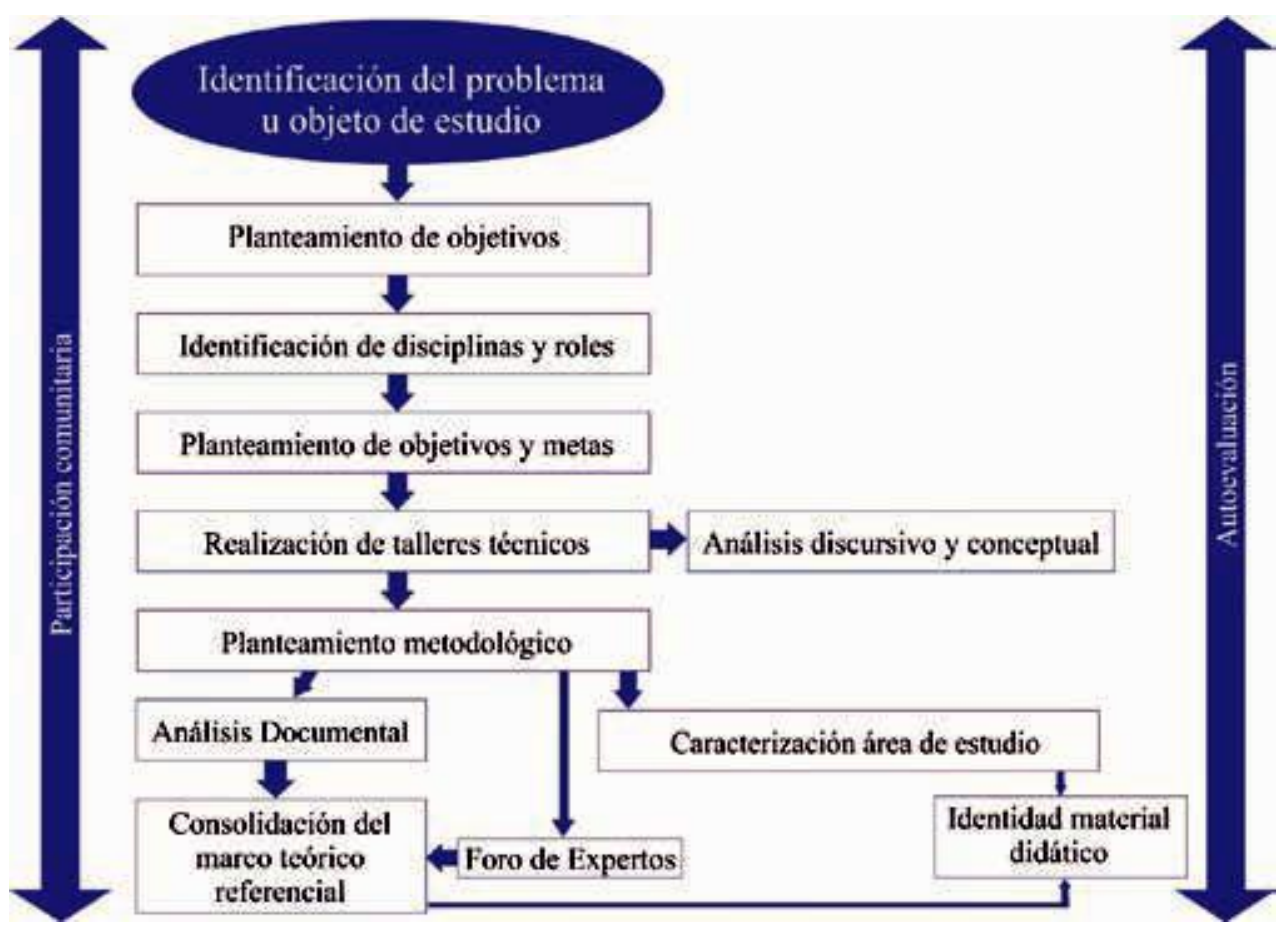

Esta ruta será explicada con mayor profundidad en los siguientes capítulos. 


\subsection{Características de los procesos investigativos}

Uno de los métodos investigativos, empleados en el diseño de las herramientas didácticas, es la etnografía; en donde se emplean herramientas metodológi-cas encaminadas a la caracterización socioeconómica de la población rural y la combinación de diferentes técnicas, como las psicométricas, entrevistas, encuestas y la observación de prácticas culturales, que contribuyen a entender y comprender las dinámicas y reglas sociales, sus pensamientos, percepcio-nes, modos de actuar cotidianos y significados de los sujetos estudiados; en tanto, se conoce mejor el grupo de estudio y se facilita la definición de gustos y preferencias; por el juego, color, mascotas, personajes; así como, las prác-ticas culturales en el manejo de los recursos naturales.

Otro de los procesos investigativos se centra en la Investigación Acción Participativa -IAP. Guzmán et al . (1994), plantea que en la IAP se siguen básicamente cuatro fases, aunque no siempre se diferencian nítidamente unas de otras, a saber:

1.) La observación participante: el investigador se involucra en la rea-lidad que se estudia, al relacionarse con sus actores y participando en sus procesos.

2.) La investigación participativa: se diseña la investigación y se eligen sus métodos, basados en el trabajo colectivo, la utilización de elemen-tos de la cultura popular y la recuperación histórica. El investigador presenta al grupo los diversos métodos disponibles para la obtención de información, explicándoles su lógica, eficacia y limitaciones, para que aquél los valore y elija en base a los recursos humanos y materiales disponibles. Para la recogida de información se usan técnicas como la observación de campo, la investigación en archivos y bibliotecas, las historias de vida, los cuestionarios, las entrevistas, etc. La información es recogida, y luego sistematizada y analizada, por la propia comuni-dad, siendo el papel del investigador de mero facilitador.

3.) La acción participativa: implica, primero, transmitir la información obtenida al resto de la comunidad u otras organizaciones, mediante reuniones, representaciones teatrales u otras técnicas, y además, con frecuencia, llevar a cabo acciones para transformar la realidad. 
4.) La evaluación: se da mediante los sistemas ortodoxos en las cien-cias sociales o simplemente estimando la efectividad de la acción en cuanto a los cambios logrados, por ejemplo en cuanto al desarrollo de nuevas actitudes, o la redefinición de los valores y objetivos del grupo. 



\section{DISEÑO DE MATERIAL DIDÁCTICO MANUAL}

\subsection{Generalidades}

La población juvenil como adulta requieren de un tipo de formación apoyada en herramientas didácticas, que faciliten un aprendizaje significativo para lograr la adopción del conocimiento agroforestal, las herramientas se deben concebir desde una aproximación socio-ambiental, valorando la cultura de la población, que al conjugarse con otros conocimientos, permiten la construcción de innovaciones y una apropiación social del conocimiento, lo cual está en concordancia con lo planteado por Ausubel (1983), quien afirma "la característica más importante del aprendizaje significativo es que, produce una interacción entre los conocimientos más relevantes de la estructura cog-nitiva y las nuevas informaciones (no es una simple asociación), de tal modo que éstas adquieren un significado y son integradas a la estructura cognitiva de manera no arbitraria y sustancial"

Según Cebrián (1992), citado por Cabero (2001), “Todos los objetos, equipos y aparatos tecnológicos, espacios y lugares de interés cultural, programas o itinerarios medioambientales y materiales educativos, en unos casos utilizan diferentes formas de representación simbólica, y en otros, son referentes directos de la realidad, estando siempre sujetos al análisis de los contextos y principios didácticos o introducidos de un programa de enseñanza, que favorecen la reconstrucción del conocimiento y de los significados culturales".

La elaboración de las herramientas didácticas que se describen a continuación, se articulan adecuadamente a satisfacer aquella demanda pertinente de educación para adultos, más aún, al considerar la necesidad que presenta la zona andina nariñense, dadas sus condiciones de producción minifundista, donde la Agroforestería se convierte en una alternativa de producción sustentable.

El diseño del material didáctico manual, se adelantó considerando el aporte interdisciplinario de ingenieros agroforestales, agrónomos, forestales, licenciados en informática, diseñadores industriales y gráficos. Estos materiales, además de ser insumos auxiliares del facilitador en el desarrollo de las capacitaciones, permiten que los participantes analicen sus medios de vida reales y reflexionen sobre las estrategias agroforestales coherentes para su contexto de vida. 


\subsection{Metodología}

Desde el paradigma cualitativo se adelantó una Investigación Acción Participativa, para la construcción de conocimiento, considerando la lúdica y los fundamentos del enfoque de medios de vida sostenibles - EMVS, planteados por Gottret (2011:10), que comprende todas aquellas capacidades, recursos y actividades que una población tiene y utiliza para buscar su bienestar y una mejor calidad de vida. De igual forma, se tomó como referente los estilos de aprendizaje planteados por (Kolb, 1976), modelo que está muy extendido para el diagnóstico en niveles de adultos, donde el aprendizaje comienza con una experiencia inmediata y concreta que sirve de base para la observación y la reflexión.

\subsection{1 Área de estudio y características generales de la población participante}

La investigación para el diseño de material didáctico manual se adelantó en la vereda Marqueza Alta, ubicada en la microcuenca Miraflores, que a su vez hace parte de la subcuenca del río Pasto, entre los municipios de Pasto y Tan-gua, con superficie de 926,5 hectáreas, delimitada por la línea de divorcio de las aguas en los 3.925 m.s.n.m. en su parte más alta y los 3.000 m.s.n.m. en su parte más baja, donde predominan suelos de origen volcánico (Cuellar, 2011).

Según datos suministrados por la alcaldía municipal de Tangua, en el año 2009, en la vereda Marqueza Alta existía una población de 589 habitantes, distribuidos 382 en su parte alta, y 207 en la parte baja. En el presente estudio, un grupo de 18 personas adultas de la comunidad, que voluntariamente desearon participar, fueron quienes activamente contribuyeron con el proceso de construcción de los materiales didácticos manuales.

\subsubsection{Método}

En la Figura 2.1, se indica la ruta del proceso de investigación para el diseño del material didáctico manual. 
Figura 2.1Ruta del proceso de investigación para el material didáctico manual

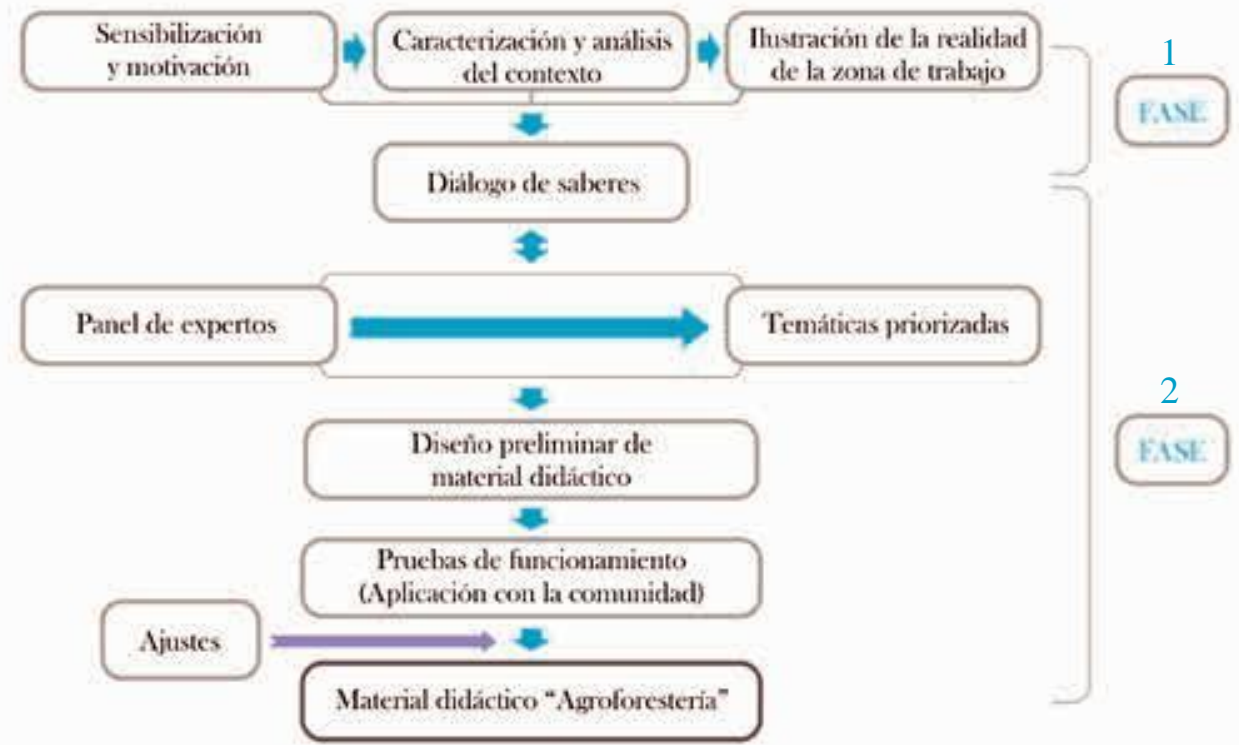

2.2.2.1 Fase 1: Identificación de características relevantes para el desarrollo del material didáctico manual: Se adelantó una revisión documental para rastrear, ubicar inventariar, seleccionar y consultar las fuentes y documentos a utilizar como materia prima de la investigación, tanto las fuentes primarias como secundarias, funcionan como verificadoras que soportan la veracidad de la información; para ello, se tuvo en cuenta el análisis de contenido, el análisis visual, la confiabilidad y validez, tal como lo plantea Galeano (2008).

Posteriormente, se organizó reuniones con la comunidad de la vereda Mar-queza Alta y el grupo de investigación (Técnicos, extensionistas, profesio-nales, líderes y estudiantes) a fin de socializar el proyecto y motivar a la comunidad para consolidar el compromiso de participación, y establecer un cronograma de actividades considerando el rol de cada uno de los participantes.

Con el fin de identificar las principales características para el desarrollo de herramientas didácticas, se realizó reuniones con el equipo técnico del proyecto; con quienes se analizó diferentes experiencias y documentos para avances en el marco conceptual. Mediante recorridos de campo, entrevistas y análisis grupal del contexto de vida se caracterizó la zona de estudio, considerando los aspectos más relevantes de vivienda, sistemas productivos y prácticas tradicionales, culturales, recreativas y de uso del tiempo libre; que determinan su identidad. 
En consideración a lo anterior, se realizó un análisis sobre apreciaciones respecto a juegos y uso del tiempo libre, por medio de la aplicación de encuestas semi-estructuradas previamente diseñadas y conformadas por ocho variables: Localidad; edad; preferencia de actividades en su tiempo libre; preferencia de color; conocimiento y preferencia de juegos tradicionales y de mesa; intere-ses y gustos particulares; y obtención de destrezas. A partir de las respuestas obtenidas, se sistematizó la información recolectada en una base de datos, y se aplicó el método de conteo y la descripción estadística de variables, tal como lo plantea (Figueras y Gargallo, 2003).

Posteriormente, se categorizó los datos, en un orden de mayor a menor frecuencia y/o porcentaje obtenido en la sistematización, y se realizó un barrido estadístico con las variables de varianza menor a uno, es decir estadísticamente similares; y que por tanto, no significan ser incidentes o de peso en el desarrollo del estudio. Se procedió al análisis de variables de tipo cuali-tativo, a través del método de Análisis de Correspondencias Múltiples - ACM (Lebart, 1974), con la utilización del software estadístico SPAD (Sisteme Protablepur 1`Analyses des Données) versión 5,6.

Las correlaciones entre caracteres de la comunidad encuestada, evidenciaron variabilidad, se elaboró el histograma de los primeros 17 valores propios, haciendo relación entre las variables y tomando como referencia los datos con una variabilidad acumulada mayor al 50\%, con los cuales se realizó el respectivo análisis de contribuciones, para identificar los principales componentes representativos o de peso específico en la encuesta aplicada; a través de la descripción y caracterización de los agrupamientos de variables.

\subsubsection{Fase 2: Diseño y elaboración del material didáctico manual: A par-tir de las principales características del medio de vida, de los participantes y teniendo en cuenta cuatro características para diseño de materiales educativos (diversidad de material, claridad en el contenido, calidad del material y ergonomía), además del aporte de un panel de expertos que determinaron las temáticas agroforestales básicas para una clara comprensión de la dinámica agroforestal de la zona Andina; se planteó la primera aproximación al diseño del material didáctico manual, el cual se ensayó con la comunidad rural mediante el desarrollo de talleres y se realizaron pruebas de funcionalidad y acogida con el apoyo de los diferentes participantes, para finalmente realizar ajustes y contar con una herramienta didáctica de calidad y eficiente.}




\subsection{Resultados}

\subsubsection{Fase 1: Identificación de características relevantes para el desarrollo de herramientas didácticas}

La sensibilización y motivación debe ser permanente a fin de mantener buenas relaciones y espacios de intercambio de conocimientos; una vez los participantes logran conocer los alcances de la investigación y manifestar su compromiso, se procede establecer los acuerdos de trabajo, aspectos que se estructuraron en cronogramas de actividades mediante visitas periódicas generando espacios de diálogo de saberes para analizar sus procesos produc-tivos e implicaciones en su vida cotidiana. De esta manera, generar confianza es fundamental para conocer más detalladamente el verdadero sentir de las mujeres y hombres, habitantes de la zona andina nariñense, al lograr conocer varios aspectos como los que se describen a continuación.

La población se encuentra en una realidad con muchas carencias (formación, económicas, apoyo y acompañamiento institucional y servicios públicos, entre otros) fácilmente observada por los pobladores y profesionales lo cual ha implicado un ejercicio dinámico de análisis y comprensión. En la zona de estudio se identificó que la presencia institucional es escasa y se presentan grandes necesidades; sin embargo, la comunidad reconoció que entidades como Parques nacionales, EMPOPASTO, la Universidad de Nariño y la Fundación Laurel - FUNLAU, han contribuido con el desarrollo de algunos proyectos, siendo importante la consulta de fuentes secundarias de información, tales como documentos sobre la zona, estadísticas, mapas, fotografías, entre otros, que permitieron mayor acercamiento con la comunidad y realizar una convocatoria para la participación activa en el proceso.

La vereda Marqueza Alta, que hace parte de la microcuenca Miraflores, donde cobra gran importancia la quebrada Piquisiqui, por ser un afluente que oferta agua al acueducto de Pasto, además, de encontrarse ubicada en una zona de gran influencia al Santuario de Flora y Fauna Galeras, donde hay agrupaciones de ecosistemas correspondientes a bosque alto andino, sub-páramo y páramo. Al evaluar la situación ambiental se deben tener en cuenta las características de la población y el manejo que le dan a los sistemas productivos, para determinar cómo afectan las actividades del diario vivir a los recursos naturales del entorno y estos a su vez como repercuten en su bienestar.

Además, debido al crecimiento poblacional, los habitantes se apropiaron de los espacios, ya que tanto el bosque como el páramo le han ofrecido servicios 
para realizar sus labores diarias y para poder sobrevivir a través de la producción de alimentos, fenómeno conocido como la ampliación de la frontera agrícola y por ende la sustitución de bosque por pastos para la crianza de animales. También es importante tener en cuenta la utilización de leña como combustible, aunque actualmente su utilización es menor.

Lamentablemente, hoy en día la ribera de la quebrada Piquisiqui, cuenta con poca protección de cobertura vegetal; que ha sido reemplazada por cultivos o pasturas, de este modo los cultivos y el ganado están colindando con la fuente de agua, afectándola negativamente. Así mismo, la presencia de árboles, arbustos y/o barreras vivas dentro de los predios es baja y poco diversa; con-siderando que en aproximadamente $100 \mathrm{~m}$. lineales, tan solo se encuentran 15 árboles en promedio, principalmente de acacia (Acacia magnium) y aliso (Alnus jorullensis $\mathrm{H}$.).

En las actividades productivas se utilizan productos químicos que contaminan el agua; los vertimientos de las aguas servidas de uso doméstico y productivas, no tienen un tratamiento; llegan directamente a la quebrada o al pozo séptico con mínimo manejo.

En la zona se presenta la agricultura minifundista sobresaliendo los cultivos de papa (Solanum tuberosum L.), ulluco (Ullucus tuberosus) y hortalizas. La actividad ganadera y la cría de especies menores (cuyes en su mayoría) son consideradas otra alternativa para la generación de ingresos económicos. La producción además es destinada primordialmente para el autoconsumo en todos los cultivos pero sólo Solanum tuberosum L., se considera cultivo comercial.

La rotación de cultivos que se práctica como característica en la zona, es la rotación papa - pasto. Los cultivos no se manejan con cultivos de cobertura forestal, por lo cual el aporte de materia orgánica al suelo es mínimo.

En la zona se realiza labranza de conservación o mínima, debido a que la mayoría de los lotes son pequeños, utilizando pica o azadón a profundidad y la yunta de bueyes. Las actividades que requieren los cultivos como la siembra, cosecha y labores culturales de los cultivos se realizan de manera manual.

En la zona la alimentación se ve influenciada por los cultivos, el transporte 
y la salida de los habitantes hacia las ciudades en búsqueda de mejores oportunidades, las parcelaciones de tierra (herencias) y la facilidad de acceso a la ciudad.

El escenario social, se caracteriza por dos patrones de comportamiento; en el primero están quienes actúan en los espacios de participación comunitaria como asistentes y en menor proporción están a quienes les gusta apoyar los procesos que contribuyen en la comunidad.

Los habitantes participan en los espacios que les brinda cuando es estrictamente necesario y en calidad de asistente. Aunque como en varias comunidades una mínima parte de los habitantes actúan como líderes y participan en espacios sociales locales y/o regionales como la junta o comités de algún tipo de organización para actividades en pro de la comunidad.

Las actividades de colaboración como mingas o mano prestada, trueques, u otros, se llevan a cabo para intercambios de bienes o servicios, cuando el fin está claro y entre integrantes de la familia y sólo con algunos vecinos. Cuando se trata de trabajos en toda la zona, se organizan grupos sectorizados y todos colaboran, siempre y cuando el fin les brinde un resultado.

Pese a muchas dificultades, se observa, igualmente, un potencial explícito para resolver la sobrevivencia cotidiana y proyectar la vida más allá de las limitaciones que la realidad le impone. Sin embargo, éste potencial, aún sin explorar, y que puede ser la fuente de las alternativas que se requieren para superar de manera endógena las carencias, es de vital importancia considerar al momento de diseñar un material didáctico pertinente para los agricultores bajo estos contextos de vida, ya que representan su cotidianidad y el aferro a su medio, aspectos que no se pueden desligar de una estrategia que facilite procesos y que estimule la confianza, la credibilidad y contribuya a elevar la autoestima para valorar su medio de vida; ya que una persona motivada aprende más fácilmente que aquella que no lo está, es así como el aprendizaje es más exitoso en un ambiente de incentivo y oportunidad que en un ámbito carente de motivaciones.

El análisis sobre tendencias de participación de personas encuestadas por género en preferencia de juegos y la estimación de frecuencias y varianzas, evidenció que hay una mayor participación de mujeres (67\%), debido a las 
distribuciones de roles en el hogar, en donde una de las múltiples actividades femeninas consiste en la asistencia y participación en reuniones de organiza-ción comunitaria.

El promedio general de edad para las personas participantes fue de 36 años, con una varianza de 14,85 y una desviación estándar de 3,85\%, existiendo una mayor representatividad de personas menores a 60 años de edad.

Respecto a la preferencia de actividades realizadas en el tiempo libre, predo-minan ver televisión y escuchar música; además, identificaron el trabajo en la huerta como una labor agradable a desarrollar en su tiempo libre y fomentar la integración familiar. Se encontró una varianza de 1,55 y una desviación estándar de 1,24\% lo que permitió inferir que hay una distribución homogénea respecto al quehacer.

Frente al conocimiento de juegos de mesa, predominaron el parqués y las cartas. La varianza respecto a la frecuencia de este cuestionario fue de $2,82 \%$ permitiendo inferir que no existe un peso específico o preferencia por algún juego de mesa particular en la zona.

Los juegos tradicionales que se reconocieron fueron las escondidas, chaza, sapo, golosa, mollejones, parqués, cucunubá, la coca, trompo, las canicas, la ronda, entre otros; el 16,67\% manifestó no conocer o recordar los juegos tradicionales de su región.

El color azul, seguido del verde y rojo fueron los de mayor preferencia; en menor cuantía el color negro, blanco, morado y rosado. La varianza en la frecuencia de esta variable corresponde a 1,90 y su desviación estándar 1,38\%.

La habilidad en juegos manuales y el deporte se considera en mayor proporción. La varianza de frecuencia para la variable contemplada corresponde a un 2,82 y la desviación de $1,68 \%$.

La preferencia de trabajo grupal por encima del individual predomina y es tendencial en las dos comunidades, posiblemente por el fomento de asociatividad por parte de entidades públicas y/o privadas en los últimos años.

Las actividades que fomentan la integración fueron descritas como meca- 
nismos de vital importancia para la consecución de armonía comunitaria. La generación de espacios de diálogo y de rescate de tradiciones, también fueron actividades consideradas. La varianza de frecuencia para dicha variable correspondió a 4,14 y su desviación estándar a 2,13\%.

\section{Categorización y selección de variables}

Debido a que en todas las variables estudiadas la varianza fue mayor a uno, no se hizo barrido estadístico y por ende no se descartó ninguna. Se categori-zaron por tanto las 10 variables respecto al criterio de mayor representativi-dad en frecuencia y/o porcentaje de las personas encuestadas, con un total de 18 casos de estudio y 36 categorías asociadas.

Posteriormente a la agrupación en las categorías se transformaron a un formato legible y trabajable para el software estadístico SPAD v 5,6

Las variables con mayor contribución, y por tanto, las más representativas y determinantes en las encuestas aplicadas, son "Conocimiento de juegos de mesa"; "Preferencia en juegos de mesa"; "Juegos tradicionales", como se observa en la Tabla 2.1, las cuales se recomienda ser analizadas con mayor profundidad en futuros estudios.

Tabla 2.1 Contribuciones acumuladas en los valores propios

* Mayores contribuciones acumuladas por parte de los encuestados

\begin{tabular}{|c|c|c|c|c|}
\hline Variable & \multicolumn{4}{|c|}{ Grupos } \\
& $\mathbf{1}$ & $\mathbf{2}$ & $\mathbf{3}$ & $\mathbf{4}$ \\
\hline Sexo & 8,1 & 3,7 & 0,0 & 0,0 \\
\hline Edad & 5,6 & 0,2 & 2,8 & 19,6 \\
\hline Preferencia tiempo libre & 8,5 & 20,1 & 18,0 & 12,1 \\
\hline Conocimiento juegos mesa* & 18,2 & 15,5 & 10,8 & 7,7 \\
\hline Preferencia juegos de mesa* & 18,0 & 8,5 & 20,5 & 11,5 \\
\hline Juegos tradicionales* & 15,0 & 22,9 & 16,0 & 8,1 \\
\hline Color preferido & 11,96 & 0,4 & 14,7 & 4,5 \\
\hline Habilidad & 0,8 & 15,4 & 10,1 & 16,9 \\
\hline Preferencia trabajo & 2,0 & 5,0 & 1,2 & 9,4 \\
\hline Aspectos a rescatar & 11,8 & 8,2 & 5,9 & 10,1 \\
\hline
\end{tabular}




\section{Agrupamiento de variables}

La organización por clústers permitió inferir que a través del análisis de las 18 personas encuestadas, existe una formación de cuatro clústers bien definidos como se observa en la figura 2.2., respondiendo a algunos aspectos característicos similares entre cada uno de los individuos encuestados, encontrándose cuatro grandes grupos.

Figura 2. 2 Análisis de clúster.

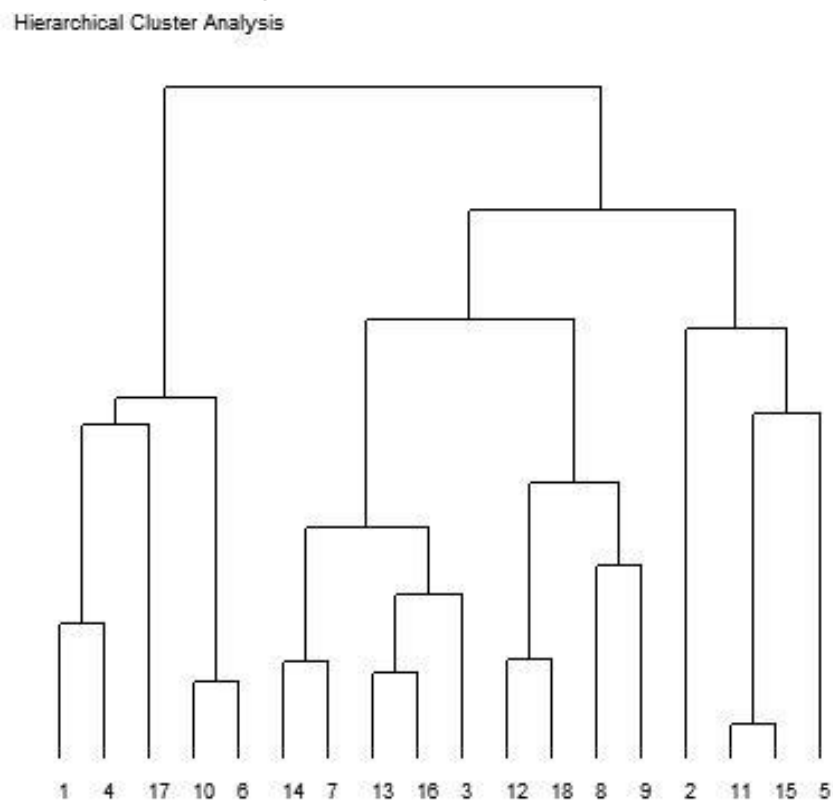

Fuente: Este estudio

- Clúster uno: Conformado por aspectos característicos y similares entre $\operatorname{los}$ individuos $1,4,17,10$ y 6 ; con un porcentaje representativo del $80 \%$, quienes respondieron la categoría 3 (No sabe/ No responde) de la variable "Conocimiento de juegos de mesa" y la categoría 3 (No conoce/ No le gusta) de la variable "Preferencia Juegos de Mesa".

- Clúster dos: Conformado por aspectos característicos y similares entre los individuos 14, 713,16 y 3 ; con un porcentaje representativo del $71,43 \%$, quienes se ubicaron dentro de la categoría 1 (Parqués), de la variable "Preferencia de Juegos de mesa". 
- Clúster tres: Conformado por aspectos característicos y similares entre los individuos 12, 18, 8 y 9; con un porcentaje representativo de $100 \%$ se encuentran los individuos cuyas respuestas se ubican dentro de la categoría 2 (Cartas) de la variable "Conocimiento de juegos de mesa".

- Clúster cuatro: Conformado por aspectos característicos - similares entre los individuos 2, 1115 y 5. Dentro del Clúster 4, con un porcentaje representativo del $100 \%$ se encuentran los individuos que respondieron a la categoría 4, dentro de la variable Preferencia a Juegos de Mesa, es decir los que no prefieren un sólo juego de mesa, o tienen otros juegos alternos a los que presentaron mayor frecuencia.

Lo anterior permite inferir, que si bien la variabilidad entre cada una de las variables evaluadas en el presente estudio es alta; existen factores determinantes que permiten orientar el diseño de los materiales didácticos, los cuales son de mayor aceptación para estas comunidades rurales; en este caso la similitud a materiales que ellos ya conocen y prefieren, tales como son los juegos del parqués y cartas (o manejo de fichas), sobre otro tipo de aspectos como son el color del material, o la edad de a quienes va dirigido.

De esta manera, se logra la ilustración de distintos escenarios reales y la idea fundamental para el diseño de la imagen más acorde que representará a la comunidad en su contexto de vida, afianzando su identidad a fin de entenderla, interpretarla y devolverla con la posterior propuesta de diseño de materiales didácticos manuales accequibles para afianzar conocimientos agroforestales pertinentes para la zona andina.

Mediante el diálogo de saberes, estos espacios de conocimiento se enri-quecen $\mathrm{y}$ fortalecen en la medida que todo el equipo de trabajo (Ingenieros agroforestales, forestales, agrónomos, licenciados, diseñadores gráficos e industriales) aportan sus ideas a fin de lograr innovadoras propuestas que sin perder su esencia de profundidad en los temas técnicos, faciliten la interacción entre los participantes, generen motivación constante, diviertan y animen a experiencias concretas enriquecedoras para contribuir a la acción y alcance en mediano plazo de una apropiación social del conocimiento. 


\subsubsection{Fase 2. Diseño y elaboración del material didáctico manual}

Para el diseño del material, se consideró dos aspectos fundamentales: los aportes realizados por el panel de expertos en agroforestería (grupo de profesionales de amplia experiencia y trayectoria en el tema) que determinaron cinco temas fundamentales a ser tratados en procesos de capacitación para la formación agroforestal y la percepción sobre gustos, preferencias de juegos y uso del tiempo libre, que permitió identificar a los juegos de mesa (parqués y cartas) como los de mayor acogida por la comunidad rural y que por tanto, alrededor de ellos se debían plantear algunos con características similares.

En este sentido, el análisis y reflexión de los elementos anteriormente planteados, conlleva a la creación de varios juegos para abordar las temáticas propuestas, bajo la premisa de acercarse a la realidad identificada, de esta manera se evidencia el proceso que implica el diálogo de saberes, donde los aportes de la comunidad participante y del equipo técnico conjuntamente con el panel de expertos representan un valioso insumo para la creación de la identidad de la región y su aproximación a escenarios agroforestales, aspectos que se evidencian a continuación en el diseño de logo y de juegos por temáticas.

\section{Diseño de logo}

Se diseñaron varias propuestas de logo para el material didáctico manual, sin embargo su selección se concretó una vez se analizó todos y cada uno de los detalles y elementos constitutivos de las propuestas, a fin de escoger la composición que reflejara las características más relevantes en cuanto a la agroforestería en el contexto de vida estudiado (Figura 2.3).

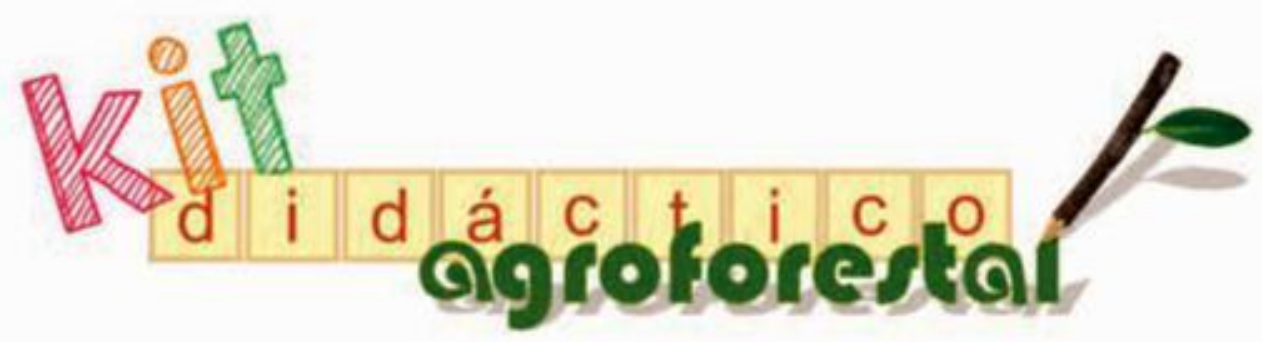


Figura 2. 3 Diseño de logos

De esta manera, el logo de mayor pertinencia para el manejo de la identidad del concepto agroforestal, fue concertado con el equipo de trabajo aprobando el nombre "Agroforestería" material didáctico, el cual integra los componentes fundamentales como cultivos, árboles y animales (Figura 2.4), logrando así, plasmar un enfoque integral.

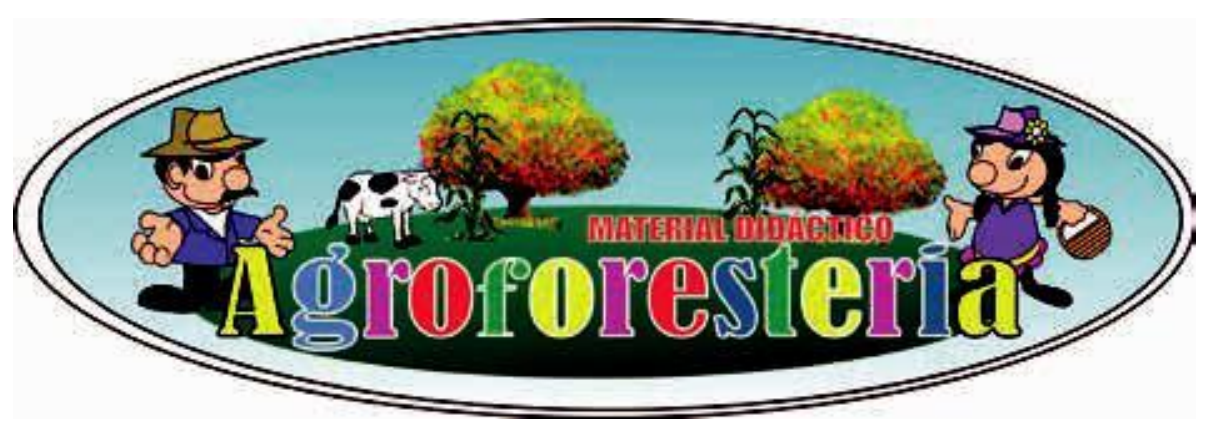

Figura 2. 4 Logo definitivo del material didáctico manual

\section{Diseño de juegos}

Una vez determinado el logo se plantearon cinco juegos, cada uno de ellos corresponde a una temática que representa los aspectos generales para emprender acciones de desarrollo agroforestal; compuestos por el contenido del juego, un instructivo de aplicación para el facilitador y sus respectivos morrales de transporte.

Para la temática "Historia, definición y función agroforestal", se propuso el juego Sendero del conocimiento; respecto a la temática "beneficios del árbol como especie multipropósito, bienes y servicios", el juego Riqueza Am.ñbiental; la temática "Clasificación de Sistemas Agroforestales por com-ponentes" con el juego ClasiSAF; para el tema "Arreglos Agroforestales", el juego Arreglotón, y para el tema de "Planificación agroforestal de fincas" se diseñó el juego Planificando Ando.

Bajo el principio de funcionalidad y con el aporte de los diferentes participantes, se logró un material de calidad y eficiencia para su aplicabilidad en 
campo; considerando cuatro aspectos que se describen a continuación:

- Diversidad de material: En esta variable se contempla que los materiales empleados en la construcción de los juegos sean seleccionados considerando el peso, volumen y facilidad para transporte, por ello, se escogió lona, papel plastificado, acrílico, espuma, mdf y cartón plastificado.

- Claridad en el contenido: A fin de lograr la apropiación del conocimiento agroforestal, los contenidos fueron seleccionados tras un proceso análisis y reflexión- crítico propositivo, permitiendo resaltar los aspectos más importantes para afianzar con los juegos. Sin embargo se considera per-tinente a futuro validar los contenidos reflejados en dichos materiales.

Calidad del material: Debido a que los materiales están diseñados para el trabajo en campo, donde los espacios de aprendizaje suelen ser limitados, estos se elaboraron con materias primas que garantizan durabilidad y resistencia; en cuanto al diseño se empleó ilustraciones que integran imagen y texto con tamaño y color que facilitan su visualización y comprensión.

- Ergonomía: Considerando que el material debe ser trasladado a diferentes zonas rurales, donde el transporte es escaso; los juegos son cargados en morrales elaborados en lona de alta resistencia y durabilidad, impermea-bles, livianos y confortables para que los técnicos-extensionistas o facilitadores los lleven sin dificultad.

El material está diseñado para facilitación de grupos entre 15 y 20 personas, dirigido a los agricultores y jóvenes tecnólogos y/o universitarios que incursionen en esta área del conocimiento. Sin embargo, es de resaltar que para su uso eficaz, se requiere una preparación adecuada del facilitador respecto a conocimientos básicos agroforestales, andragogía, participación comunitaria y uso de la lúdica en estrategias de trabajo grupal.

Para el correcto uso del material didáctico, se propone su utilización mediante el desarrollo de talleres, donde el facilitador juega un papel importante como orientador de toda la dinámica durante el proceso de enseñanza - aprendizaje.

A continuación se describe cada uno de los cinco juegos que conforman el material didáctico, los cuales se diferencian por color, de acuerdo al nombre y temática a tratar, a fin de identificar claramente la etapa de formación del 
proceso agroforestal.

\subsubsection{Juego Uno: "Sendero del Conocimiento"}

Considerando que son muchos los sucesos que han marcado la historia agro-forestal, se ha diseñado un contexto natural a manera de un gran territorio que ilustra los principales hitos del desarrollo agroforestal en relación a su definición y función.

Temática: Historia, definición y funciones de la agroforestería.

Objetivo: Conocer los principales eventos de la historia agroforestal, su defi-nición y las funciones claves para contextualizar y sensibilizar a la comuni-dad en su importancia.

Ideas claves:

1. Definición de agroforestería

2. Reconocimiento de la importancia de la agroforestería.

3. Valoración de la importancia del árbol en distintas combinaciones dentro de la finca.

Instrucciones de aplicación:

- Se organiza a los participantes en dos grupos, cada uno de ellos reci-be un nombre seleccionado por los participantes.

- Se asigna a un participante como ficha para que transite por el sende-ro a medida que se lanza el dado.

- En orden cada el primero de los participantes del grupo lanza el dado.

- Si el dado cae en un número el jugador ficha avanza el número de casillas indicado en el dado y el facilitador del juego lee una ficha de ideas claves.

- Si el dado cae en el color naranja hay cambio de jugador ficha y el nuevo debe resolver una trivia.

- Si el dado cae en color verde hay cambio de jugador ficha y el nuevo jugador debe realizar una penitencia.

- Si el dado cae en color azul hay cambio de jugador ficha y el nuevo jugador debe realizar un cambio en el juego.

- Los jugadores avanzan por el sendero y al final el grupo que primero llegue a la meta y logre hacer un recuento de todo lo explicado a lo 
largo del sendero es el grupo ganador.

Contenido del juego:

Morral de transporte del juego, guía del facilitador, tapete gigante, dado, tapete de ubicación de fichas, fichas de trivias, cambios y penitencias (Figura 2.5).

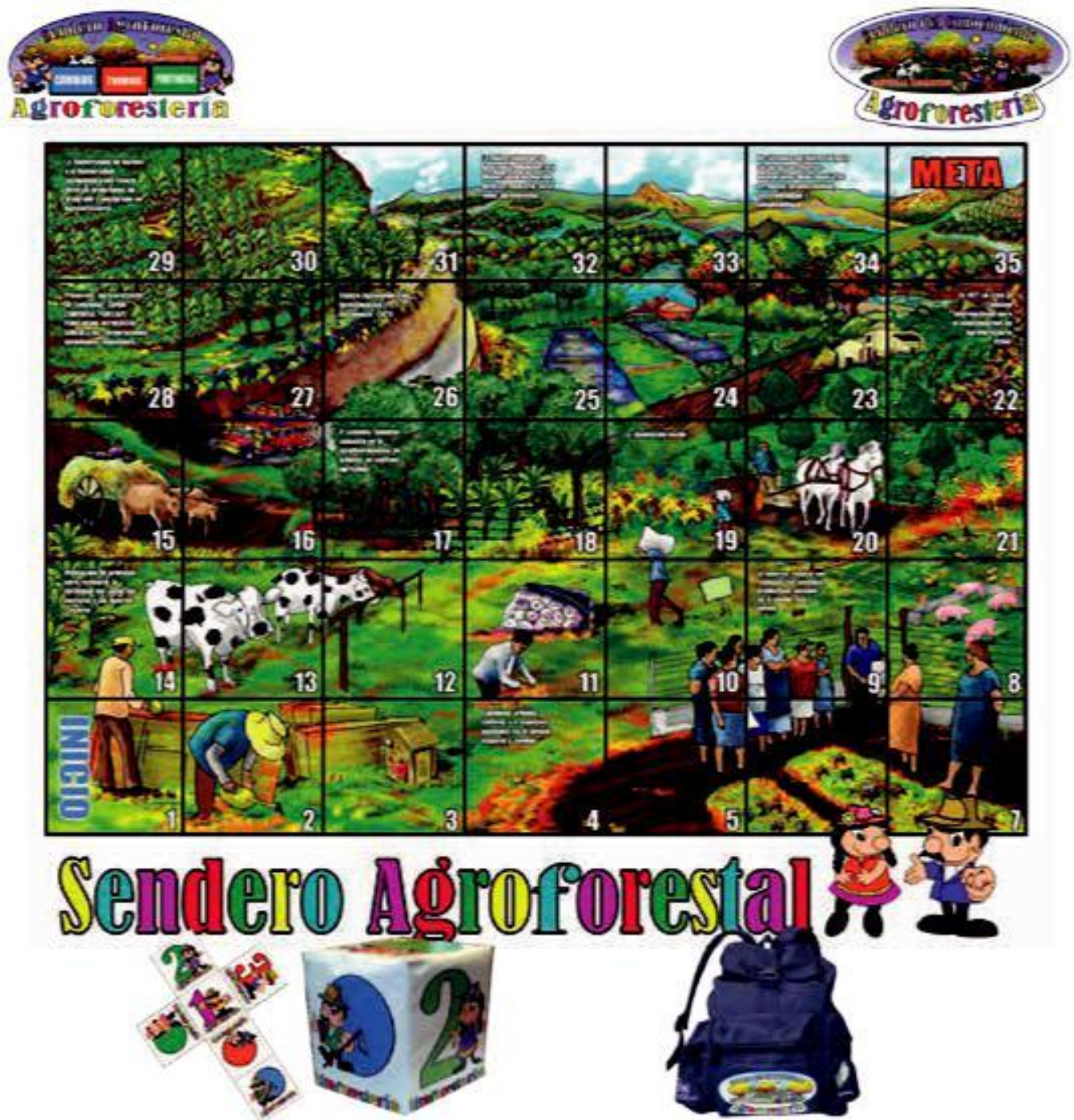


Figura 2. 5 Componentes del juego "Sendero del conocimiento"

\section{- Aspectos conceptuales para la temática 1: Historia e importancia agroforestal}

\section{Historia}

Los sistemas agroforestales se consideran de las más antiguas prácticas de cultivo utilizados en el mundo. Sin embargo, el interés en ellos, desde un punto de vista político y científico empezó a tomar forma después de los años 70, a raíz de las crecientes dudas sobre la eficiencia de las políticas de desa-rrollo vigentes, que no parecían enfrentar adecuadamente las necesidades del creciente número de pobres rurales (Nair, 1993).

Los intentos por definir agroforestería comienzan entre 1977 y 1979. Las primeras definiciones mencionaban específicamente la inclusión del árbol como factor fundamental, asumió como madera o algún otro uso forestal. Posteriormente, el término "leñosas perennes" fue propuesto y aceptado para sustituir "árbol” (Somarriba, 1990).

La agroforestería nace como una práctica productiva, cuando el hombre comenzó a practicar el cultivo de roza y quema, o el arte de la utilización de árboles para restaurar la fertilidad del suelo durante un período de barbecho; en la limpieza de zonas boscosas y dejarlas en barbecho después de unos pocos ciclos de cultivo, así, se inició la costumbre de plantar y sembrar árboles en zonas rurales (Nair, 1993).

Con la agricultura desarrollada en las diferentes civilizaciones del mundo, la importancia de los árboles disminuye, ya que los agricultores a menudo tien-den a favorecer los monocultivos. Sin embargo, el monocultivo no perduro por mucho tiempo, la agricultura de tala y quema siguió siendo el uso del suelo predominante en muchos países en vías de desarrollo, manejo que se utiliza en Europa hasta principios de este siglo (Nair, 1993).

Otras formas de mezcla de árboles con las actividades agrícolas ha evolucionado en diferentes civilizaciones y constituyen hoy en día las prácticas agrícolas que han sido ampliamente estudiadas durante los últimos 20 años (Nair, 1985). Ejemplos famosos son los parques de África, considerados como "la más grandes de un solo uso de la tierra agrícola en el África subsahariana” 
(Vandenbelt, 1990), el uso de árboles de sombra para los cultivos de plantación, como el café Coffea arabica L., o el cacao Theobroma cacao L. (Beer, et al., 1998), los huertos agroforestales tropicales (Torquebiau, 1992) y agro-forestales multiestrato del Sur Este de Asia (Gouyon et al. 1993). Estos son algunos ejemplos de lo que hoy se conoce como agroforestería, en donde los árboles son una parte integral de estos sistemas de cultivo para apoyar la agricultura. Aunque el objetivo final de estas prácticas no era la producción de árboles, sino la producción de alimentos.

Varios acontecimientos en el área de investigación y desarrollo agrícola durante los años 1960 y 1970, instituciones como el Grupo Consultivo de Investigación Agrícola (CGIAR) y el Centro Internacional de investigación agrícola (CIIA), se establecieron en diferentes partes del mundo para llevar a cabo investigaciones con el objetivo de mejorar la productividad agrícola de los principales cultivos (o animales) de los trópicos. En 1997 se estableció el Consejo Internacional para la Investigación en Agroforestería (ICRAF), como una organización internacional para apoyar, planificar y coordinar, en una escala mundial, la investigación que combina los sistemas de gestión de la tierra de la agricultura y los bosques.

El desarrollo de variedades de alto rendimiento de los cereales y las tecnolo-gías relacionadas con el esfuerzo conjunto de algunos centros y los programas internacionales pertinentes allanó el camino para lo que se convirtió en lo conocido como la Revolución Verde (King, 1979). Sin embargo, pronto se dieron cuenta que muchas de las tecnologías de la revolución verde, deman-daba de un mayor uso de fertilizantes, herbicidas, pesticidas y maquinaria, que fueron más allá del alcance de un gran número de agricultores de escasos recursos en los países en desarrollo.

Hoy en día, la agroforestería se utiliza más como un sistema agrícola, en particular para los pequeños agricultores; su potencial se está convirtiendo rápidamente en un sistema reconocido en el uso de la tierra que es capaz de producir madera y alimentos en un mismo espacio, a su vez influye en la conservación y rehabilitación de los ecosistemas.

\section{Definición}

El interés y preocupación por definir la agroforestería surgió a finales de los 
años setenta, Combe y Budowski (1979), la definieron como el conjunto de técnicas de manejo de tierras, que implican la combinación de los árboles forestales ya sea con la ganadería o con los cultivos. Poco después, Lundgren y Raintree (1982), propusieron (y se aceptó inmediatamente) el término leñoso perenne en sustitución de árbol. Este cambio permitió abarcar los sistemas agroforestales basados en el uso de arbustos, palmas, hierbas leñosas gigantes (como los bambúes) y hasta enredaderas leñosas perennes.

Por su parte el ICRAF, define la agroforestería como una denominación colectiva para sistemas de uso de tierra y prácticas agrícolas, en las cuales se integran especies leñosas perennes en forma deliberada con cultivos y/o animales en la misma unidad de manejo de tierra. La integración puede ser en una combinación espacial o en secuencia temporal. Normalmente, existen interacciones tanto ecológicas como económicas entre los componentes leñosos y los no leñosos (Lundgren y Reintree, 1982).

Posteriormente, Somarriba (2012), simplificó la definición, considerando la agroforestería, como una forma de cultivo múltiple que satisface tres condiciones básicas: 1) existen al menos dos componentes que interactúan biológicamente; 2) al menos uno de los componentes es una leñosa perenne; 3) al menos dos especies son manejadas con fines "agrícolas" en el sentido amplio de la palabra (incluyendo ganadería).

La agroforestería se fundamenta en principios y formas de cultivar la tierra basada en mecanismos variables y flexibles en concordancia con objetivos y planificaciones propuestos, permitiendo al agricultor diversificar la produc-ción en sus fincas o terrenos, obteniendo en forma asociativa madera, leña, frutos, plantas medicinales, forrajes y otros productos agrícolas (Ramírez, 2005). Garantizando a largo plazo una productividad aceptable y aplicando prácticas de manejo compatibles con las tradiciones de la población local (Musálem, 2001).

\section{Funciones de la agroforestería}

El desarrollo de la agroforestería responde a las necesidades y condiciones de muchas zonas tropicales, donde la agricultura y forestería convencionales por si solas no han podido satisfacer las necesidades (Jiménez y Muschler, 2001). Un sistema agroforestal para alcanzar sus efectos potenciales debe 
tener tres atributos: productividad, sostenibilidad y adoptabilidad:

- La productividad: el sistema produce bienes, mercancías y servicios reque-ridos por los productores por unidad de tierra (rendimiento por hectárea), aumentando los rendimientos de los cultivos asociados y de los productos arbóreos, la reducción de necesidad de insumos externos y una mayor eficiencia de la mano de obra.

- La sostenibilidad: el sistema mantiene o aumenta su productividad en el tiempo: producir conservando y conservar produciendo, correspondiente a su capacidad para satisfacer las necesidades siempre en aumento de la humanidad sin afectar, y de ser posibles, el recurso base del que depende el sistema.

- La adoptabilidad: implica que el sistema sea replicable y que sea aceptado por el agricultor, aún con las limitaciones de mano de obra, recursos económicos, insumos y servicios posibles.

Los sistemas agroforestales son una solución a los problemas de degradación de la tierra y del agua, y como respuesta a la escasez de alimento, leña, ingreso, forraje animal y materiales de construcción. Además se puede aplicar en sistemas de producción intensiva y extensa, como también para peque-ños productores y agricultura de subsistencia (Mendieta y Rocha, 2007). La agroforestería es conocida por la potencialidad de los árboles fijadores de nitrógeno para mejorar la fertilidad de las tierras cultivadas y de las áreas de pastizal; la resistencia de ciertos árboles a la sequía (muy importante en las zonas áridas); la función de las cortinas rompevientos en la protección de las tierras cultivadas y de las áreas de pastizal; la contribución de los árbo-les forrajeros ricos en proteína para la producción ganadera, y el poten-cial comercial de algunos tipos de árboles cultivados. Además, las prácticas agroforestales son apropiadas para una amplia variedad de sitios, tales como tierras con pendiente o tierras planas (Mendieta y Rocha, 2007).

La agroforestería se considera una herramienta fundamental en la búsqueda de la seguridad alimentaria, la autosuficiencia de los agricultores y la conservación de los recursos naturales. Como ciencia moderna; busca validar y maximizar los beneficios de las interacciones del suelo, plantas, animales, atmosfera y el hombre. Para implementar estos beneficios, la agroforestería busca prácticas para enfrentar el crecimiento acelerado de la población, la pobreza rural y la degradación ambiental a través de la optimización de los 
efectos benéficos de las interacciones del componente leñoso con el componente animal y/o cultivo, para reforzar y establecer la sostenibilidad en la parcelas de los agricultores, mediante la promoción de la diversificación productiva y capacitación en el manejo de sistemas multiestratos (Palomeque, 2009).

Aunque la agroforestería no es una panacea para resolver todos los proble-mas de desarrollo rural, ésta contribuye a solventar problemas bien conocidos en tres situaciones comunes en el tópico según Nair y Muschler (1993):

- En los trópicos húmedos, la agroforestería juega un papel importante para mantener la fertilidad del suelo.

- En zonas con pendientes fuertes (laderas, colinas, montañas), la agro-forestería contribuye a controlar la erosión.

- En zonas semiáridas y subhúmedas, frecuentemente bajo uso excesi-vo para pastoreo, la agroforestería ayuda a combatir la desertificación.

Sin embargo, a pesar de las funciones positivas de los árboles en los SAF también puede haber efectos negativos sobre el cultivo o el ambiente, al causar sombra excesiva al cultivo, competir por luz, agua y nutrientes con los cultivos, hospedar plagas y enfermedades, efectos alelopáticos (Jiménez y Muschler, 2001). 


\subsubsection{Juego dos: "Riqueza Ambiental"}

Mediante un rompecabezas con un paisaje típico de la zona andina, se resalta los beneficios del árbol como especie multipropósito, que ofrece bienes y servicios ecológicos y socioeconómicos, destacando las ventajas y desventajas de su uso y manejo en los distintos sistemas de producción.

Temática: Bienes y servicios de la agroforestería.

Objetivo: Identificar las principales fortalezas y debilidades de la agroforestería en un contexto de vida integral.

\section{Ideas claves}

1. Reconocimiento de los principales bienes y servicios de la agroforestería.

2. Valoración de la importancia de un adecuado manejo agroforestal.

\section{Instrucciones de aplicación}

- Se organiza a los participantes en cuatro grupos, quienes colocan un nombre a su grupo.

- Cada grupo recibe un rompecabezas donde se evidencia un paisaje y lo arma rápidamente. Cada grupo puede corroborar si su rompecabezas es correcto observando el telón que muestra el paisaje, el cual se ubica en un lugar visible para todos los participantes.

- Una vez que los equipos armen el rompecabezas deben analizar en grupo la figura y en papel bond con marcadores escribir tres bienes y tres servicios de la agroforestería.

- Un representante de cada grupo expone el resultado del trabajo grupal.

- Al final el facilitador reitera la importancia de la agroforestería en el contexto de la región donde se aplica el juego.

\section{Contenido del juego}

Morral de transporte del juego, guía del facilitador, telón del paisaje del rom-pecabezas, cuatro rompecabezas (Figura 2.6). 
Figura 2. 6 Componentes del juego

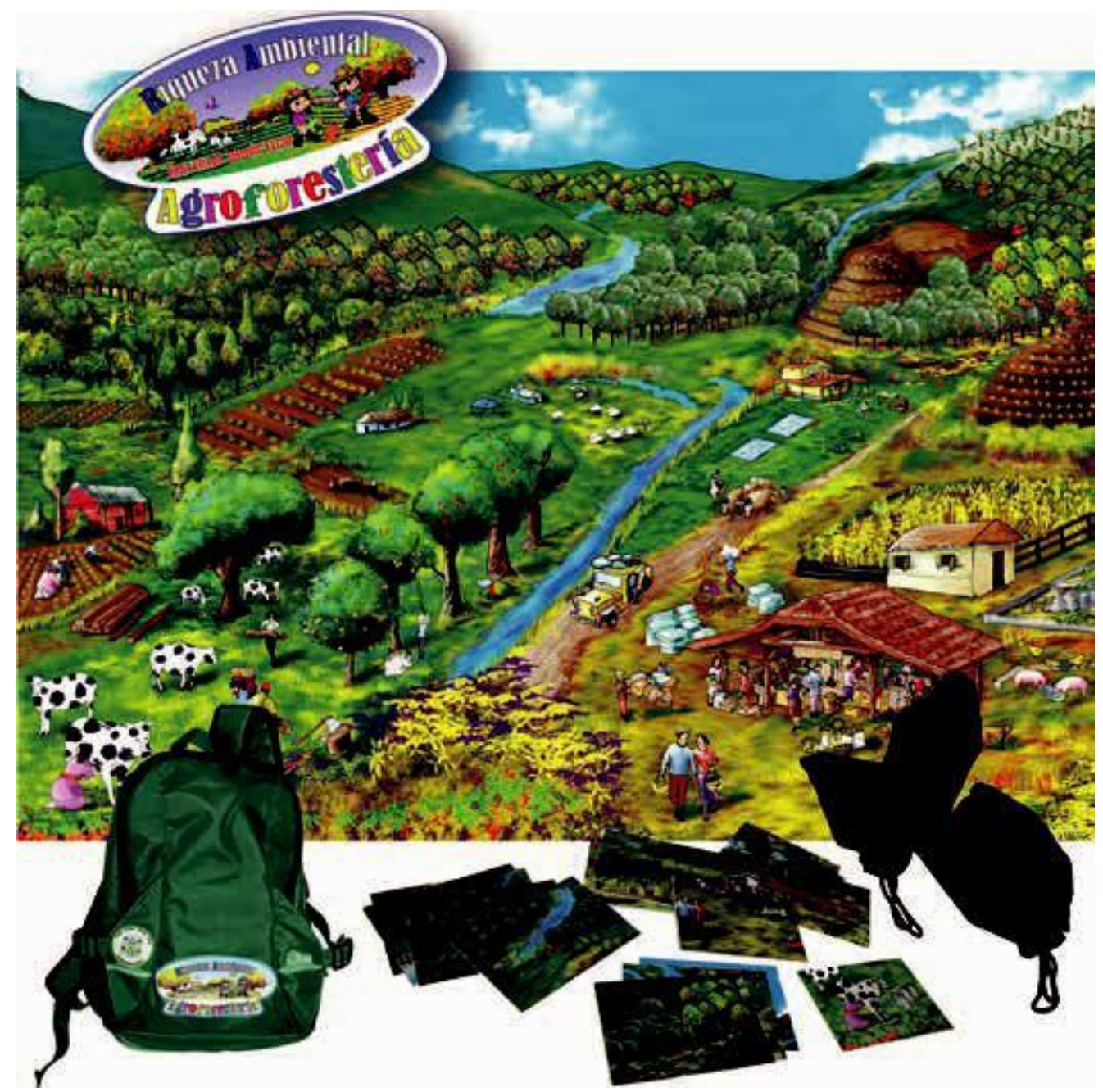

"Riqueza Ambiental"

\section{- Aspectos conceptuales para la temática 2: Ventajas y desventajas de la agroforestería}

Entre las fortalezas de la agroforestería encontramos las siguientes:

- Aumento de la productividad de un área determinada a través del arreglo espacial de la asociación de árboles y otras especies. Se logra mejor utilización del espacio vertical y del período de cultivo y se imitan patrones ecológicos naturales en cuanto a forma y estructura y se capta mejor la energía solar. 55 
- Mantenimiento o incremento de la productividad del sitio, se regresa mayor biomasa al sistema (materia orgánica), lo cual es de mejor calidad, presentando, una recirculación más eficiente de nutrientes, incluyendo su ascenso desde las capas más profundas del suelo.

-Es muy apropiado para zonas marginales ya que es probable que tenga mayor resistencia a la variabilidad de la precipitación pluvial y puede practi-carse en pendientes más pronunciadas.

-Microclima más moderado, disminuye los efectos perjudiciales del sol, el viento y la lluvia sobre los suelos.

-Mayor protección contra erosión por viento y agua (menos impacto erosivo de las gotas de lluvia y escorrentía superficial).

-Los árboles leguminosos (y algunos de otras familias) fijan e incorporan nitrógeno atmosférico y este aporte minimiza el gasto en fertilizantes.

-Los animales consumen la cobertura herbácea que puede competir con los árboles, dificultar el manejo e incrementar el riesgo de incendios en plantaciones forestales. En sistemas silvopastoriles con árboles frutales o palmas, el pastoreo facilita la cosecha de los frutos.

-En el caso de silvopastoriles, hasta el $70 \%$ de la biomasa producida por los cultivos asociados y el forraje de algunas especies de árboles fijadores de Nitrógeno (AFN) se complementan en su contenido de nutrientes (energía, proteína, vitaminas y minerales) y pueden ser utilizados en la alimentación animal, sin crear competencia por los productos de consumo humano.

-Se mejora la estructura del suelo (más agregados estables) y se evita la formación de capas duras.

- La diversidad de especies evita la proliferación de insectos y puede haber influencias benéficas debido a mutualismos.

-Se favorece la fauna silvestre, la que, en algunos casos puede ser una apropiada fuente de proteína.

- El agricultor (especialmente el de escasos recursos) se autoabastece de leña, 
postes, madera, frutos, forraje, productos medicinales, etc.

- Los árboles constituyen un "capital en pie", un seguro para emergencias; cuando se necesita dinero rápidamente.

- Se evita dependencia de un sólo cultivo y se reducen los problemas asocia-dos con lluvias irregulares, fluctuaciones de precios, dependencia de produc-tos importados (plaguicidas, fertilizantes) y aparición de plagas.

- Puede proveer beneficios socioeconómicos y culturales, entre los cuales puede mencionarse la disminución de los riesgos económicos para el agricultor al lograr diversificar la producción; el empleo de mano de obra familiar, con una mejor integración de los miembros de la familia al proceso productivo y el mantenimiento de costumbres o prácticas de uso de la tierra, de fuerte arrai-go cultural, lo cual puede considerarse en una mejora de la calidad de vida.

Entre las debilidades de la agroforestería encontramos las siguientes:

-Puede disminuir la producción de los cultivos principalmente cuando se uti-lizan demasiados árboles (competencia) y/o especies incompatibles.

-Pérdida de nutrientes cuando la madera y otros productos forestales son cosechados y exportados fuera de la parcela.

-Interceptación de parte de la lluvia, lo que reduce la cantidad de agua que llega al suelo (importante en zonas secas).

-Daños mecánicos eventuales a los cultivos asociados cuando se cosechan o se podan los árboles, o por caída de gotas de lluvia desde árboles altos.

-Los árboles pueden obstaculizar la cosecha mecánica de los cultivos.

-El microambiente puede favorecer la presencia de algunas plagas y enfermedades.

- Puede requerir más mano de obra, convirtiéndose en un factor negativo cuando la mano de obra es escasa y cara, y cuando la mecanización puede ser la mejor solución. 
- Mayor complejidad del sistema agroforestal puede dificultar labores de manejo.

- Menor disponibilidad de crédito, asistencia técnica e incentivos gubernamentales.

- Menor conocimiento de potencialidades y manejo de los sistemas agroforestales.

2.3.2.3 Juego tres: Clasificación de sistemas agroforestales "ClasiSAF"

Es una ruleta que gráficamente muestra los componentes agroforestales y sus interacciones que conllevan a su clasificación; en él se resaltan las principa-les características de los sistemas silvoagrícola, agrosilvopastoril y silvopas-toriles, facilitando la comprensión de los conceptos.

Temática: Clasificación de los sistemas agroforestales por componentes

Objetivo: Identificar los principales componentes de los sistemas agroforestales y su influencia en su clasificación.

Ideas claves

1. Los sistemas agroforestales, responden a necesidades específicas y esto, determina un orden espacial y/o temporal dentro de la finca.

2. La presencia de componentes, define el tipo de sistema agroforestal.

Instrucciones de aplicación

- Se organiza a los participantes en tres grupos, cada uno de ellos recibe el nombre de uno de los tres sistemas agroforestales (silvoagrícola, silvopastoril, agrosilvopastoril).

- Todos los participantes se ubican alrededor de la ruleta y se les asigna un número.

- El dinamizador anuncia la salida y todos los participantes giran alrededor de la ruleta cuando el dinamizador dice un número la persona a la que le corresponde el numero toma una ficha del centro de la ruleta la lee en voz alta si le sale una característica de los sistemas agrofores-tales la ubica donde considera corresponde pero si le sale una peniten- 
cia debe reunirse con su grupo y cumplirla.

- El jugador nombrado va saliendo del juego.

- Los jugadores continúan girando alrededor de la ruleta y avanza la misma dinámica al final el grupo que llene primero las diez características de su sistema agroforestal es el ganador y el resto de grupos deben terminar de completar las características de los sistemas correspondientes.

\section{Contenido del juego}

Morral de transporte del juego, guía del facilitador, tapete gigante de la rule-ta, fichas de características de los tres sistemas (Figura 2.7).

\section{Figura 2. 7 Componentes del juego "Clasi-SAF”}

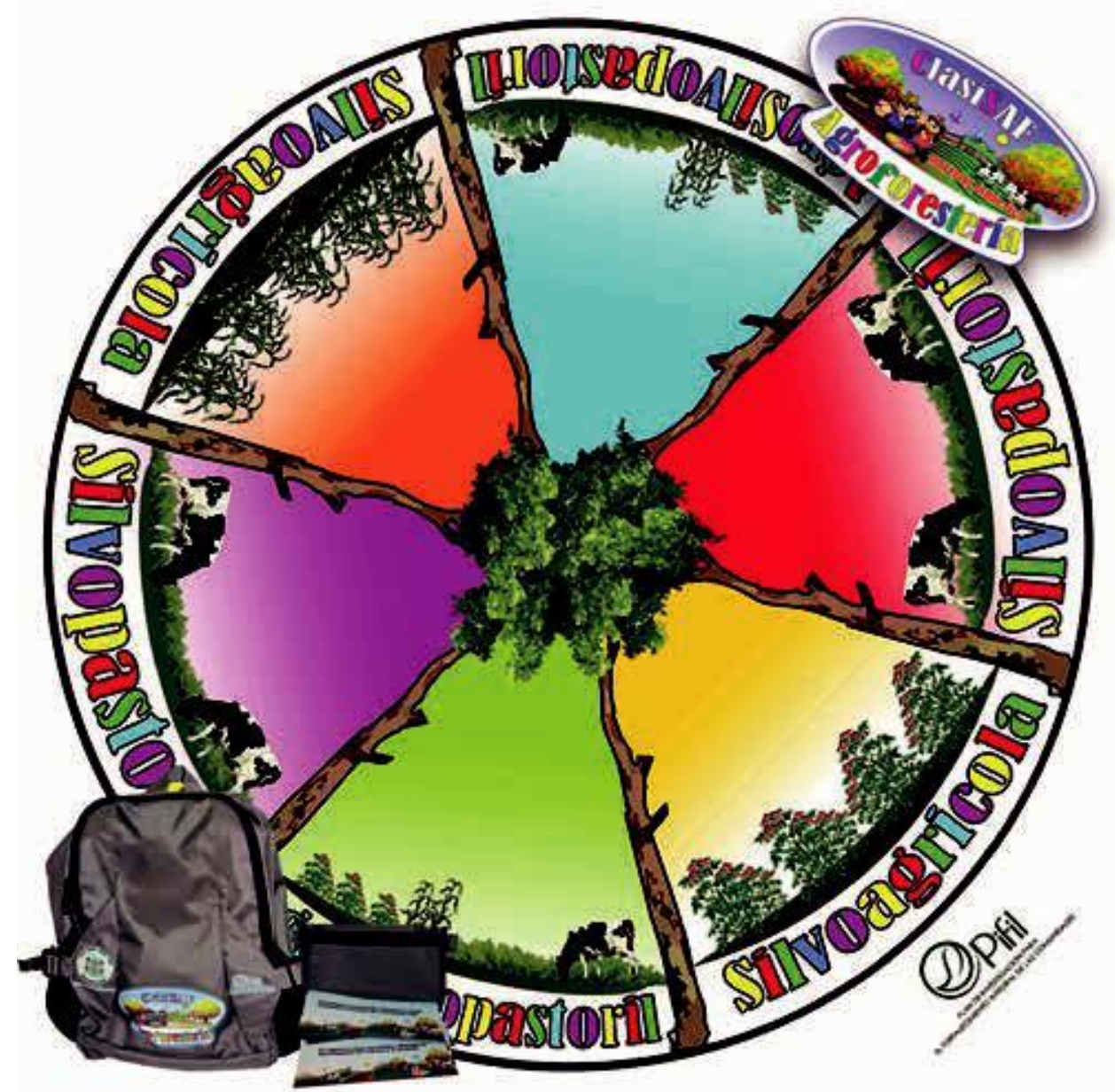




\section{- Aspectos conceptuales para la temática 3: Clasificación de siste-mas agroforestales y criterios y formas de clasificar los SAF}

Los sistemas agroforestales se clasifican según su estructura en el espacio, su diseño a través del tiempo y la función de los diferentes componentes, además de los objetivos de la producción y las características sociales y eco-nómicas prevalentes.

Nair (1985), sugiere una clasificación donde se consideran los aspectos estructurales y funcionales para agruparlos en las siguientes categorías: los sistemas silvopastoriles (árboles asociados con ganadería), los sistemas agro-silvoculturales o silvoagrícolas (árboles combinados con cultivos), sistemas silvopastoriles (cultivos combinados con ganadería) y sistemas agrosilvopas-toriles (árboles con cultivos y ganadería).

Los sistemas silvopastoriles, es una opción de producción pecuaria que invo-lucra la presencia de las leñosas perennes (árboles o arbustos), e interactúa con los componentes tradicionales (forrajeras herbáceas y animales), todos ellos bajo un sistema de manejo integral (Pezo y Ibrahim, 1999). Esta actividad optimiza la producción pecuaria, mejorando la calidad del alimento y a la vez, generar un ingreso adicional por la venta de la madera a través de la plantación de especies que permitan rehabilitar suelos degradados, que sean de rápido crecimiento y que aseguren a los ganaderos competir, ventajosa-mente, en su mercado (Trujillo, 2008).

Los Sistemas agrosilvicolas, comúnmente incluyen árboles y cultivos temporales (anuales o perennes), pudiéndose decir igualmente que son los que combinan la agricultura y los bosques (Vélez y Moreno, 1993).

Los Sistemas agrosilvopastoriles, consisten en alternar árboles, cultivos de temporada y pastizales para sostener la producción animal en el mismo espacio y tiempo.

Esas categorías se subdividen de acuerdo con criterios de arreglo espacial (sistemas mixtos densos, sistemas en franjas, etc.); de arreglo temporal (sistemas secuenciales, coincidentes, interpolados, etc.); funciones de los componentes (leña, forrajes, cercos vivos, conservación de suelos, etc.); zonas agroecológicas donde se los practica (sistemas agroforestales para zonas de 
altura, para zonas semiáridas, etc.); y aspectos socioeconómicos (sistemas para altos o bajos insumos, etc.). De esa manera la clasificación es dinámica y no meramente descriptiva (Nair, 1985).

Montagnini (1992), los clasifica según su estructura y función en el espacio y tiempo, dándole importancia a la función de los diferentes componentes:

Sistemas agroforestales secuenciales: en ellos existe una relación cronológica entre las cosechas anuales y los productos arbóreos; es decir, que los cultivos anuales y las plantaciones de árboles se suceden en el tiempo (manejo de barbechos y los sistemas taungya).

Según Rivas (2005), en los sistemas secuenciales, las cosechas y los árboles se turnan para ocupar el mismo espacio, los sistemas generalmente empiezan con cosechas agrícolas y terminan con árboles, la secuencia en el tiempo mantiene la competencia a un mínimo, los árboles en un sistema secuencial deben crecer rápidamente cuando los cultivos no lo están haciendo, deben reciclar minerales de las capas de suelo más profundas, fijar nitrógeno y tener una copa densa para ayudar a suprimir plantas indeseables.

Sistemas agroforestales simultáneos: consisten en la integración simultánea y continúa de cultivos anuales o perennes, árboles maderables, frutales o de uso múltiple, y/o ganadería (asociaciones de árboles con cultivos anuales o perennes, huertos caseros o mixtos y sistemas silvopastoriles).

En estos sistemas los árboles compiten principalmente por luz, agua y mine-rales, la competencia es minimizada con el espaciamiento y otros medios, los árboles en un sistema simultáneo no deben crecer tan rápido cuando la cosecha está creciendo también rápidamente, para reducir la competencia, los árboles deben tener también raíces que lleguen más profundamente que las de los cultivos, y poseer un dosel pequeño para que no los sombreen de-masiado (Rivas, 2005).

\subsubsection{Juego cuatro: "Arreglotón"}

Este juego representado en un árbol y su interacción con el suelo en un área determinada, evidencia la importancia de los arreglos agroforestales, toda vez que se consideran como un gran tesoro para el desarrollo sustentable en la medida en que se implementen como alternativas productivas pertinentes 
y adecuadas a las condiciones socioambientales actuales.

Temática: Arreglos agroforestales más comunes.

Objetivo: Conocer los principales arreglos agroforestales y reconocer su im-portancia.

Ideas claves:

1. Características de los distintos arreglos agroforestales.

2. Reconocer uso de distintas especies en los arreglos agroforestales.

3. Los sistemas agroforestales, presentan una dinámica en el orden espacial (Horizontal y vertical) respecto a los cultivos y/o animales, constituyéndolos en arreglos agroforestales.

Instrucciones de aplicación:

- Se organiza a los participantes en dos grupos, cada uno de ellos recibe un nombre escogido por el grupo.

- Los participantes de cada grupo se numeran y en turnos alternos lanzan tres pelotas para lograr el mayor puntaje.

- Cuando el jugador logra ingresar las pelotas en las casillas de puntos positivos tiene derecho a sacar una hoja verde del gran árbol, la cual corresponde a un tipo de arreglo agroforestal, el jugador lee en voz alta la descripción del arreglo y la ubica en el árbol.

- Cuando el jugador ingresa las pelotas en las casillas de puntos negativos tiene derecho a sacar una hoja seca, la cual corresponde a una penitencia, el jugador la lee en voz alta y con su grupo debe cumplirla.

- El grupo ganador es el que logra mayor puntaje y debe hacer un recuento de todos los arreglos identificados en el árbol.

\section{Contenido del juego}

Morral de transporte del juego, guía del facilitador, lona de árbol gigante, pelotas, hojas fichas de arreglos y penitencias, tallo de árbol con orificios (Figura 2.8). 
Figura 2. 8 Componentes del juego "Arreglotón”

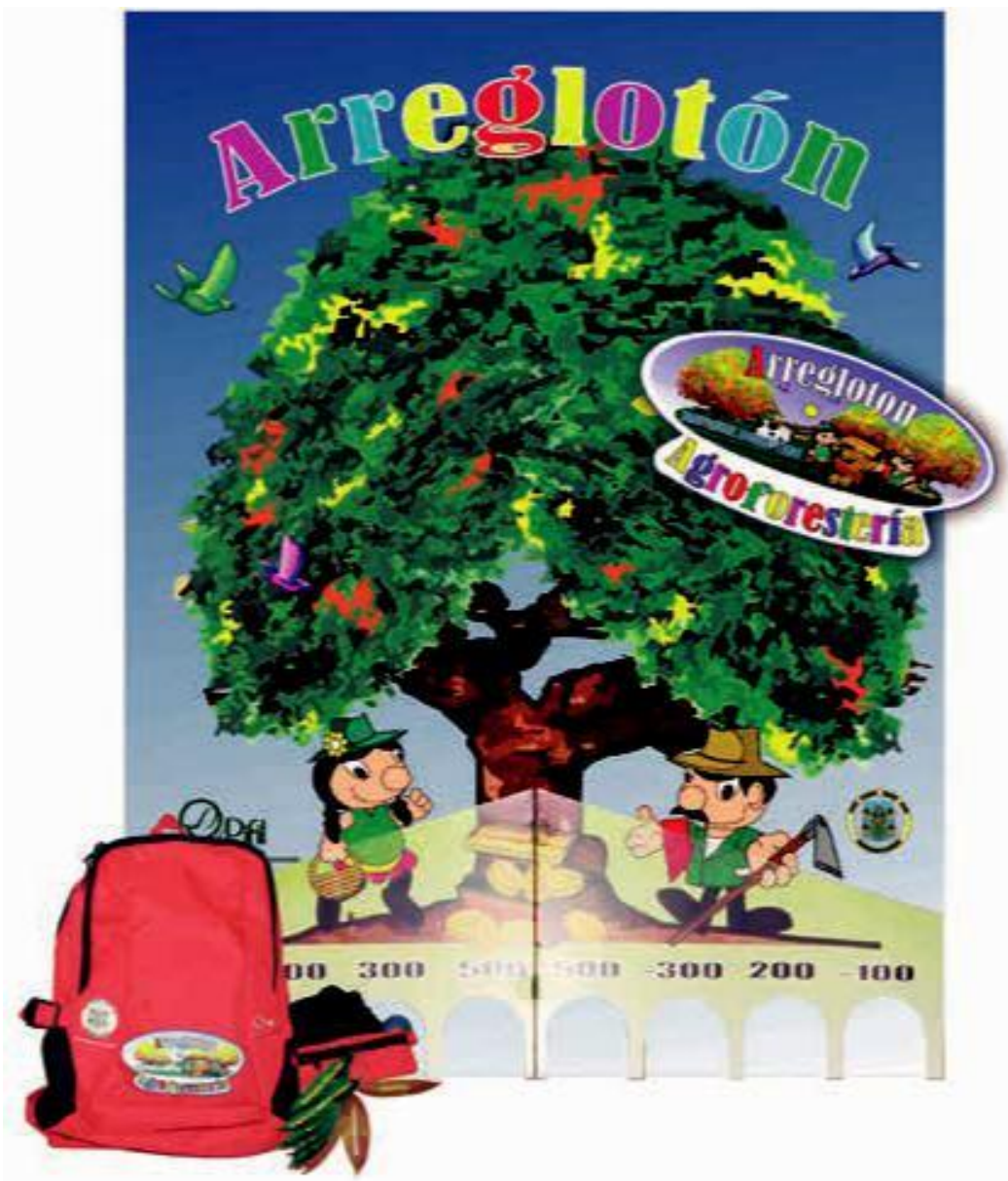

\section{Aspectos conceptuales para la temática 4: Arreglos agroforestales}

\section{Principales arreglos agroforestales:}

1. Agricultura migratoria: La agricultura migratoria comprende sistemas de subsistencia orientados a satisfacer las necesidades básicas de alimentos, combustible y habitación; sólo ocasionalmente llegan a construir una fuente de ingresos por medio de la venta de excedentes de algunos productos (Nair, 1993). Es un sistema en el cual el bosque se corta y se quema para cultivar la tierra por un periodo de 2 a 5 años; luego del periodo de cultivo continúa la fase de descanso o barbecho, que dura generalmente de 5 a 20 años (Jiménez y Muschler, 2001). 
La función principal del barbecho es, en la mayoría de los casos, mejorar las condiciones químicas, físicas y biológicas del suelo, de tal manera que este sea aprovechado para el establecimiento de cultivos que en el momento en que la parcela fue abandonada al final del ciclo anterior (Montagnini, 1992). Después de la quema, predomina en la vegetación pionera que invade el área resultante en lo que se conoce como bosques oligárquicos (Peters, et al., 1989).

2. Barbechos mejorados: Los barbechos o períodos de descanso, es el tiempo durante el cual las especies invasoras naturales o latentes se les permite ponerse al por sucesión natural después de un recorte período (Nair, 1993). El objetivo del periodo de descanso en los barbechos mejorados es que per-mita un sistema rotacional en la cual se favorecen ciertos árboles de regene-ración natural y/o se plantan nuevos árboles (Kass, 1998).

Estos árboles son generalmente: especies leguminosas que fijan nitrógeno del aire, acumular nutrientes de sistema, especies de rápido crecimiento y especies que rebrotan de raíz, cuyos tocones se dejan en el campo durante el período de cultivo (Montagnini, 1992). También, se busca especies de valor comercial, la vegetación de barbecho se enriquece con árboles frutales, maderables o de otros usos importantes (Jiménez y Muschler, 2001).

3. Sistema taungya: El arreglo "taungya" combina la producción de árboles con la siembra de cultivos básicos antes y/o durante los primeros años del establecimiento de la plantación (Montagnini, 1992). Es un sistema en el cual el bosque se corta y se quema para cultivar la tierra por un periodo de 2 a 5 años; luego del periodo de cultivo continúa la fase de descanso o barbecho, que dura generalmente de 5 a 20 años (Jiménez y Muschler, 2001). Este sistema es utilizado tanto por gobiernos y particulares como modelo para establecer reforestaciones a bajo costo, en la cual árboles y cultivos crecen de manera simultánea durante el periodo de establecimiento de la plantación forestal (Vélez, 1993). Otras funciones son la acumulación de CO2, liberación de oxígeno, cobertura permanente del suelo, generación de empleo rural.

4. Árboles en cultivos perennes: Consiste en la combinación simultánea de árboles con cultivos perennes, tales como el café (Coffea arabica L.), y cacao (Theobroma cacao L.). Generalmente son sistemas del cultivo intercalado donde el árbol contribuye productos adicionales, mejora el suelo o microclima o sirve de tutor para cultivos de enredadera como pimienta negra (Piper nigrum L.), o vainilla (Vanilla planifolia Mill). Los árboles pueden ser maderables como nogal cafetero (Cordia alliodora (Ruíz \& Pav.) Cham.), cedro (Cedrela odorata L.); especies leguminosas de uso multiple como guama 
(Inga edulis Mart), matarratón (Gliricidia sepium (Jacq.) Kunth Ex Walp) y eritrinas o frutales como citricos (Citrus spp), aguacate (Persea americana Mil) L.), o macadamia (Macadamia spp). (Jiménez y Muschler, 2001).

$\mathrm{Su}$ función principal es mantener o mejorar la productividad del sistema mediante la protección de los cultivos del intenso calor y lluvias y aumentar el ciclaje de nutrientes. Adicionalmente el sistema brinda otros productos y servicios (frutas, madera, leña, plantas aromáticas y medicinales, acumulación de $\mathrm{CO} 2$, liberación de oxígeno, conservación del suelo, diversificación del paisaje, alimento y refugio de fauna silvestre).

En el caso de árboles con cultivos de ciclo corto, aunque estos no necesitan una sombra permanente, que puede impedir o disminuir su crecimiento, una sombra ligera o transitoria puede ser muy provechosa en ciertos momentos: en la época más delicada de desarrollo del cultivo (germinación y crecimiento inicial), en los períodos de sequía y en las horas más calurosas, los árboles asociados a los cultivos perennes pueden jugar un papel de fertilización del suelo (Ospina, 2003).

\section{Leñosas como soportes vivos para cultivos trepadores o de enredadera:}

Las especies de árboles útiles al arreglo se plantan por lo general en estacas grandes, permitiendo las podas de copa continuas, son de copa estrecha y preferiblemente que fertilicen el suelo a través de incorporación de fertilizante orgánico y nitrógeno. Plantados muy cerca, en curvas de nivel, los arbustos pueden formar barreras vivas muy resistentes gracias a sus raíces profundas.

Estas barreras vivas son más duraderas. Este sistema se refiere a la utilización de especies leñosascomo soporte o tutores de algunos cultivos, como el ñame (Dioscorea spp)., el maracuya (Passiflora edulis Sims), la vainilla (Vanulla planifolia Mill.) y hortalizas como el pepino (Cucumis sativus L). o el tomate (Lycopersicon esculentum P. Mill.) (Jimenez, et al., 2001). Los árboles o arbustos utilizados pueden tener otras funciones como producción de leña postes, abono verde, forraje, conservación de suelo, etc. Entre las especies más utilizadas para este fin están matarratón (Gliricidia sepium (Jacq.) Kun-th Ex Walp), chachafruto (Erythrina edulis Triana Ex. Micheli), leucaena (Leucaena leucocephala (Lam) de Wit) y flemingia (Flemingia macrophylla (Willd.). (Jiménez y Muschler, 2001).

Según Cálix y Castillo (2000), los soportes vivos son árboles que deben reunir ciertas caracteristicas para permitir el buen desarrollo y producción del 
cultivo: Se debe propagar por estacas, para ser utilizados directamente. Deben producir raices profundad y crecer con rapidez. Deben soportar la poda frecuente. Deben tener una vida útil igual o mayor a la vida productiva del cultivo (alrededor de 15 años). Tener suficiente resistencia para soportar el peso del cultivo en producción.

6. Huertos caseros: Los huertos caseros tradicionales ocupan un lugar muy singular en los SAF. Ningún otro es tan diverso en cantidad de especies y variedades, complejo y variado en estructuras y posibles asociaciones y tan completo en sus funciones (Lok, 1998). Son una asociación íntima de árboles y/o arbustos de uso múltiple con cultivos anuales y perennes y animales en las parcelas de hogares individuales. El sistema es manejado por mano de obra familiar (Nair, 1993). Su tamaño generalmente es menor a una hectárea.

Entre las características más sobresalientes de los huertos caseros encontramos según (Gliessman, et al., 1981) son sistemas con pocas necesidades de ingresos y capacidad constante de egresos para el consumo. La necesidad de mano de obra se escalona durante el año y no se concentra en épocas cortas. Se depende más de la mano de obra familiar. Los huertos caseros tienden a mantener la producción durante todo el año y juegan el papel primordial de suplir los alimentos básicos a nivel familiar siendo agro-ecosistemas con demandas económicas reducidas, apropiados para personas de escasos recursos. Ecológicamente, son sistemas agrícolas muy parecidos a los ecosistemas naturales, debido a la gran diversidad de especies, alta capacidad a la captura de la radiación solar, mecanismos de control biológico, ciclos cerrados de nutrientes, uso eficiente del espacio y alto grado de estabilidad. Económicamente, son sistemas agrícolas con mucha resistencia a la fluctuación e inseguridad del mercado, debido a la gran diversificación de sus productos.

7. Cultivo en callejones: Consiste en la siembra de cultivos anuales en los espacios (callejones) entre hileras de especies leñosas, preferiblemente leguminosas de rápido crecimiento. Los árboles están orientados de manera que minimizan la sombra dentro de los callejones o en líneas de contorno en laderas para minimizar erosión (Jiménez y Muschler, 2001).

Los árboles son podados frecuentemente y las podas son depositadas en el área de los cultivos con la finalidad de proveer nutrientes. La poda de los árboles reduce la competencia por luz, favoreciendo a los cultivos. Si los árboles son leguminosos, el nitrógeno se constituye en el principal elemento aportado por las podas para los cultivos (Navia, 2001).

Las especies leñosas más destacadas en el cultivo en callejones son la Leu- 
caena (Leucaena leucocephala (Lam) de Wit), matarratón (Gliricidia sepium (Jacq), Kunth Ex Walp), carboncillo (Calliandra calothyrsus Meisn) y poró (Erytrina poeppigiana (Walp.)) Of Cook. Los cultivos más usados han sido maíz (Zea mays L.), sorgo (Sorghum bicolor L. Moench), frijol (Phaseolus vulgaris L.) (Jiménez, et al., 1998).

8. Árboles para conservación de suelo: Los árboles y arbustos que se plantan asociados a obras de conservación de suelos como acequias de ladera, drenajes, taludes, franjas contra la erosión, terrazas, zanjas de filtración, entre otras. Su función básica es controlar la erosión, mantener la fertilidad del suelo o ambas, a través de la estabilización de las estructuras, reducción de la escorrentía superficial, aporte de biomasa y ciclaje de nutrientes. Uno de los ejemplos tipicos de esta práctica agroforestal son las barreras vivas de leñosas, plantadas en contorno y a distancias muy cortas entre árboles, con la base tejida y otros materiales para retener los sedimentos y proteger obras de conservación (Jiménez y Muschler, 2001).

9. Cercas vivas: Una cerca viva es una línea de especies leñosas o arbustos que delimitan y restringen el paso de personas y animales a una propiedad o parte de ella. Generalmente está asociada con ecosistemas, cultivos agricolas, pasturas, otros SAF y viviendas (Ospina, 2003). Las cercas vivas casi siempre se complementan con el uso de alambre de púas. El establecimiento de cercas vivas implica una reducción en costos con respecto a las cercas muertas, reduce la presión sobre el bosque por la búsqueda de postes y leña y además ofrece follaje en cantidad y de calidad durante la época seca, además de ofrecer frutas (Beer, et al., 2004).

Las ventajas del uso de cercas vivas se pueden resumir de la manera siguiente: Rinden diversos productos de valor económico, como alimento humano, fo-rraje, productos medicinales, leña y nuevos postes para cercas. Protegen a los cultivos y animales contra el viento. Sirven como barrera para detener la erosión y tienenun efecto beneficioso para el suelo. Generalmente duran mucho tiempo. Tienen un costo relativamente bajo. 10. Bancos forrajeros: Consiste en establecer áreas forrajeras en bloques compactos con especies leñosas sembradas a alta densidad. Se siembran con el propósito de maximizar la producción de biomasa con alta calidad nutritiva para la suplementación aniaml, se sumistra como forraje de corte o permitiendo el ingreso de los animales a la plantación. Se denomina como 
banco de proteína, si la especie forrajera tiene más de $15 \%$ de proteína cruda; si la especie forrajera presenta altos niveles de energía digerible (más del $70 \%$ de digestibilidad), se denomina como banco energético. $\mathrm{Al}$ cumplirse en un banco forrajero los dos requisitos anteriores se denomina como banco energético-proteico (Jiménez y Muschler, 2001).

Las especies forrajeras son sometidas a periódicos cortes y acarreo para animales. Esta tecnología agrforestal, de tipo intensivo y altas densidades de siembra, generalmente requiere mucha mano de obra y aplicación de abonos y otros insumos agricolas (Ospina, 2003).

Los bancos forrajeros tienen como propósito fundamental complementar la dieta alimenticia de los animales, especialmente durante la época de escasez de pastos. Las especies mas utilizadas por su alto valor forrajero son:matarra-tón (Gliricidia sepium (Jacq.) Kunth Ex Walp), poró (Erythrina poeppigiana (Walp.) Of Cook), Pito (Erythrina berteroana Urb.), cachimbo (Erythrina fusca Lour.), morera (Morus spp). (Pezo e Ibrahim, 1999).

11. Árboles y arbustos dispersos en potreros: Consiste de árboles, arbustos o ambos en los potreros, sin un arreglo espacial definido y con objetivos diversos tales como: producción de madera, leña, frutos, fuente de ramoneo, provisión de sombra, mejoramiento del suelo bajo árboles y refugio para ganado. El establecimiento se puede dar por: remanentes de bosque natural, por procesos de suseción vegetal, a travéz de la plantación de árboles y arbustos remanentes o la introducción de especies en praderas ya existentes (Pezo e Ibrahim, 1999).

12. Pasturas en callejones: Se refiere a la práctica agroforestal en la que los cultivos anuales son sembrados en los espacios que quedan entre las lineas de una especie leñosa, generalmente leguminosas, que es podada a intervalos regulares para evitar competencia y proveer un mantillo a lo cultivos (Kang, et al., 1990).

En este sistema, las leñosas son sometidas a podas periodicas y el follaje resultante es depositado como mulch sobre la superficie del suelo o incorpo-rado como abono verde (Kang, et al., 1990). El forraje suministrado de los árboles leguminosos tambien es utilizado como forraje suplementario para animales, o son podadas ocasionalmente para porpositos forrajeros durante el periodo seco (Atta-Krah, 1993). 


\subsubsection{Juego cinco: "Planificando Ando"}

El juego consiste en el uso de maquetas que representan terrenos con distintas condiciones de topografía, suelos y agua, planificadas de acuerdo a los recursos económicos con que se cuenta, además permite conocer los lineamientos requeridos para la planificación de fincas, que a su vez se encuentra articulado, a los principios del manejo de cuencas hidrográficas.

Objetivo: Analizar las principales características de la finca para la planifica-ción agroforestal sustentable.

\section{Ideas claves}

1. Criterios para el establecimiento de arreglos.

2. Especies más empleadas en el altiplano andino.

3. Visión holística de la planificación agroforestal.

\section{Instrucciones de aplicación}

- Se organiza a los participantes en seis grupos, cada uno de ellos reci-be el nombre seleccionado por los participantes.

- El facilitador con la ayuda de un participante hacen de almacén para vender los elementos a los participantes.

- Cada grupo recibe una cantidad de dinero \$20.000 con lo cual puede comprar distintas elementos para poner a producir su finca (terreno, casa, animales, cultivos, arboles) estos elementos tienen un precio (ver lista de precios).

- Cada terreno tiene una fuente de agua que rodea su finca la cual debe tenerse en cuenta al momento de la planificación.

- El grupo debe analizar su terreno la disponibilidad de recursos y pla-nificar su producción teniendo en cuenta los conceptos fundamentales de la agroforestería.

- A los 10 minutos de iniciado el juego el facilitador anuncia que se presenta una gran helada y que los cultivos que no son protegidos con árboles que brinden microclimas serán afectados. El facilitador pasa por cada grupo y los que no tengan la combinación de árboles y cultivos tendrán punto negativo los que si demuestren distintos arreglos agroforestales tendrán punto positivo.

- A los 15 minutos el facilitador anuncia fuerte sequía y pasa por los 
grupos los que tengan protección de fuente hídrica tendrán punto posi-tivo de lo contrario punto negativo.

- Al final del juego cuando ya todos terminen de planificar su finca cada grupo socializa su trabajo el cual será analizado con todos los par-ticipantes, gana el grupo que mayor cantidad de puntos positivos tenga y que tenga una planificación integral.

Contenido del juego: Morral de transporte del juego, guía del facilitador, maquetas, fichas, plastilina, lista de precios (Figura 2.9).

Figura 2. 9 Componentes del juego

"Planificando Ando"

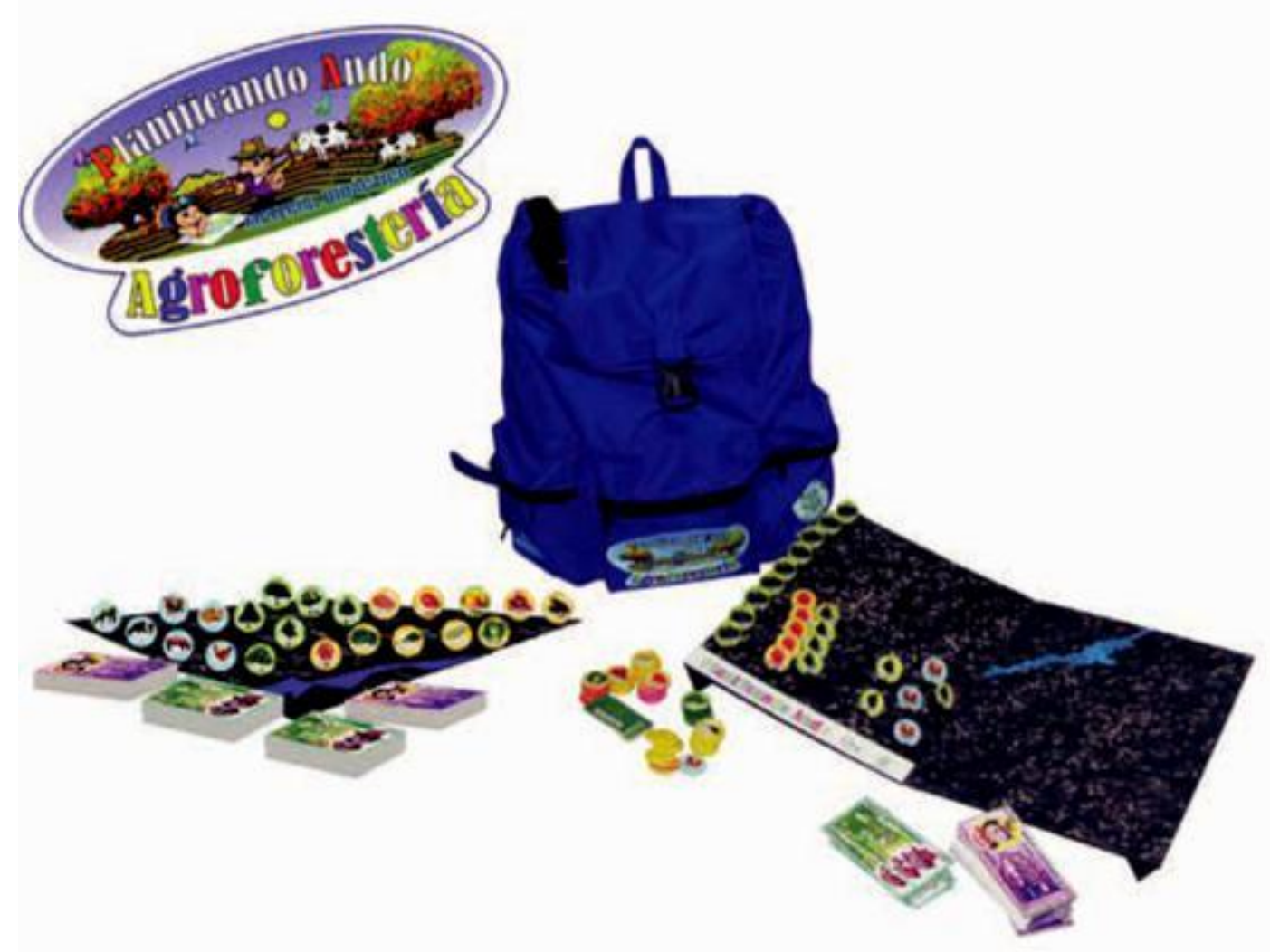




\section{- Aspectos conceptuales para la temática 5: Planificación de fincas agroforestales}

\section{La agroforestería en el manejo de las cuencas hidrográficas de la zona andina}

Según Jiménez, et al. (2001), desde el punto de vista geográfico la cuenca hidrográfica es una unidad natural, cuyos límites físicos son definidos por la divisoria superficial de las aguas que mediante precipitaciones y la existencia de flujos o caudales, permite configurar una red de drenaje superficial que canaliza las aguas hacia el río, al mar, o a otros cuerpos de agua.

El manejo de cuencas es un proceso integrado donde se conjugan dos gru-pos de acciones: las orientadas a aprovechar los recursos naturales presentes (usarlos, transformarlos, consumirlos) con propósitos de crecimiento económico y otras orientadas a manejarlos (conservarlos, recuperarlos, proteger-los) con el fin de buscar la sostenibilidad ambiental y el uso adecuado de los recursos. Estos dos grupos deben ejecutarse en función de la intervención humana y sus necesidades, lo que requiere la participación de los usuarios, habitantes y actores que tienen intereses en la cuenca, con el fin de buscar la equidad social y el desarrollo integral (Jiménez, et al., 2001).

El objetivo fundamental del manejo de cuencas es conocer las interacciones hidrológicas, ecológicas, biofísicas y humanas y luego aplicar este conocimiento a la rehabilitación de áreas degradadas, a la conservación de los recursos naturales y a mejorar el uso de la tierra. Es aquí donde la agrofores-tería se convierte en una opción tecnológica importante para cumplir con este objetivo (Ibid, 2001).

El uso intensivo e indiscriminado de fertilizantes químicos, irrigación inadecuada, control químico de plagas y enfermedades, monocultivo, etc., son problemas reales que afectan las cuencas y para algunos de los cuales, la agroforestería puede contribuir como una herramienta útil en la solución o mitigación.

Entre las contribuciones de la agroforestería al manejo de cuencas hidrográficas encontramos la captación, almacenamiento y regulación de las corrientes o flujos de agua, reduciendo la incidencia y la magnitud de las inundaciones, 
efecto esponja de la vegetación (cultivos y leñosas), regulación del flujo hídrico sub-superficial, recarga y mantenimiento del manto freático y la aguas subterráneas, mejoramiento de calidad de aguas, estabilización del flujo hídrico base y controlando los torrentes (Ibid, 2001).

El manejo de los sistemas agroforestales en las cuencas contribuyen a la estabilidad, formación y fertilidad de los suelos, control de erosión, deslizamientos y arrastre de masas, mejoramiento de la estabilidad de la cuenca y mantenimiento de su potencial productivo, reducción de los factores de tensión o desestabilizadores asociados a la agricultura migratoria y ganadería intensiva, incendios forestales, deforestación, regulación de la temperatura ambiental, regulación de vientos, manteniendo la estabilidad y la dinámica de los ecosistemas sosteniendo la diversidad genética parte esencial para el desarrollo de la agricultura, la industria y la medicina (Ibid, 2001).

\section{Criterios para el establecimiento de arreglos agroforestales}

El propósito es proporcionar orientación al productor sobre la manera de adaptar ciertos criterios para el establecimiento de un arreglo agroforestal. La selección y combinación de las especies dependen del objetivo de la producción y de las expectativas del productor. Raintree (1987), planteo cuatro etapas mínimas para realizar el diagnóstico y diseño de un sistema de producción agroforestal:

Prediagnóstico: Consiste en un proceso previo, en el cual el facilitador realiza una visión general de los sistemas en la finca, se evalúa las estrategias y objetivos de la producción.

Diagnóstico: Se ofrece una visión de la finca, del agricultor, la familia y el entorno biofísico, económico y social. Del componente leñoso dentro de la finca y las oportunidades y limitaciones que la acompañan. Se realizan preguntas como: ¿Qué podemos hacer para utilizar de forma óptima las leñosas perennes de la finca para lograr las metas del grupo familiar?, ¿Cómo?, ¿Es adoptable?, ¿Cuáles ajustes serán necesarios?

Diseño: Se realiza la evaluación de las alternativas seleccionadas respondiendo a los criterios de productividad, sostenibilidad y potencial de adop-ción. Trata de la búsqueda de las oportunidades que permitan manejar, en forma óptima el componente leñoso en los sistemas de producción de la finca. 
Se evalúan las oportunidades razonando sobre la situación actual y sobre el potencial del componente leñoso en los diferentes sistemas de producción.

En el diseño de los arreglos, se intenta responder a preguntas específicas, como: ¿Qué oportunidad tenemos de incrementar la producción maderable en el lote equis? ¿Qué secciones de las plantaciones lineales permiten la introducción de más cítricos, maderables, postes de cerca o leña? ¿Cómo aprovechar el potencial de los caminos internos para producir frutales y al mismo tiempo mejorar el paisaje de la finca? ¿Cómo incrementar los benefi-cios y servicios que ofrecen varios tipos de leñosas perennes en los potreros? ¿Qué especie de arbusto utilizar para hacer setos que aíslen visualmente la casa de la calle?.

Planificación: se inicia la planificación del sistema agroforestal a implantar en la finca, se trabaja en conjunto con el agricultor las decisiones basadas en el análisis de los objetivos, el facilitador indica qué hacer, cómo hacerlo, quiénes lo harán y cuándo lo harán. El nivel de detalle de planes decisión del planificador. Se realizan preguntas como: ¿Qué hacer para desarrollar el sistema mejorado?, ¿Qué se hará en investigación y desarrollo para realizar y ejecutar las opciones planteadas?.

En la fase de diagnóstico de la finca se debe tener en cuenta, las siguientes dimensiones (Somarriba, 2009): biofísico, agroforestal, social y económico - financiero.

Dimensión biofísico: se evalúa las características biológicas y físicas de la finca y de sus usos de tierra, identificando las oportunidades que estas ofrecen para mejorarlos agroforestalmente. Teniendo en cuenta los siguientes aspectos: La asignación a las actividades productivas y no productivas de la finca (análisis de superficies),se le pide al agricultor que dibuje un mapa de su finca, que luego se verifica y ajusta mediante un recorrido de campo con él y una corta entrevista donde se anotan los usos y áreas. Las plantaciones en líneas (análisis lineal), requiere otros recorridos, donde con ayuda del agricultor se verifican colindancias, linderos, divisiones internas, caminos, ubicación de las cercas vivas, rompevientos u otro tipo de plantación lineal. Las oportunidades y limitaciones de la finca y de su entorno ambiental, se realiza un FODA (fortalezas, oportunidades, dificultades y amenazas) de la finca y de sus usos de tierra para mejorar los SAF allí presentes, por ejemplo: excesiva pendiente, vientos fuertes, variaciones de drenajes buenos o malos suelos, entre otros. 
Dimensión agroforestal: en éste, se pretende responder a las siguientes preguntas: ¿Dónde están las leñosas perennes de la finca? y ¿En cuáles sistemas de cultivo o líneas?, ¿Cuáles son? (composición botánica), ¿Cuántas son? (abundancia), ¿Qué bienes y servicios proveen al productor?, ¿Qué efectos provocan sobre los otros componentes de los sistemas de cultivos? (Interacciones). Esta información se recolecta mediante recorridos, identificación de especies, conteos y se anota en formularios. Se estiman las producciones con el agricultor y se identifican sus percepciones sobre los efectos negativos de las leñosas perennes sobre los otros componentes de los sistemas de producción.

Dimensión social: el objetivo es conocer la composición familiar, el ciclo de vida las herencias, etc., para así determinar los objetivos, visión del futuro, oportunidades y limitaciones del grupo familiar, de la finca y de sus sistemas de producción.

Esta información se obtiene mediante entrevista, encuestas semiestructuradas y un formulario para anotar los datos de la familia. Se conversa con el agricul-tor y los miembros de la familia, tratando de que respondan a las siguientes preguntas: ¿Cuáles son los objetivos del productor y de su familia?, ¿Cuáles son las expectativas sobre el desarrollo personal? ¿Cuáles son las fuentes de ingresos y los sistemas de producción más importantes de la finca?, ¿Cómo ven el futuro?, ¿Cómo sera su finca dentro de cinco años y cómo era hace cinco años?, ¿Cómo ve el futuro de sus hijos en términos de empleo y educación?, ¿Qué limitaciones tiene y cuáles son los principales problemas?, ¿Cuáles son sus ventajas? (Somarriba, 1998).

Dimensión económico - financiero: se pretende lograr una visión de los factores de producción (tierra, mano de obra y capital) y externos (mercados, comercialización, precios asistencia técnica y legislación forestal) que afectan las decisiones de manejo de la finca. Los datos se obtienen mediante una o varias entrevistas y formularios sobre manejo, costos, insumos, productos y precios, ¿Cuáles son las oportunidades y limitaciones de la finca?, ¿Hay mercado cercanos, buenas vías de comunicación, alternativas de empleo, disponibilidad de mano de obra, tierras buenas y abundantes?, ¿Cómo se perciben los precios de los insumos y de la mano de obra? 


\section{Manejo y evaluación de sistemas agroforestales}

El establecimiento de un sistema agroforestal involucra la selección y elección de las especies de cada componente, su diseño sobre el terreno y a lo largo de una secuencia temporal, las actividades de manejo y la evaluación de su funcionamiento (CATIE, 2001).

El manejo de sistemas agroforestales, tiene como objetivo recuperar, mante-ner o aumentar el nivel de productividad del sistema a largo plazo y favorecer la conservación de los recursos disponibles. El manejo incluye el estable-cimiento y cuidados de cultivos y de otras plantas asociadas, el uso de los suelos, el control de plagas (en un sentido amplio), el uso óptimo del sistema desde el punto de vista de los beneficios por obtener.

Por lo anterior, las técnicas generales de manejo están dirigidas a: proteger el suelo contra la pérdida de la capacidad productiva, mantener el balance del ciclo de nutrimentos, asegurar el suministro de agua y nutrimentos para los cultivos, lograr un buen nivel de producción.

\section{Cómo buscar el sistema agroforestal más adecuado}

Algunos de los criterios para estimar sí una tecnología es apropiada para los pequeños agricultores, son los siguientes: debe ayudar a resolver uno varios de los principales problemas de producción; ser compatible con el sistema agrícola existente: si su aplicación requiere que se modifique todo el sistema, no será aceptada, debe utilizar los recursos al alcance del agricultor pobre: si su funcionamiento demanda de recursos que el agricultor no tiene, no va a funcionar (CATIE, 2001).

Para la evaluación de un sistema pueden ser utilizadas las siguientes preguntas: Luego de adoptada la práctica o sistema, ¿Cómo está la finca en comparación con las condiciones anteriores? (está mejor, igual o peor), ¿Cuál es la productividad del sistema? (producción, rendimientos), ¿Cuál es el impacto ambiental del sistema? ¿Hay erosión, contaminación, otros problemas?, ¿Han adoptado la misma práctica otros agricultores del área?, ¿Qué proporción de ellos lo ha hecho?, ¿Qué aspectos del sistema no han aceptado?, del total de agricultores que adoptaron la práctica, ¿cuántos la están utilizando todavía?, ¿En qué porcentaje del área se podría aplicar el sistema?, ¿Cuál sería el impacto que el 
uso del sistema podría tener sobre el manejo del mismo? (Montagnini, 1992; CATIE, 1993). A largo plazo, hay que evaluar el sistema desde el punto de vista de su sostenibilidad.

\section{Consideraciones técnicas en el manejo de arreglos agroforestales}

Cercas vivas usadas como árboles forrajeros: según Pezo e Ibrahim (1999), las leñosas perennes que se utilizan en cercas vivas no sólo sirven para delimitar potreros o la propiedad, si no que regularmente cumplen algún propósito adicional en la finca (Budowski, 1981; Bazil, et al., 1994). Algu-nas son forrajeras como matarratón (G. sepium (Jacq.) Kunth Ex Walp.), poró (Erytrina poeppigiana (Walp.) Of Cook, L.), leucaena (L. leucocephala (Lam) de Wit.), ramón (Brosimun alicastrum Sw.). Otras son frutales como los cítricos (Citrus spp). y el marañón (Anacardium occidentale L). y también ornamentales como palma de yuca (Yucca elephantipes Baker in Regel). Otros son maderables como el ciprés (Cupressus lusitánica L.), cedro (Cedrella odorata L.), teca (Tectona grandis L.), caoba (Swietenia macrophylla King.), eucalipto (Eucalyptus spp.)

Para el establecimiento de este tipo de cercas vivas generalmente se utilizan estacas de 5 a $15 \mathrm{~cm}$ de diámetro y 2 a 2,5 m de largo, de esta manera se busca que los nuevos brotes que emergen después de su siembra queden fuera del alcance del ganado en pastoreo (Víquez, et al,. 1993). Las estacas empleadas para este propósito con frecuencia son ramas de árboles adultos presentes en las cercas vivas.

Especies que se propaguen por estacas se almacenan en posición vertical bajo sombra por 1 - 2 semanas. Antes de sembrar, cortar el extremo basal en bisel. La distancia de siembra entre estacas varía, generalmente se da un espaciamiento de 1 a $2 \mathrm{~m}$., y se entierran a una profundidad de 20 a $40 \mathrm{~cm}$., de preferencia colocar el alambre 3 - 6 meses después de la siembra. Diferir la primera poda de las cercas hasta por lo menos un año después de establecidas.

Para conseguir una producción alta y sostenible de biomasa comesti-ble, es importante el manejo de las podas; las cuale s se recomiendan cada cuatro a seis meses. Al realizar podas estratégicas a finales de las lluvias, se dispone de forraje verde durante el periodo seco. En el caso de Gliricidia sepium, durante el periodo seco, para obtener el forraje 
necesario para suplementar con proteína cruda un novillo de $300-400 \mathrm{~kg}$ de peso que pastorea en potreros de pasto jaragua (Hyparrhenia rufa Nees), se deben podar de 3 -5 árboles/día por animal.

Bancos forrajeros de leñosas perennes: se refiere a especies capaces de persistir bajo un régimen de podas frecuentes e intensas, que muestren una alta tasa de rebrote, presenten una buena proporció de hojas con una calidad nutritiva aceptable y una buena palatabilidad (Pezo y Ibrahim, 1999). Es-pecies con potencial usadas en áreas con un periodo seco estacional de 3 a 6 meses de duración se destacan: leucaena (Leucaena leucocephala (Lam) de Wit.), guácimo (Guazuma ulmifolia Lam.), cratilia (Cratylia argéntea (Desv.) Kuntze), ramón (Brosimum alicastrum Sw.), morera (Morus spp.), nacedero (Trichanthera gigantea (Humboldt \& Bonpland) Kuntze.) Para tropico humedo se destacan: matarratón (Gliricidia. sepium (Jacq.) Kunth Ex Walp.), poró (Erytrina poeppigiana (Walp.) Of Cook, L.), hibisco (Hibiscus rosa-sinensis L.), caliandra (Calliandra calothyrsus Meissner.), albizia (Albizias spp.).

Para bancos forrajeros manejados bajo corte, se recomienda el establecimiento a distanciamientos entre hileras de $0,8-1 \mathrm{~m}$, y de 0,25 a $0,50 \mathrm{~m}$ entre plantas. Si el sistema es para pastoreo/ramoneo, debe ampliarse la distancia entre surcos para facilitar el acceso y el desplazamiento de los animales, así como prevenir los daños por pisoteo.

En ecosistemas con periodos de sequía bien definido, pueden usarse estacas de 30 a $50 \mathrm{~cm}$ de largo, colocadas inclinadas o en posición vertical; pero es más conveniente si la siembra se hace con plantones producidos en vivero. Cuando se usa estacas, se puede conseguir un desarrollo de raíces más profusas si se hace una incisión (pelado) en la porción que va hacia el fondo del surco.

La primera defoliación se debe efectuar cuando las plantas han alcanzado de 1 a 1,5 m de altura. La máxima producción de biomasa comestible ocurre cuando esta presenta el 50 y $60 \%$ de la biomasa total. Esta coincide con el inicio de la caída de hojas de las ramas inferiores de la planta. Para la ma-yoría de leñosas perennes es apropiado efectuar las podas cada 3 a 4 meses, este intervalo puede prolongarse en zonas menos húmedas y en zonas más frías. Cabe resaltar que el intervalo ente defoliaciones tiende a ser menor en bajo pastoreo, que bajo corte. 
Para asegurar la persistencia de los árboles, es importante regular la carga animal y establecer un esquema de pastoreo rotacional, con un periodo de ocupación menor de 7 días y un periodo de descanso de 60 a 80 días, estos sistemas son capaces de sostener cargas equivalentes a 2,5 UA/ha; sin embargo, ésta puede variar en función del nivel de oferta de biomasa comestible.

Pasturas en callejones (Mendieta y Rocha, 2007): Cuando el manejo se realiza bajo corte se pueden establecer callejones de $3 \mathrm{~m}$ entre hileras simples ó de $6 \mathrm{~m}$ cuando se utilizan hileras dobles de leñosas (el distanciamiento entre la doble hilera será de 0,7 a 1,0 m). Dentro de los surcos se establecen tres o cuatro surcos donde se establece la forrajera de corte.

Las leñosas perennes que se reproducen por semilla, ej. Leucaena (Leucaena. leucocephala (Lam) de Wit), en regiones con poca restricción de lluvias, pueden sembrarse directamente. Realizar la siembra al inicio de las lluvias, al chorro corrido en surcos de 1 a $2 \mathrm{~cm}$ de profundidad. Se requieren apro-ximadamente $6 \mathrm{~kg}$ de semilla/ha. El distanciamiento entre plantas, luego del raleo, es de 0,7 a 0,9 m. En el trópico seco, es más recomendable hacer los viveros 2 a 3 meses antes del inicio de las lluvias, aquí los distanciamientos entre plantas deberán ser de 0,75 a 1,0 m.

Las especies gramíneas, como pasto elefante (Pennisetum purpureum Schumach), se establecen por tallos de por lo menos 3 a 4 entrenudos. Estos deben co-locarse horizontalmente, al chorro corrido (en cadena simple o doble), en surcos de $10 \mathrm{~cm}$ de profundidad. Tapar con tierra sin compactar fuerte. Pas-turas que se reproducen por semilla como Brachiaria brizantha, Brachiaria decumbens, serán sembradas dentro de los callejones en surcos de 0,8 a 1,0 $\mathrm{m}$. Se requiere de 4 a $6 \mathrm{~kg}$ de semilla de buena calidad, sembrada a 1 a $3 \mathrm{~cm}$ de profundidad. Especies que se reproducen por material vegetativo como estrella africana (Cynodonn plectostachyus (K. Schum) Pilger), pueden sem-brarse al voleo o en surcos de 0,75 a 1,0 m dentro de los callejones. Se requiere aproximadamente de 1 a 1,5 toneladas de material vegetativo. Previo a la siembra, por cualquiera de los métodos indicados, será recomendable preparar el terreno. La siembra de las gramíneas deberá efectuarse cuando la leñosa tenga por lo menos $0,50 \mathrm{~m}$ de altura.

Cuando el manejo se realiza bajo pastoreo, el diseño más recomendado es el de hileras alternas de seis metros de largo y seis metros entre las mismas, 
pero en forma alterna, después de que termina el seto se dejan cuatro metros sin leñosas, para que los animales puedan pasar de un callejón al otro. Este tipo de arreglo espacial posibilita la mayor movilidad de los animales dentro del sistema y por lo tanto un consumo más homogéneo tanto de la leñosa como de la arbustiva. El primer corte o pastoreo en el trópico con sequía es-tacional se debe esperar hasta 12 ó 18 meses después de establecido, mientras que en el trópico húmedo el corte de uniformización se puede realizar a los ocho meses.

El sistema de pastoreo más recomendable es el rotacional, consiste en ajustar la intensidad de defoliación al nivel de oferta de las leñosas y herbáceas. En temporadas de crecimiento acelerado se puede acortar el período de descanso, incrementar la carga y/o alargar el período de ocupación. Si la leñosa no se recupera adecuadamente alargar el período de descanso y acortarlo, cuando el remanente de la leñosa sea elevado después del pastoreo.

La pastura en callejones puede sostener 2 a 3 unidades animal/ ha, en la época húmeda y de 2,0 a 2,5 unidades animal/ha, en la época seca. Según esto se puede producir de 600 a $700 \mathrm{~kg}$ de carne/ha/año en las zonas de trópico húmedo y de 450 a $650 \mathrm{~kg}$ de carne/ha/año en el trópico seco. Con este sis-tema se pueden obtener incrementos hasta del $20 \%$ en la producción de leche vendible/vaca en sistema de doble propósito.

Cercas vivas como barreras de protección. Constituyen una forma de cultivo en callejones en terrenos con pendiente pronunciadas (Pezo e Ibrahim, 1999). El objetivo principal de la siembra de leñosas en contorno, es la protección contra erosión, al reducir la velocidad de del agua y atrapar particulas de suelo. El follaje que se poda de las barreras puede ser utilizado como ali-mentos para animales estabulados, cuando las especies son palatables. Entre las especies de leñosas más utilizadas se pueden citar: matarratón (Gliricidia sepium (Jacq.) Kunth Ex Walp.), leucaena (Leucaena leucocephala (Lam) de Wit), leucaena de montaña (L. diversifolia), calliandra (Callindra calo-thyrsus), flemingia (Flemingia macrophylla (Willd) Merr.), acacia (Acacia villosa (Sw.) Willd.).

Para que una barrera sea efectiva en el control de erosión, las leñosas deberán sembrarse muy densamente en una hilera simple o doble (con disposición en triangulo o tresbolillo). Los distanciamientos entre plantas en la barrera, son 
entre 5 a $20 \mathrm{~cm}$ dependiendo de la especie (ej. G. sepium). En terrenos con pendientes muy pronuncidas se recomienda a $10 \mathrm{~cm}$ con estacas en forma de exis (ej. Morus alba). La distancia entre las barreras esta en funcion de la pendiente,erodabilidad del suelo, cobertura vegetal entre barreras, sistema de labranza, arreglo espacial y cronológico de los cultivos entre barreras, magnitud e intensidad de la precipitación. La inclusion de pasturas de habito rastrero en el espacio entre las barreras, incrementa el potencial para contro-lar le erosión en terrenos con pendientes pronunciadas.

Cercas vivas como linderos maderables. Los linderos maderables son siembras de árboles en línea en los límites de parcelas agropecuarias o fincas, plantados con el objetivo principal de producir madera o postes (Méndez, et al., 2000). Los criterios para seleccionar especies, son: valor comercial de la especie, crecimiento apical rápido, auto poda en condiciones de campo abierto, disponibilidad de semilla, susceptibilidad a plagas y enfermedades, copa delgada y/o abierta, poca exigencia en el manejo. Entre las especies más utilizadas están: eucalipto (Eucalyptus deglupta Blume.), acacia (Acacia mangium Willdi.), nogal cafetero (Cordia alliodora (Ruíz \& Pav.) Cham.), teca (Tectona grandis L.), terminalia (Terminalia ivorensis), roble (Tabebuia rosea (Bertol.) Bertero ex A.DC).

Se recomienda un ahoyado de 25 x 25 x $25 \mathrm{~cm}$ (también se puede utilizar pseudoestacas de 5 a $10 \mathrm{~cm}$ de tallo y 10 a $20 \mathrm{~cm}$ de raíz pivotante), cuando se plantan en terrenos menos fértiles, es aconsejable hacer un ahoyado de 40 x 40 x 40, aplicar boro y materia orgánica, por lo menos una semana antes de la siembra, para favorecer el desarrollo radical inicial del árbol.

El espaciamiento de la plantación en linderos, dependerá de los objetivos de la misma. Para producción de leña, los distanciamientos dentro de la línea pueden ser menores a $2,5 \mathrm{~m}$. para producción de madera deberán ser mayores a $3 \mathrm{~m}$, sin embargo, es fundamental el manejo de los raleos de la plantación. La siembra, se debe hacer al inicio de las lluvias.

Se debe tener en cuenta, las siguientes actividades de manejo, necesarias para lograr un ,buen desarrollo de los linderos maderables:

- Rodajas o rondas: consiste en mantener un circulo de $1 \mathrm{~m}$ de diámetro alrededor del árbol, al menos el primer año de sembrado, para favo- 
recer el crecimiento del árbol, la agresividad de las malezas y el sitio donde sea plantado el lindero. Generalmente las deshierbas se hacen de forma manual; se deshijan algunas especies sembradas por pseudoesta-cas como el nogal cafetero (C. alliodora (Ruíz \& Pav.) Cham.), teca ( $T$. grandis L.). Los brotes deben dejarse hasta que alcancen alturas de 0,5 a $1 \mathrm{~m}$; los cuales, seleccionados con criterios de tamaño, vigor, forma recta y salud.

- Las podas: permiten el mejoramiento de la producción de la calidad de madera, los árboles en linderos tienden a ramificar más que en plantaciones en bloque debido a la menor competencia lateral. Los raleos, se deben realizar lo más temprano posible o cuando las copas de los árboles se entrecruzan, un manejo oportuno permite a la plantación es-timular el crecimiento de las copas de los árboles remanentes buscando un engrosamiento de los fustes. Con las labores de raleo, se adecua el espacio al crecimiento del árbol, además permite obtener un ingreso extra al aprovecharse los árboles raleados como postes o leña.

Cercas vivas como cortinas Rompevientos: La funcion de las cortinas rompevientos radica en el control de la erosion del suelo causada por el viento. La efectividad de la cortina esta en función de: altura, forma, permeabilidad al paso del viento, velocidad del viento. Las cortinas deben estar orientadas en forma perpedicular a la dirección de los vientos predominantes, el efecto cortavientos se puede incrementar con la disposición de dos o mas hileras, tambien introduciendo especies arbustivas delante de los árboles como hilera adicional (Méndez, et al., 2000). Pezo e Ibrahim (1999), plantean que entre las especies de árboles más usadas con las leguminosas arbóreas, como: poró (Erytrina poeppigiana (Walp.) Of Cook, (L. leucocephala (Lam) de Wity.), mataratón (Gliricidia sepium (Jacq.) Kunth Ex Walp.); otras fijadoras de ni-trógeno como aliso (Alnus acuminata); árboles maderables como el ciprés (Cupressus lusitánica L.), cedro (Cedrella odorata L.), eucalipto (Eucalyp-tus spp.), pinos (Casuarina spp.).

El espaciamiento dependerá de los habitos de crecimiento de las especies utilizadas, la calidad del sitio y el tiempo de mantenimiento. En terminos generales el distaciamiento entre árboles y filas es de 1,5 m x 1,5 m (maderables $2 \mathrm{~m}$ x $2 \mathrm{~m}$ ). las distancias entre lineas de cortinas rompevientos deber ser de 15 a 20 veces la altura de la linea: considerándose que a esta distancia entre lineas hay un efecto protector. 
Prácticamente cualquier leñosa perenne puede ser incluida en el sistema, siempre y cuando por su morfología y rapidez de crecimiento, respondan a las necesidades de protección fijadas para el sistema. Cuando se estable-cen filas multiples de árboles y arbustos en una cortina, se recomienda que en el borde (primera fila) se coloquen arbustos de copa densa, amplia y de crecimiento rapido; mientras en las filas posteriores se siembren árboles de rapido crecimiento, resitentes al frío, a los agentes patógenos o plagas, y que presenten copa densa (Pezo e Ibrahim, 1999).

\section{Desarrollo de talleres empleando "Agroforestería” material didáctico}

Teniendo en cuenta que cada uno de los cinco juegos que conforman el material didáctico, están diseñados para abordar una temática agroforestal, se recomienda que el facilitador elabore su guía de trabajo para cada taller; donde se detalle la forma de utilización de juego, integrando otras actividades de refuerzo y que faciliten la construcción de conocimientos agroforestales. A continuación se explica los aspectos generales a tener en cuenta.

Ejemplo de guía de trabajo (modificado de: Caliva, 2009; Restrepo, et al., 2008).

Tema de taller: corresponde a cada una de las cinco temáticas anteriormente descritas.

Introducción: Presentación de todos los participantes. Explicación por parte del facilitador de los objetivos y finalidad del taller. Establecimiento de las reglas o instrucciones del juego durante el taller. Presentación y concertación de la agenda prevista.

Metodología de trabajo: Una vez reunido el grupo, se procede a nombrar un coordinador que se encargará de sintetizar las ideas y exponerlas posteriormente en la sesión al grupo. Se puede pedir a los participantes que escriban en un papel sus expectativas frente al taller simplemente que las expresen de manera verbal e ir consignándolas en una hoja de papel periódico.

La motivación debe ser permanente durante todo el taller. Para ello el facilitador puede apoyarse en el desarrollo de dinámicas y juegos en los momentos en los que lo considere oportuno y sin abusar en su utilización. 
Desarrollo: se lleva a cabo los contenidos previstos a través de la utilización de diferentes técnicas: Exposición a cargo del facilitador. Trabajo en grupos sobre los temas donde los participantes van expresando su opinión, en la medida en que se aplica el juego pertinente para la temática tratada. Para ello el facilitador podría explicar las reglas verbalmente o utilizar guías escritas de trabajo, en las cuales precisará lo que cada grupo debe hacer y la forma en que presentará los resultados de su ejercicio ante los demás.

Socialización de los ejercicios: Cada grupo presentará los resultados de su ejercicio, a través de la técnica solicitada. El coordinador de cada grupo elabora una síntesis de la discusión y de las opiniones de cada participante. Al finalizar el coordinador presenta la síntesis al grupo en la sesión plenaria y los otros grupos harán una retroalimentación analizando aspectos positivos y por mejorar.

Evaluación: El facilitador con la ayuda de los participantes consignará los elementos centrales desarrollados en el taller así como los aportes hechos durante el mismo. El facilitador puede diseñar formatos para la evaluación o hacerla de manera oral en la plenaria. También puede retomar los papeles en los que las personas consignaron sus expectativas o la cartelera en la que el mismo las consignó y preguntar si se lograron o no.

\section{Pruebas de funcionamiento: Aplicación de "Agroforestería" material didáctico con comunidades rurales}

El material didáctico se ensayó con la comunidad rural mediante el desarrollo de talleres y se realizaron ensayos de funcionalidad y acogida con el apoyo de los diferentes participantes como se observa en la figura 2.10, para finalmente realizar ajustes y contar con herramientas didácticas de calidad y eficientes.

La Innovación, creatividad y diversión para un aprendizaje significativo que integra y dinamiza la apropiación social del conocimiento se ve reflejada en el uso del material didáctico por la comunidad. 
Figura 2.10 Aplicación del material

Figura 2. 10 a Aplicación del material

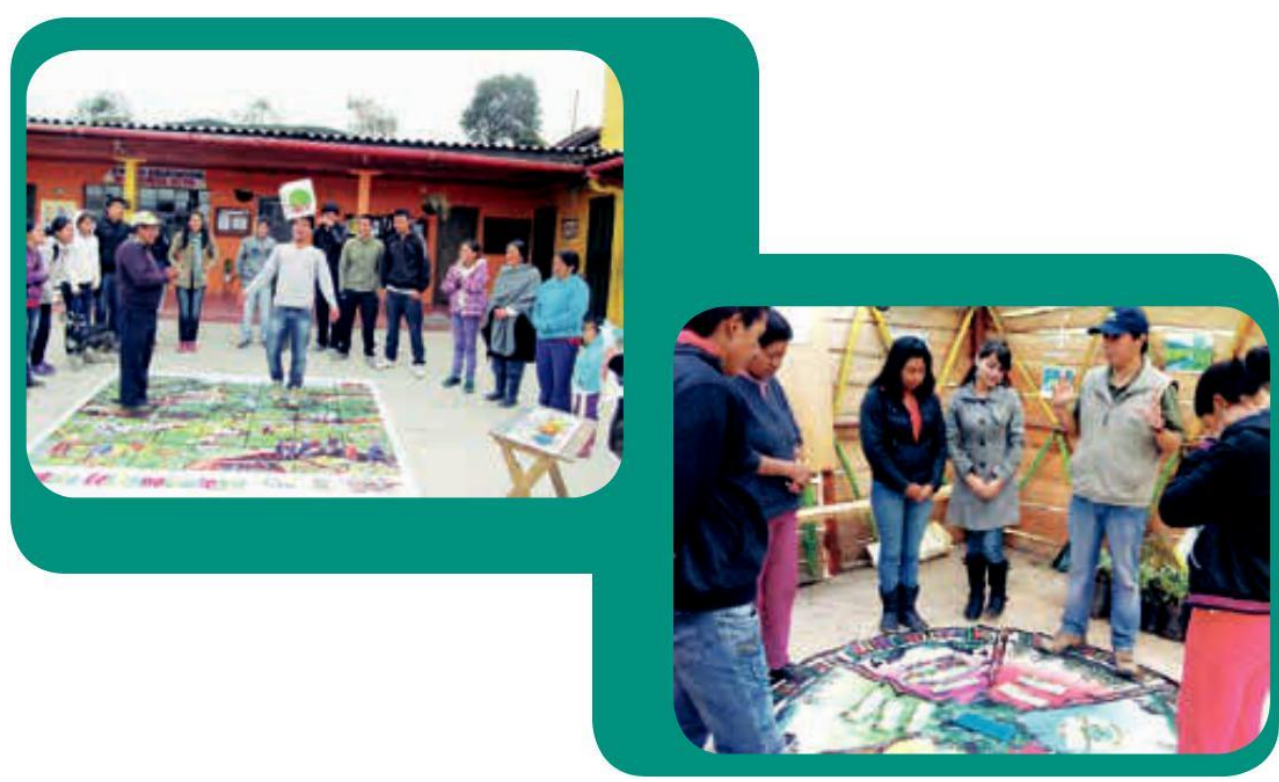

Figura 2.10 b Aplicación del material

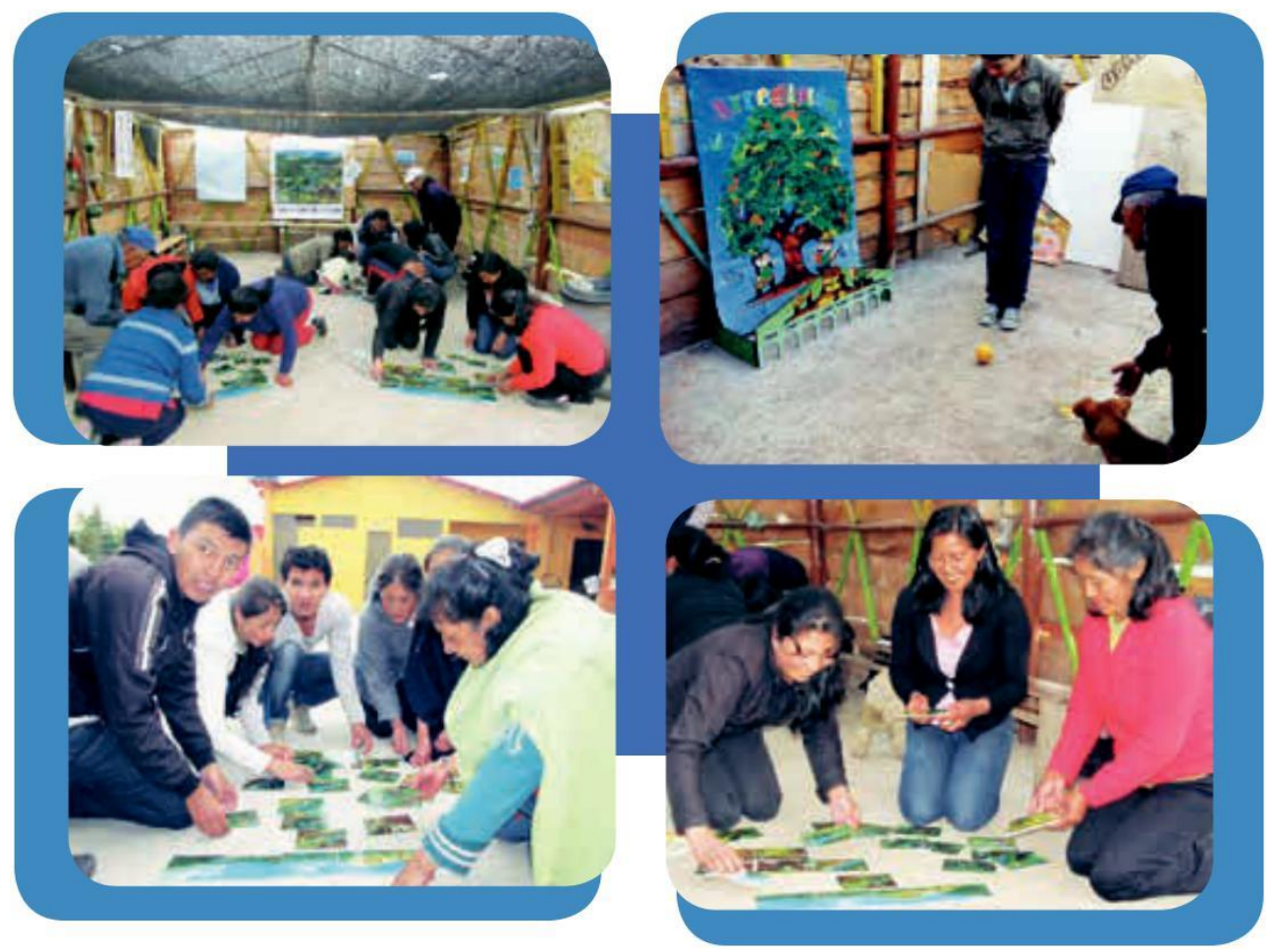




\section{DISEÑO DE MATERIAL DIDÁCTICO DIGITAL}

\subsection{Generalidades}

Las investigaciones sobre material didáctico, han sido variadas y abordadas desde diferentes enfoques, Tejada (2009), señala que en los procesos de aprendizaje, los contenidos deben estar relacionados con la realidad fuera de aula. Para ello, es fundamental la innovación e implementación de TIC. Berwal (1987), indica la importancia y utilidad pedagógica de los medios de comunicación en los procesos de enseñanza- aprendizaje.

Tomando como referencia a Contreras (1990), citado por Pages (1994), los procesos de enseñanza-aprendizaje son "simultáneamente un fenómeno que se vive y se crea desde dentro, esto es, procesos de interacción e intercambio regidos por determinadas intenciones (...), en principio destinadas a hacer posible el aprendizaje; y a la vez, es un proceso determinado desde fuera, en cuanto que forma parte de la estructura de instituciones sociales entre las cuales desempeña funciones que se explican no desde las intenciones y actuaciones individuales, sino desde el papel que juega en la estructura social, sus necesidades e intereses...Es un sistema de comunicación inten-cional que se produce en un marco institucional y en el que se generan estra-tegias encaminadas a provocar el aprendizaje”.

En un trabajo investigativo realizado por Busstra, et al., (2007), para promover el aprendizaje activo de las teorías socio- psicológicas, plantean que el material de aprendizaje digital proporciona la oportunidad de generar estímulos poderosos en los estudiantes, al realizar acciones distintas de la lectura de la literatura o la asistencia a clases. La utilización de material de aprendizaje digital, hace posible el uso de elementos visuales; tales como, diagramas interactivos, animaciones y videoclips, que son más elaborados que los libros texto (Mayer y Moreno, 2002). Los estudiantes pueden aprender mejor con el diseño de multimedia, que combinan palabras e imágenes, a diferencia de los modos tradicionales que implican las palabras solas (Mayer, 2003).

En un estudio realizado por Pilatou, et al., (2010), cuyo objetivo fue detectar las concepciones de estudiantes de la escuela primaria (10 años) sobre el "fenómeno de efecto invernadero" y cómo puede afectar a las condiciones climáticas, a partir del diseño, implementación y evaluación de una educa- 
ción adecuada, basado en material digital e impreso para hacer frente a dificultades de aprendizaje de los estudiantes con un enfoque de enseñanza constructivista innovador colaborativo, utilizando las TIC; los resultados mostraron que el nuevo entorno de aprendizaje les ayudó a crear representaciones mentales adecuadas sobre los fenómenos estudiados.

Según Marqués (2001), el Software, con carácter educativo es: el componente lógico que incorpora los conceptos y metodologías pedagógicas a la utiliza-ción del ordenador, buscando convertir éste, en un elemento activo dentro del proceso enseñanza-aprendizaje.

El software educativo, tiene las siguientes características:

- Están diseñados con finalidad didáctica

- Usan el ordenador como soporte

- Son interactivos

- Individualizan el trabajo de los estudiantes y

- Son fáciles de usar

Según Sánchez (1999), el software de carácter educativo presenta ventajas como:

- Permite la interactividad con los estudiantes, retroalimentándolos y evaluando lo aprendido.

- Facilita las representaciones animadas.

- Incide en el desarrollo de las habilidades a través de la ejercitación.

- Permite simular procesos complejos.

- Reduce el tiempo de que se dispone para impartir una gran cantidad de conocimientos facilitando un trabajo diferenciado.

- Facilita el trabajo independiente y a la vez un tratamiento individual de las diferencias.

- Permite al estudiante introducirse en las técnicas más avanzadas e ir de la mano con la tecnología.

El objetivo del diseño de software, es aplicar un conjunto de principios, conceptos y prácticas que llevan al desarrollo de un sistema a producto de alta calidad; su meta es implantar correctamente todos los requerimientos del usuario y causar placer a quienes lo utilicen. El Diseño de Arquitectu- 
ra, permite analizar la efectividad del diseño para cumplir requerimientos establecidos y reducir los riesgos asociados con la construcción de software (Camacho, et al., 2004).

Según Pressman (2005), el diseño lo determina en los siguientes aspectos:

Diseño a nivel de componentes: se basa en la información desarrollada como parte del modelo de requerimientos y se representa como parte del modelo arquitectónico. El proceso de diseño en el nivel de componentes, incluye una secuencia de actividades que reduce poco a poco el nivel de abstracción con el que se representa el software, ilustra en definitiva al software en un nivel de abstracción cercano al código.

Diseño de la interfaz de usuario: es el elemento más importante de un sistema basado en computadora. Si la interfaz estuviera mal diseñada, afectaría mucho la capacidad del usuario de aprovechar el poder computacional y el contenido de información de una aplicación. El proceso general de la interfaz de usuario, comienza con la creación de diferentes modelos de funciona-miento del sistema.

A nivel mundial, para el intercambio de conocimientos agroforestales, se ha implementado las TIC, a partir del diseño de software con este enfoque (aca-démico a nivel superior e investigativo); entre los que se destacan: modela-miento - WaNuLCAS; sistema de manejo agroforestal - Silvia, simulador de bosques - SExl-FS; evaluador de paisajes - FALLOW; generadores de caudal hídrico - SLIM, series temporales de lluvias -Spat Rain, entre otros (World Agroforestry Centre, 2011). Sin embargo, existe la falencia de un software más amigable dirigido a jóvenes rurales, que sirva como herramienta peda-gógica para la aprehensión de este conocimiento.

Las TIC, son herramientas que procesan, almacenan, sintetizan, recuperan y presentan información de forma variada (Lavado, 2011); posibilitan la transversalidad en todas las áreas del saber expresando experiencias demostra-tivas donde los niños se motivan para manejar el lenguaje y desarrollar sus habilidades básicas como: comprender, analizar, sintetizar, hacer referencias y deducciones (Galvis, et al., 2012). En este sentido, las TIC, son útiles y contribuyen para la enseñanza aprendizaje de los diferentes temas relacionados con la agroforestería (León, et al., 2014); considerada como una alternativa 
para optimizar los sistemas tradicionales de agricultura y de silvicultura regional y amortizar sus impactos socio-ambientales, orientada a mejorar la calidad de vida de los productores rurales (World Agroforestry Centre, 2011).

En Nariño, departamento de vocación agrícola, caracterizado por el minifundio y explotación inadecuada de los recursos naturales, en especial el suelo y la flora; que en algunos casos, se sobreexplota por las actividades agrope-cuarias que sobrepasan su capacidad de resiliencia; siendo una de las causas, la falencia de modelos pedagógicos que conduzcan a la valoración y aprovechamiento adecuado de los recursos naturales e implementación de tecnologías acordes a la realidad socio-ambiental, cultural y económica; entre ellas, la agroforestería y estructuración de herramientas didácticas basadas en tecnologías de la información y la comunicación.

La presente investigación tuvo como objetivo la creación de una herramienta para facilitar la aprehensión del conocimiento agroforestal. Inició con un proceso diagnóstico trabajando con estudiantes de las Instituciones Educa-tivas Municipales de Mocondino y Cabrera. Para el diseño, se contó con la participación de ingenieros: agrónomo, forestal y agroforestal; diseñador gráfico y licenciado en informática.

El software se caracteriza por contener interfaces amigables y dinámicas, con lenguaje claro, que despierta interés en los jóvenes por su innovación; Robey (2007), plantea que la información se puede transmitir de manera más llamativa por diferentes medios, como texto, imagen, sonido, animaciones, entre otros.

Integrar curricularmente las TIC en el proceso de aprendizaje, implica emplearlas de forma creativa, transparente y pertinente en el quehacer pedagógico, y no sólo como una forma alternativa y llamativa de presentar información (León, et al., 2014); es necesario convertirlas en herramientas de apoyo al proceso de aprendizaje; es decir, teniendo siempre en mente que se usan con el objeto de aprender; Marqués (2001), explica que la combinación de los elementos interactivos y la facilidad en el manejo de las herramientas, incrementa la capacidad de aprehensión de conocimientos y el interés por parte de los estudiantes.

El Software Educativo para la Enseñanza Agroforestal SEAf "Mundo Agro- 
forestal" está diseñado con fines didácticos, para ser interactivo y fácil de manejar. Esta investigación hace parte del macro proyecto denominado "Herramientas didácticas para la adopción de sistemas agroforestales en la zona Andina del departamento de Nariño" apoyado por la Vicerrectoría de Investigaciones Postgrados y Relaciones Internacionales de la Universidad de Nariño y desarrollado por el grupo de investigación, Plan de Investigación para el Fortalecimiento Integral de las comunidades-PIFIL, con el objeto de diseñar y validar un software educativo con enfoque agroforestal; conside-rando la ruralidad del departamento de Nariño, según el DANE (2010), más del 53\% de la población vive en el sector rural; así como la necesidad de capacitación de los jóvenes en temas relacionados con el campo, entre ellos: manejo y conservación de recursos naturales y sistemas productivos susten-tables como los sistemas agroforestales (SAF).

Ésta investigación se basó en lineamientos de la apropiación social del conocimiento, entendida, por COLCIENCIAS (2012), como un proceso de comprensión e intervención de las relaciones entre tecno-ciencia y sociedad, construido a partir de la participación activa de los diversos grupos sociales que generan conocimiento más allá de las sinergias entre sectores acadé-micos, productivos y estatales; integrando apropiación e innovación en un mismo plano.

Para el diseño, la implementación de herramientas participativas, juega un papel importante; por ello, se utilizaron cuatro tipos:

1. Técnicas de dinámica de grupos: es fundamental para trabajar con grupos de personas y lograr su participación efectiva. Se aplica a todas las herra-mientas de trabajo grupal. Entre las más comunes, se tienen: mesa redonda, debate dirigido, foro, plenaria, discusión de gabinete, sociodrama, entrevista pública y colectiva, entre otras. Para esta técnica es importante considerar unas reglas mínimas, entre las que se sugieren:

- Realizar actividades rompe-hielo, antes de cualquier actividad o apli-cación

de técnicas; su propósito es ganar la confianza del o los participantes.

- Es Importante que los participantes tengan claro el objetivo y el rol que están cumpliendo en el proceso.

- Respeto por la opinión de los demás. 
- Cuando existan disensos, buscar la mediación, a partir de actividades grupales que permitan mediar las opiniones y de esta manera poder llegar a consensos.

- El facilitador deberá tener la habilidad de saber escuchar y de resumir las ideas de los participantes.

2. Técnicas de visualización. Por medio de representaciones gráficas se logra la participación de personas con diferentes grados y tipos de educación, y se facilita la sistematización de conocimientos y el consenso. Las técnicas de visualización pertenecen a unos grandes tipos:

- Las matrices: son cuadros que permiten organizar y presentar la información e ideas de forma lógica, para fines de cruzar diferentes criterios (matrices de clasificación y de priorización) o de presentar ideas de forma jerárquica (matrices de planificación y otras).

- Los mapas y esquemas: son representaciones simplificadas de la realidad; tiene muchas aplicaciones en las fases de diagnóstico y análisis, y en la mayoría de los casos, sirven de punto de partida para los procesos de desarrollo.

- Los flujogramas: son un tipo de diagrama, que presenta en forma esquemática las relaciones entre diferentes elementos, como relaciones de causa - efecto, secuencias de eventos.

- Los diagramas temporales: son representaciones de la presencia/ ausencia, o de la variación en intensidad de ciertos fenómenos en el tiempo.

3. Técnicas de entrevistas y comunicación oral: los métodos de entrevista y comunicación oral adaptados al enfoque participativo, a diferencia de los métodos tradicionales, no están orientados sólo a la estadística, sino a asegurar la triangulación de información desde diferentes puntos de vistas, representativos de los miembros de la comunidad o de la variabilidad de actores. Para el caso de encuestas y entrevistas, la experiencia ha indicado la importancia de iniciar con diálogos informales, antes de la aplicación del o los instrumentos; tener claridad de los objetivos; debe ser lo más corta posible; debe ser clara en su lenguaje y construcción de preguntas; se debe 
evitar hacer preguntas o variables que no son de relevancia para el logro de los objetivos.

4. Técnicas de observación de campo: buscan recolectar en el terreno, en forma grupal, informaciones que serán analizadas posteriormente usando las técnicas de visualización. Para el diseño del Software Educativo, es fundamental porque la identificación de iconos y elementos articuladores del territorio, contribuyen con la identidad del material didáctico. Para ello se recomienda:

- Realizar recorridos de reconocimiento del área de estudio, en lo posible con algunos líderes comunitarios, quienes serán los guías;

- Hacer un registro fotográfico preliminar, desde la visión técnica de los investigadores;

- Seleccionar algunas fotografías para ser utilizada en los procesos de socialización del proyecto.

- Programar recorridos con los diferentes actores, para que ellos identifiquen los íconos y característica relevantes, que pueden ser incluidas dentro del software.

Las herramientas, junto con los diferentes métodos de participación como la IAP (Investigación acción participativa), dan la posibilidad de dinamizar el proceso de generación y aprehensión de conocimientos e ideas, así como afianzar la confianza con los facilitadores e investigadores.

La IAP, plantea la necesidad de desarrollar una metodología de investiga-ción que rompa con la dicotomía entre la teoría y la práctica, entre el sujeto y el objeto de estudio -el investigador y el investigado-, y reconozca que en la acción y en la práctica, hay la posibilidad de una acumulación de conocimiento científico (Fals, 2008). Se presenta como una práctica social de producción de conocimientos, que involucra a la comunidad en el entendi-miento y solución de sus problemas, y la transformación social (Corporación Red País Rural, 2010); se trata de una acción, en la que los participantes investigan, modifican y re-investigan dentro del proceso de investigación (Lobera, 2009).

En conclusión las aplicaciones multimedia y el uso de las tecnologías son las principales herramientas que hoy en día han contribuido a la comunidad edu- 
cativa a mejorar el proceso enseñanza - aprendizaje; considerando que los estudiantes se muestran interesados por herramientas diferentes a las tradicionales utilizadas por los docentes; además, al docente, las aplicaciones les facilitan la enseñanza; haciendo que los estudiantes tomen mayor atención, el docente innove con dichas herramientas ya sea desde el hogar, el aula, el cibercafé; donde puede reforzar la colaboración e Interacción, simular, y en algunos casos mejorar, la clase convencional.

\subsection{Metodología}

\subsection{1 Área de estudio y características generales de la población participante}

La investigación se realizó en dos instituciones educativas municipales pertenecientes a la subcuenca del río Pasto, con estudiantes entre los 11 y 19 años de edad. La Institución Educativa Municipal Cabrera, localizada en el corregimiento de Cabrera, municipio de Pasto, Nariño, Colombia; a una altu-ra de 3.000 m.s.n.m, temperatura promedio de $8^{\circ} \mathrm{C}$ y una población de 1.333 habitantes (DANE, 2012).

La Institución Educativa Municipal Mocondino, localizada en el corregimiento del mismo nombre, municipio de Pasto, Nariño, Colombia; ubicada a una altura de 2.800 m.s.n.m, temperatura promedio de $14^{\circ} \mathrm{C}$ y una población de 6.800 habitantes aproximadamente. (Ministerio de tecnologías de la información y las comunicaciones de la República de Colombia, 2.008). En la figura 3.1, se relaciona el número de estudiantes participantes por grado e institución.

Figura 3. 1 Relación de número de estudiantes por institución educativa y grado

Fuente: Este estudio

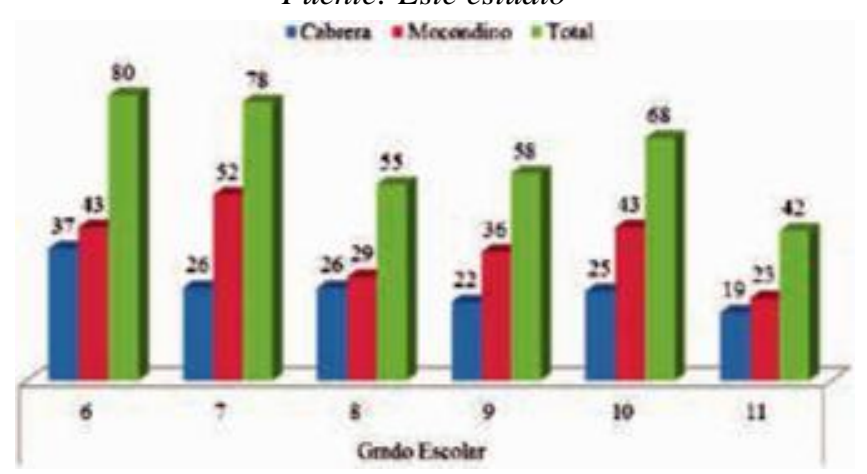


De los 381 estudiantes, el $62 \%$ corresponde a mujeres; en su mayoría, provie-nen de un núcleo familiar campesino, con una unidad familiar promedia de cinco integrantes; cuya actividad económica principal es la agropecua-ria, en unidades de producción mini y microfundistas, que por lo general no superan la hectárea (León, et al., 2014).

\subsubsection{Métodos}

A través de uso de la etnografía y con el enfoque de Investigación Acción participativa - IAP (Fals, 2008), se diseñó el Software Educativo Agroforestal, a partir de los conocimientos, gustos y preferencias de los actores involucrados (estudiantes y expertos en el área de la agroforestería) (Figura 3.2).

Figura 3. 2 Ruta metodológica para el diseño de Software Educativo

Agroforestal Fuente: Este estudio

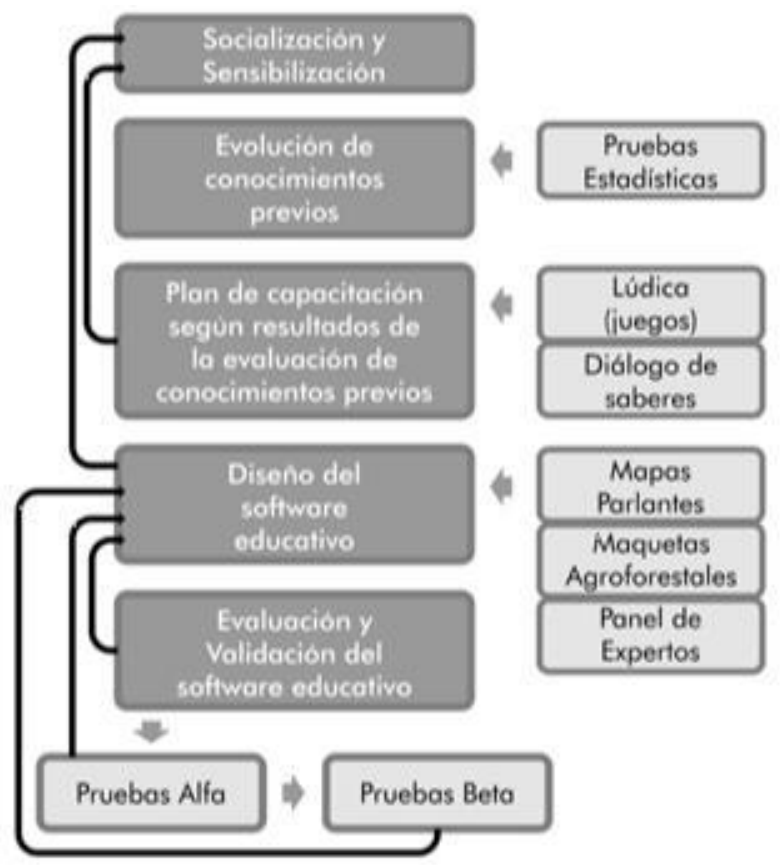

Socialización y Sensibilización. Antes de iniciar el proceso de diseño, el pro-ceso de sensibilización es fundamental, ya que a través de él se generan las confianzas para que la población pase de ser objeto de estudio a sujeto de desarrollo; en esta etapa se da a conocer los objetivos que se persiguen en la investigación (para este caso en particular), la metodología y el rol que ellos van a cumplir durante el tiempo de duración de ésta. 
Evaluación De Conocimientos Previos (Diagnóstico): En el diseño del software, fue importante evaluar el conocimiento previo que tenían los participantes sobre la agroforestería; para ello, la utilización de encuestas fue un método acertado; se emplearon dos: la primera comprendió cuatro variables (sistema productivo en la fincas, importancia de los árboles, participación en las labores de finca y conocimientos sobre temáticas agroforestales); en la segunda encuesta, se evaluó los gustos y preferencias en cinco variables (color, personajes animados, juegos, actividades y paisajes). Con los resultados de las encuestas, se realizó un análisis de correspondencias múltiples (ACM), valores propios y contribución de las variables por medio del software estadístico SPAD V 5.6.

Capacitación a los Estudiantes sobre Agroforestería: Al considerar que el diseño del software debe ser participativo, los aportes de los participantes es fundamental, por ello, el conocimiento de la temática específica es necesaria; para el caso de esta investigación los resultados de los conocimientos previos demostraron limitación en la agroforestería, antes de iniciar con el diseño, se hizo necesario capacitar a los estudiantes, por medio de la utilización de recorridos de campo, uso de la lúdica y videos.

Diseño del Software Educativo: La estructuración del software, comprende los elementos mostrados en la Figura 3.3.

Figura 3. 3 Elementos constitutivos en la estructuración del Software

Educativo Agroforestal-SEAf Fuente: Este Estudio

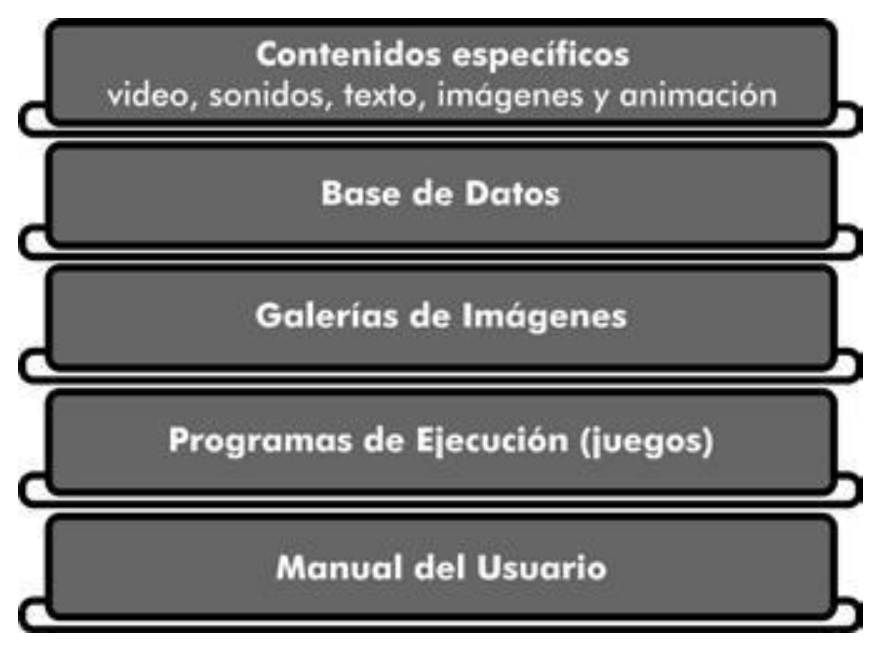


El uso del programa de creación y manipulación de gráficos vectoriales FlashCs4, se diseñó el SEAf, con el apoyo de un equipo interdisciplinario, quienes analizaron la información de base y determinaron los componentes del SEAf, considerando contenidos y juegos de evaluación y recreación en relación a definiciones sobre temáticas afines al medio ambiente y agroforestería.

En los mapas parlantes (visión histórica, presente y futura), los estudiantes plasmaron la situación actual de los sistemas productivos de sus fincas y plantearon su deseo de cambio a futuro (cinco años). De igual forma, median-te la lúdica, el diálogo de saberes y la construcción colectiva de maquetas agroforestales, se generaron directrices y pautas de gran importancia, para ser incluidas en el SEAf. Por otro, lado el integrar la técnica de panel de expertos, permitió definir los textos del software, los cuales tienen un compo-nente técnico, pero también unos refuerzos, a partir de juegos de evaluación y seguimiento de los aprendizajes.

Evaluación y validación del Software Educativo Agroforestal SEAf. "El software se desarrolla como un producto que va ser usado por muchos clientes, no es practico realizar pruebas de aceptación formal con cada uno de ellos. La mayoría de los constructores de productos de software usan un proceso llamado pruebas Alfa y Beta para descubrir errores que al parecer sólo el usuario final es capaz de encontrarlo" Pressman (2010:400). Las Pruebas alfa: las realiza el usuario en presencia de personal de desarrollo del proyecto haciendo uso de una máquina preparada para las pruebas; es decir, se realiza en un ambiente controlado. Las Pruebas beta: las realiza el usuario después de que el equipo de desarrollo les entregue una versión casi definitiva del producto; por lo general el desarrollador no está presente; es decir, se realiza en un ambiente que no puede controlar el desarrollador.

Se aplicó una prueba Alfa, con cinco estudiantes seleccionados al azar por cada grado e institución, lo que permitió determinar el nivel de entendimiento y aceptación del SEAf y definir los campos con necesidad de corrección y ajuste.

Se efectuó una prueba Beta, empleando una encuesta conformada por nueve preguntas categorizadas en: armonía de interfaces, color, sonido, navegación y diseño; aplicada a una muestra al azar de 20 personas, que no hicieron parte de los momentos anteriores, pero que tenían la connotación de ser futuros 
usuarios del software; quienes fueron los encargados de valorarlo para procesos de aprendizaje.

\subsection{Resultados}

\subsubsection{Evaluación de conocimientos previos (Diagnóstico del conocimiento agroforestal)}

Se evidenció que en promedio el 95\% de los participantes no tenían conocimiento agroforestal, pero si sobre la importancia del árbol en sus fincas. La Secretaría Educación Municipal de Pasto (2012), manifiesta que en el sector rural es notable la baja profundización en los conocimientos, desmotivación y poca orientación de las capacidades del estudiante; además, de la falta de pertinencia y relación entre lo que se desea aprender y lo que se ofrece en el establecimiento educativo. El acceso a las TIC es limitado; sin embargo, con el programa "Computadores para educar" las instituciones cuentan con unidades de PC de escritorio y mejoramiento de infraestructura tecnológica; sin embargo, no son suficientes para el número de educandos.

En los resultados sobre conocimientos relacionados con la agroforestería que manifestaron los estudiantes (Figura 3.4 y 3.5).

Figura 3. 4 Participación y conocimientos, importancia del árbol en sistemas productivos

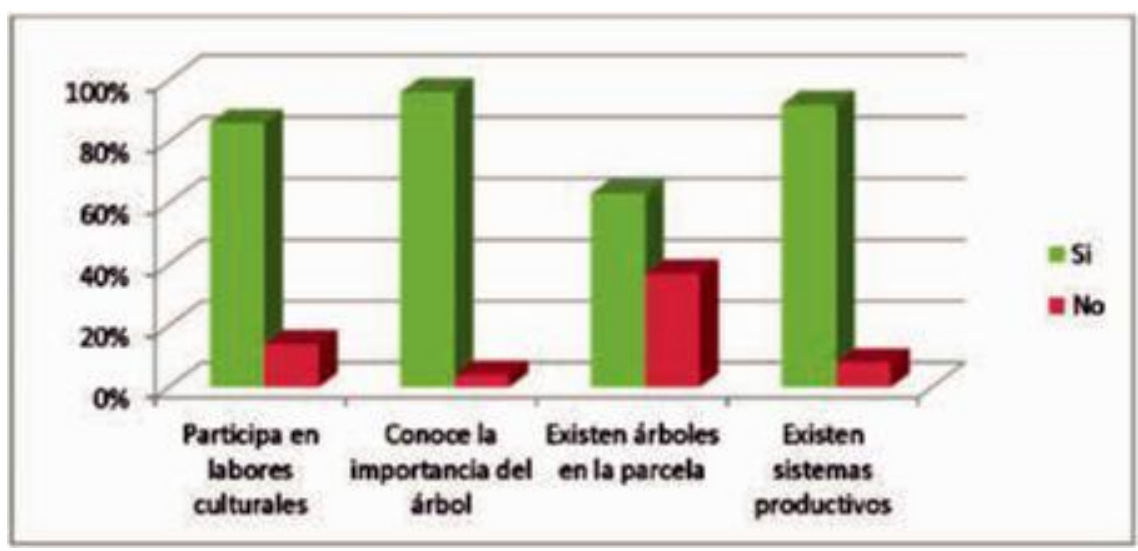


Figura 3. 5 Elementos integradores del conocimiento agroforestal

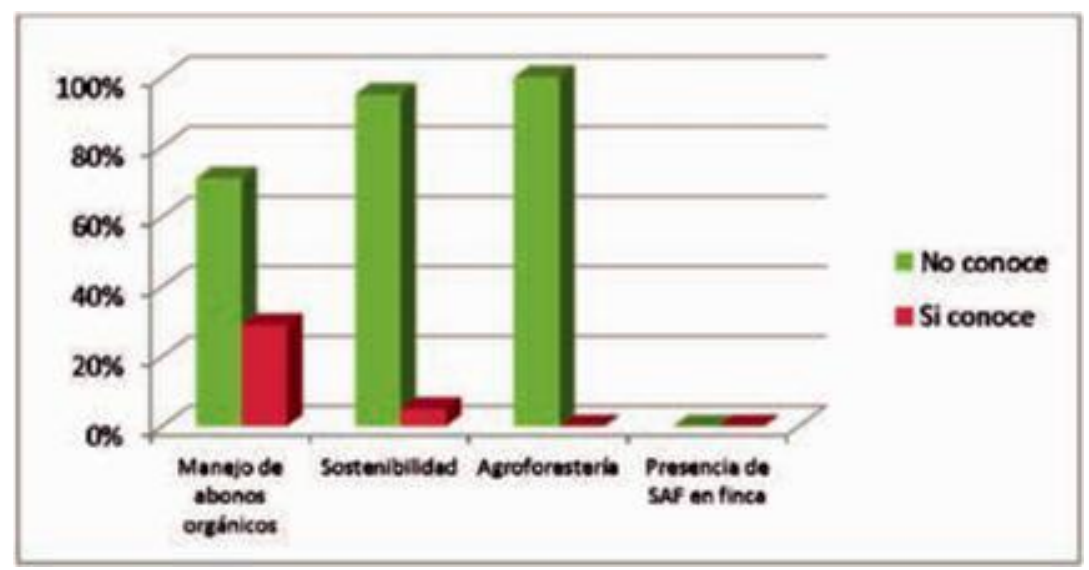

Como se muestra en la figura 3.4, la gran mayoría de estudiantes identifican un sistema productivo en sus fincas; destacándose los cultivos de: cebolla (Allium fistulosum L)., papa (Solanum tuberosum L), zanahoria ( Daucus carota L.), remolacha Beta (vulgaris L)., repollo (Brassica oleracea L.), maíz (Zea mayz L.), frijol (Phaseolus vulgaris L.), arveja (Pisum sativum L.), acelga Beta (vulgaris var cicla L)., coliflor (Brassica oleracea var botrytis L.), mora (Rubus glaucus B.), calabaza (Cucurbita máxima D.), brócoli (Brassica oleracea var itálica P.), fresa (Fragaria vesca C.), ruda (Ruta gra-veolens L.), manzanilla (Matricaria chamomilla L.), caléndula (Calendula officinalis L.), cilantro (Coriandrum sativum L.).

El Plan de Desarrollo del municipio de Pasto 2012-2015 "Transformación productiva" (Honorable Concejo Municipal de Pasto. 2012), afirma que su población rural, se caracteriza por tener una economía basada en la producción agropecuaria de pequeños productores. El 87\%, son predios con una área promedio de 0,5 a 5 ha, con producción en cultivos de Solanum tubero-sum L, especialmente sobre los corregimientos de Santa Bárbara, Catambu-co, La Laguna y El Encano; hortalizas Allium fistulosum L, B. oleracea var botrytis L, B. oleracea var itálica P, entre otras; en los corregimientos de Gualmatán, Buesaquillo, Cabrera, Catambuco, San Fernando, Mocondino y Obonuco; cultivos de Rubus glaucus B., en los corregimientos del Encano y Santa Bárbara; y en La Caldera, Coffea arabica L.

Se observó que en la mayoría de las fincas hay presencia entre dos y tres árboles, destacándose: eucalipto (Eucalyptus globulus L.), pino (Pinus sp 
L.), ciprés (Cupressus sempervirens L.), aliso (Alnus jorullensis H.), arrayan ( Myrcianthes leucoxyla O.); y frutales perennes como: tomate de árbol (Cyphomandra betacea C.), capulí (Prunus serótina K.), reina Claudia (Prunus sp L.) y chilacuán (Carica gouditiana L.).

En el componente árbol, en la Figura 3.4, se evidenció que la mayoría de estudiantes conoce la importancia de éstos; sin embargo, manifiestan que por ser Unidad Agrícola Familiar (UAF) menor a una hectárea, no es posible su inclusión dentro de sus parcelas; aunque después del proceso de capacitación y en la construcción del mapa visión de futuro (sueño), incluyen este componente en forma de arreglos agroforestales, lo que se convierte en un indicador de la incidencia que tuvieron los procesos de capacitación y actividades lúdicas en la aprehensión del conocimiento en este campo.

Lo anterior concuerda con los planteado por Padilla (1995), dice que en la región Andina, las parcelas con árboles o arbustos asociados con cultivos, pastos y animales, no han sido instaladas bajo concepción agroforestal, pero funcionan y cumplen sus roles como tal; éstas, pertenecen a campesinos que han heredado la parcela y mantienen el conocimiento que les fue trasmitido de sus antepasados; hay conciencia que es necesario manejarlas, pero se necesita conocer las tecnologías de manejo empezando por las propias, las que se practican en los Andes, las qué sean familiares y estén de acuerdo con la cul-tura agrocéntrica Andina, las que están siendo aplicadas en forma espontánea por los campesinos y aquellas que se conducen con apoyo de instituciones especializadas.

En el análisis de correspondencia múltiple - ACM, se pudo observar que predominó el conocimiento sobre la importancia de los árboles $(\mathrm{V} 3=\mathrm{si}$ saben, 252 estudiantes) y la necesidad de implementar árboles en sus predios (V4= si, 252 estudiantes); lo cual, puede ser atribuido al entorno rural donde la educación ambiental ha tenido un fuerte énfasis en la conservación de los recursos naturales, en donde la flora asume un papel preponderante; sin embargo, debido al nulo conocimiento del término agroforestería y sus implicaciones, fue necesario buscar estrategias para fortalecer éste en el campo de los SAF. Burbano (2013), plantea la importancia de la educa-ción en la modalidad agropecuaria para la sostenibilidad a nivel de finca y región y para la recuperación de conocimientos y saberes propios de la sociedad nariñense. 
En la Figura 3.5, se observa el bajo conocimiento agroforestal; por lo cual, los estudiantes manifiestan la importancia de abordar desde la infancia temas enfocados en la conservación de los recursos naturales y los beneficios de implementar sistemas agroforestales en sus fincas. Sentandreu (2012), plan-tea que en la pre-adolescencia (11 a 14 años), el individuo puede identificarse con su educador, ya sea padres, profesores, entre otros, buscando modelos a imitar, en relación a la conducta o toma de decisiones; por tanto, los medios audiovisuales y juegos utilizados en el proceso de capacitación, despertaron el interés de los estudiantes por aplicar abonos orgánicos, incluir el compo-nente arbóreo e iniciar actividades de manejo de residuos.

En relación a los abonos orgánicos y su importancia, tan sólo un 27\%, de los estudiantes tenían un conocimiento previo, en consecuencia, son poco usa-dos en los sistemas productivos. El ACM, arrojó respuestas predominantes negativas (V5= no sabe, 169 estudiantes) por su preferencia a los insumos químicos; expresado en los beneficios de los fertilizantes, fungicidas e insecticidas; lo que conduce a cuestionar sobre la necesidad de explorar otro tipo de opciones más amigables con el ambiente, ya que en muchas fincas las áreas de producción son tan pequeñas que fácilmente podrían realizar un manejo agroecológico.

La carencia de opciones amigables con el ambiente, puede obedecer a la falta de presencia institucional que ofrezca capacitación y ejecución de programas agroecológicos; a pesar de que el Ministerio de Agricultura y Desarrollo Rural ofrece este tipo de servicios a través de sus programas; que reconocen su gran potencial para impulsar la productividad, promover la tecnificación del sector primario y fortalecer la articulación del país al mercado global; que dinamiza y gestiona el Plan Nacional de Desarrollo 2.010 - 2.014 "Prosperi-dad para todos" (Ministerio de Agricultura y Desarrollo Rural, 2013).

Al analizar el ACM de conocimientos sobre agroforestería (V8), sostenibilidad (V9) y sistemas agroforestales (V10), predomina el desconocimiento (256 estudiantes equivalentes al 91\%), lo cual puede obedecer a la carencia de formación integral por parte de las instituciones educativas; en donde los procesos de educación ambiental se orientan a la conservación de los recur-sos naturales en forma aislada de los sistemas productivos, por tanto, se deben articular los proyectos ambientales escolares - PRAE, con los proyec-tos ciudadanos de educación ambiental - PROCEDA; acordes al contexto, a 
los medios de vida y a las tendencias de capacitación y orientación profesional, articulados a los planes educativos institucionales - PEI.

Según la FAO (2008), la implementación de programas de educación rural deben tener una formación académica coherente con sus modos de vida, creencias, saberes y prácticas cotidianas; ejemplo de ello, es el modelo pedagógicos "Escuela Nueva", programa de desarrollo rural integrado DRI, plan de fomento educativo para áreas rurales de municipios pequeños y escuelas urbano-marginales, proyecto de educación rural PER, entre otros.

\subsubsection{Capacitación a los estudiantes sobre agroforestería}

Considerando que alrededor del $75 \%$ de los participantes, no conocía sobre temas afines a la agroforestería; con docentes de las instituciones educativas involucradas, estudiantes e investigadores se decidió adelantar procesos de capacitación, en:

- Sistema productivo agrícola y pecuario

- Agricultura, monocultivo

- Abonos orgánicos

- Producción

- Procesos erosivos, riesgos, amenazas y vulnerabilidades

- Deforestación, reforestación, amenaza, sostenibilidad

- Agroforestería

El proceso de capacitación permitió sensibilizar y captar la atención de los estudiantes hacia la importancia de los recursos naturales y el buen manejo de prácticas agroecológicas; además de contribuir a la identificación de los elementos requeridos para el diseño del SMAf (contenido, personajes, imágenes y juegos); en este particular, Marín y Jurado (2010), opinan que el estudiante se puede involucrar con todo el empeño en algún proyecto, si juega un papel significativo en la elección y planificación del mismo, al ver reflejadas sus motivaciones, gustos y preferencias.

Por ello, de enseñanza aprendizaje, se soportó en el modelo de Kolb (1984), citado por Romero, et al., (2010), sobre los estilos de aprendizaje, plantea que para aprender algo se requiere de cuatro fases: 
- De una experiencia directa y concreta; es decir un alumno activo

- De una experiencia abstracta; es decir, cuando se lee sobre algo o alguien lo relata; lo que se define como un alumno teórico.

- Experimentando de forma activa con la información recibida; es decir un alumno pragmático.

Saarikoski, et al., (2001), manifiesta que al presentar información mediante diferentes estrategias pedagógicas, se favorecen los estilos de aprendizaje y el éxito académico; de igual manera, aprenden con más efectividad cuando se les enseña con base en sus estilos de aprendizaje predominantes (Alonso, et al., 1999); por ello, las personas poseen diversas formas de darle significado a las cosas en función de sí mismas; por eso se aprende de manera diferente (Romero, et al., 2010).

La situación plasmada en los mapas parlantes, evidencia que los estudiantes identificaron los sistemas de producción actuales, donde prevalecen los monocultivos y potreros desnudos. Mediante un diálogo de saberes, ellos plantearon en el mapa su visión a futuro, donde incluyeron el componente perenne leñoso en forma de arreglos agroforestales; demostrándose la actitud favorable del estudiante para su aprendizaje significativo, es decir, se logró conectar el nuevo conocimiento con el existente, modificando su estructura cognitiva; Ausubel (1983), manifiestan que el estudiante relaciona el mate-rial educativo con la situación nueva de aprendizaje.

Leonel, et al., (2013), señala que los materiales educativos son importantes en el reconocimiento socio-cultural y motivacional; en donde el juego, en especial el tradicional permite revelar a que cultura social pertenece el sujeto y la noción de cohesión social, cobra todo su sentido y espacio; privilegián-dose una concepción del mismo sujeto, la cultura, el enseñar y el aprender, sobre: la naturaleza, la comunicación y el sentido de conocimiento.

\subsubsection{Diseño del Software educativo.}

Una vez capacitados en las temáticas relacionadas se inicia el proceso de diseño; para ello, la implementación de los mapas parlantes evidenció que lo estudiantes lograron conjugar los conocimientos en la visión de finca comparándola con la de sus compañeros, observándose amplia comunicación, espacios de análisis y planteamiento de hipótesis que conllevaron a vivencias 
motivadoras por el tema en cuestión y despertó mayor interés por el aprendizaje agroforestal.

En el diagnóstico de gustos y preferencias, el análisis de componentes múlti-ples, mostró que los colores preferidos (V14) son el verde (126 estudiantes) y el azul (64 estudiantes); los personajes favoritos (V17) son los encontrados en la era de hielo (89 estudiantes) y el gato con botas (47 estudiantes); el pai-saje preferido (V19) es el bosque (89 estudiantes) y las actividades que más les gustan son las competitivas (263 estudiantes), al aire libre (263 estudian-tes) y grupales (257 estudiantes).

Durante las diferentes fases de desarrollo de un software es importante la obtención de información relevante, Galeano (2008), infiere que debe permitir diseñar una interfaz cercana a sus capacidades físicas cognitivas a sus gustos y expectativas, convirtiendo al usuario en coocreador; lo que se conoce como Diseño Centrado en el Usuario- DCU. Antón (2.003), argumenta que es necesario definir perfiles de usuario (donde se detallan datos de preferencias de contenido, consumo, entorno) al momento de trabajar con sistemas digitales que permiten una personalización del producto y por ende una maximización de los recursos en oferta y demanda.

El análisis del histograma de valores propios, permitió identificar que los cinco primeros factores explican en conjunto el 34,27\% de la variabilidad; entre los que sobresalen como el primer factor, los colores preferidos, explicando el $7 \%$ de la variabilidad. El segundo, tercero, cuarto y quinto factor (personaje preferido, paisaje favorito, juegos y área preferida) explican el $6,4 \% ; 4,99 \% ; 4,61 \%$ y $4,46 \%$, respectivamente.

Falguera (2010), al estudiar el comportamiento del individuo como consumidor de algún bien o servicio, plantea que al conocer sus necesidades y hacer el producto más aceptable, se llega a repercutir en su voluntad, por tanto, la aplicación del SEAf, permitió influir en los procesos de apropiación del conocimiento agroforestal, señalado principalmente por la aceptación de esta TIC por parte de la totalidad de los estudiantes involucrados.

En el Análisis de contribuciones de las variables; Se pudo establecer que las variables que más contribuyeron a la conformación de los factores fueron: existencia de árboles $(\mathrm{V} 2=10,8)$, materia preferida $(\mathrm{V} 15=10,1)$, existencia 
de sistemas productivos $(\mathrm{V} 1=9,9)$ y participación en las labores del predio $(\mathrm{V} 5=8,9)$; variables relacionadas en su mayoría con el entorno de los estudiantes (sistemas productivos).

Cortes y García (2009), afirman que en el desarrollo del niño y/o adolescente influyen los espacios físicos y las situaciones sociales; así mismo, Carvajal (2011), manifiesta que el entorno forma parte del sentido comunitario, reflejándose en la preocupación del individuo por éste y su participación para mejorarlo. En este sentido, el SEAf, le permite al usuario repensar su terri-torio y en las formas de actuar frente a él, en tanto, lo orienta a conocer buenas prácticas agrícolas para una posible adopción de sistemas agroforestales, como una opción de desarrollo local. Sares (2010), opina que el estudiante se puede involucrar con todo el empeño en algún proyecto, si juega un papel significativo en la elección y planificación del mismo, al ver reflejado sus motivaciones, gustos y preferencias.

En el diseño participativo del SEAf, se observó el interés y mejoramiento en el conocimiento agroforestal, al plantear la inclusión del componente leñoso perenne dentro de monocultivos y potreros desnudos, en una distribución espacial y temporal, evidenciándose, la importancia de capacitación previa por medio de videos y juegos; así como su motivación, al ser considerados participantes activos para su diseño.

Skinner y Gonzás (2007), manifiestan que el aprendizaje es significativo cuando existe motivación, el "querer aprender", a través de juegos, actividades artísticas, videos, entre otros; además, Villamizar (2007), infiere que la motivación, requiere de conocimientos previos, la inteligencia y la experiencia.

Dentro del diseño del SEAf, se cuenta con diferentes ventanas interactivas, como la que se aprecia en la Figura 3.6. 
Figura 3. 6 Menú principal del Software Educativo "Mundo

Agroforestal" Fuente: este estudio

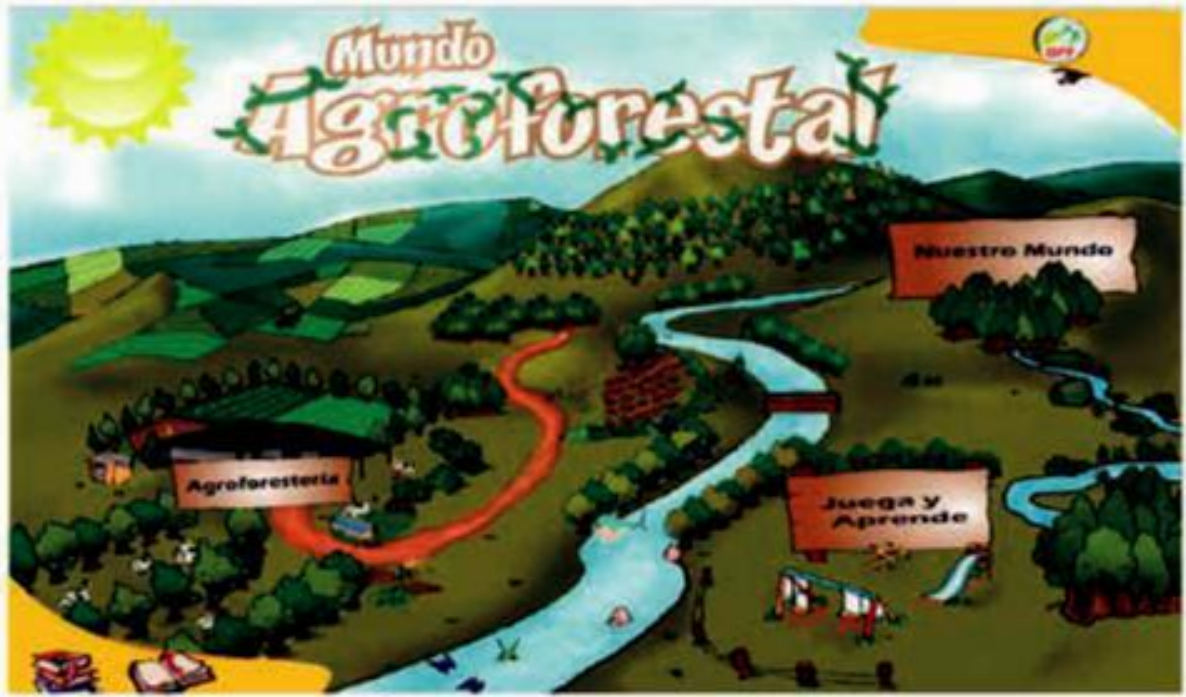

Entre las ventanas, se tienen:

- Diccionario ambiental: Tiene los conceptos generales sobre recursos naturales y sistemas productivos agropecuarios, que introduce al estu-diante en el conocimiento agroforestal. (Figura 3.7).

Figura 3. 7 Ventana diccionario del software educativo "Mundo Agroforestal"

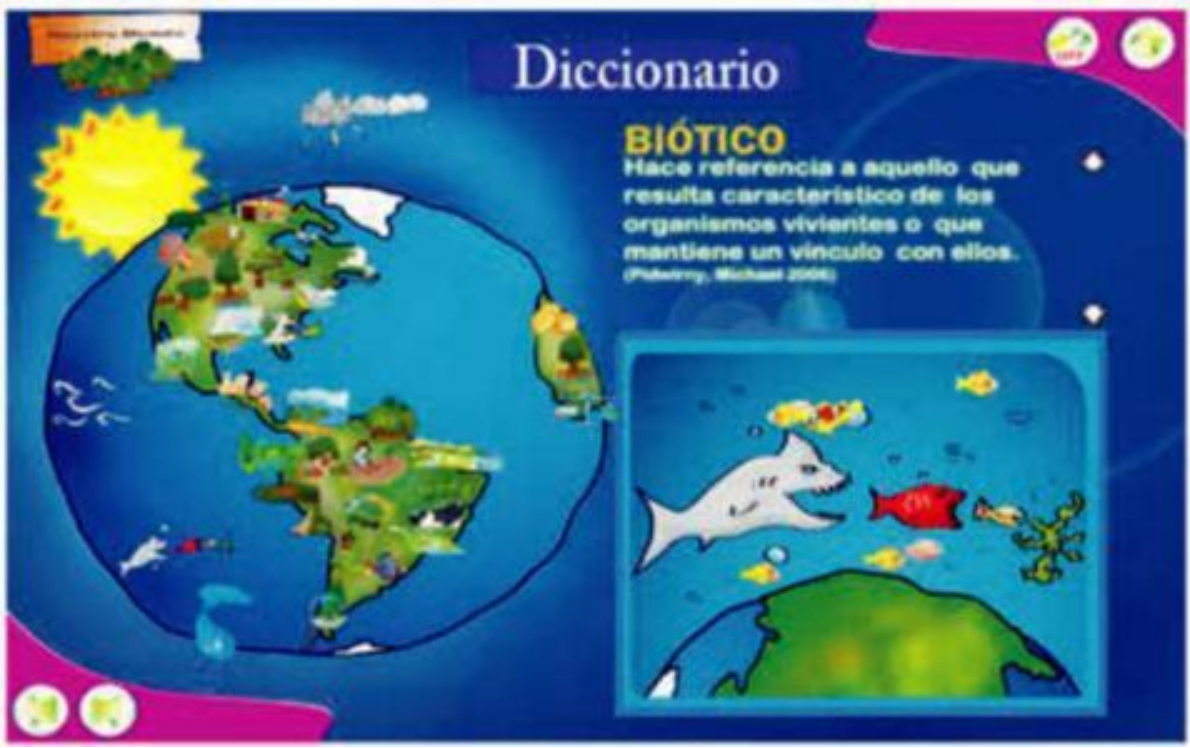


- Agroforestería: Aborda su definición, clasificación y potencialidades (Figura 3.8).

Figura 3. 8 Ventana agroforestería del software educativo "Mundo Agroforestal"

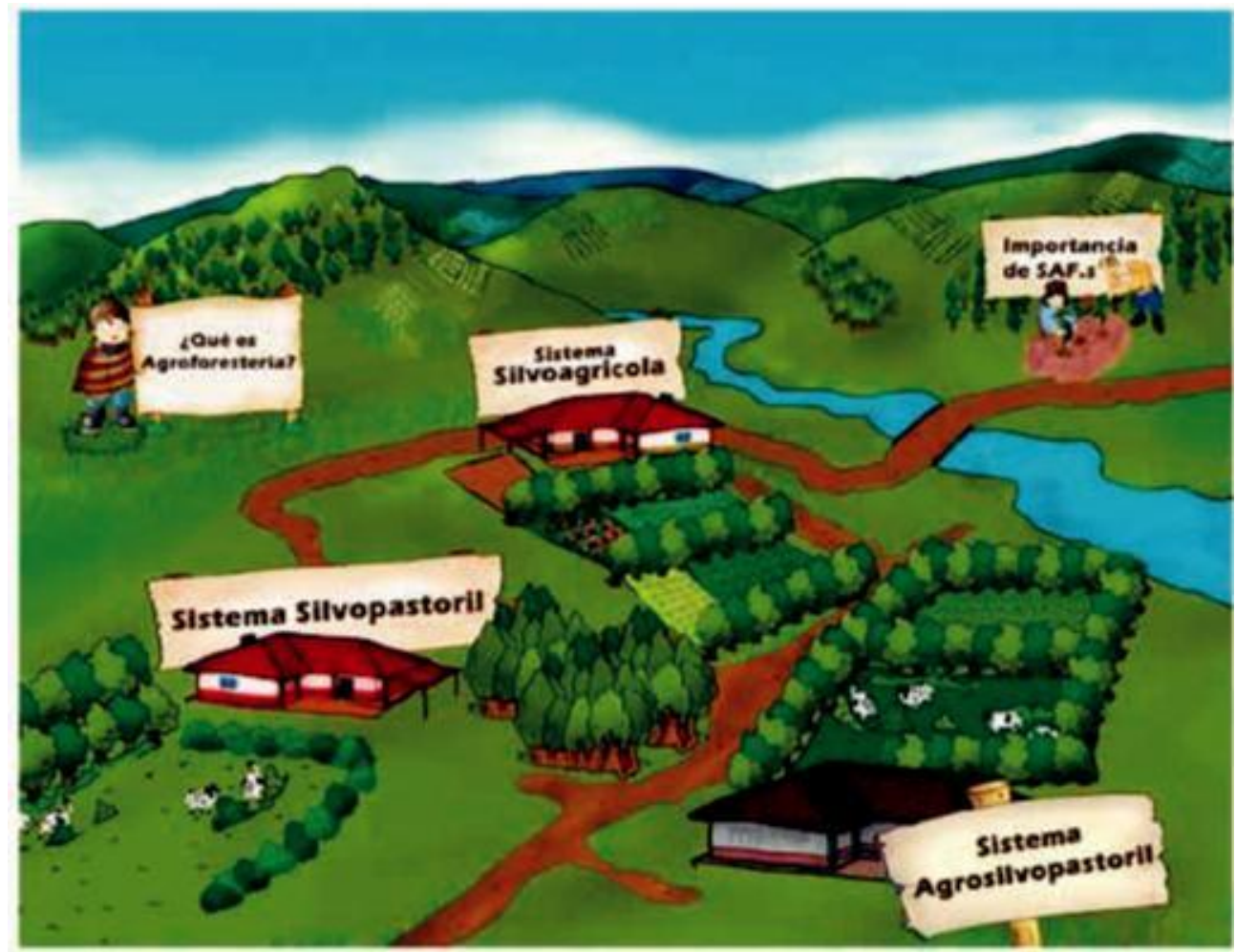

- Juegos: Tienen el propósito de reforzar los conocimientos adquiridos por medio de cuatro juegos (Figura 3.9): 1. "ENLÁZATE": permite relacionar la imagen o definición con la palabra que le corresponda.

2. "NARANJO DE RECUERDOS": el objetivo del juego, es potencializar la memoria, a través de la retención de imágenes y formación de parejas. 3. "DICHO Y HECHO": pretende inducir al estudiante a la reflexión, con respecto a los aspectos claves en el conocimiento sobre recursos naturales y agroforestería por medio de la ordenación de frases. 4. "TRIVIAMBIENTE": su objetivo es reforzar los conceptos encontrados en el diccionario. Los participantes deben responder las preguntas, entre cuatro opciones de respuesta. 
Figura 3. 9 Ventana juegos del software educativo "Mundo Agroforestal"

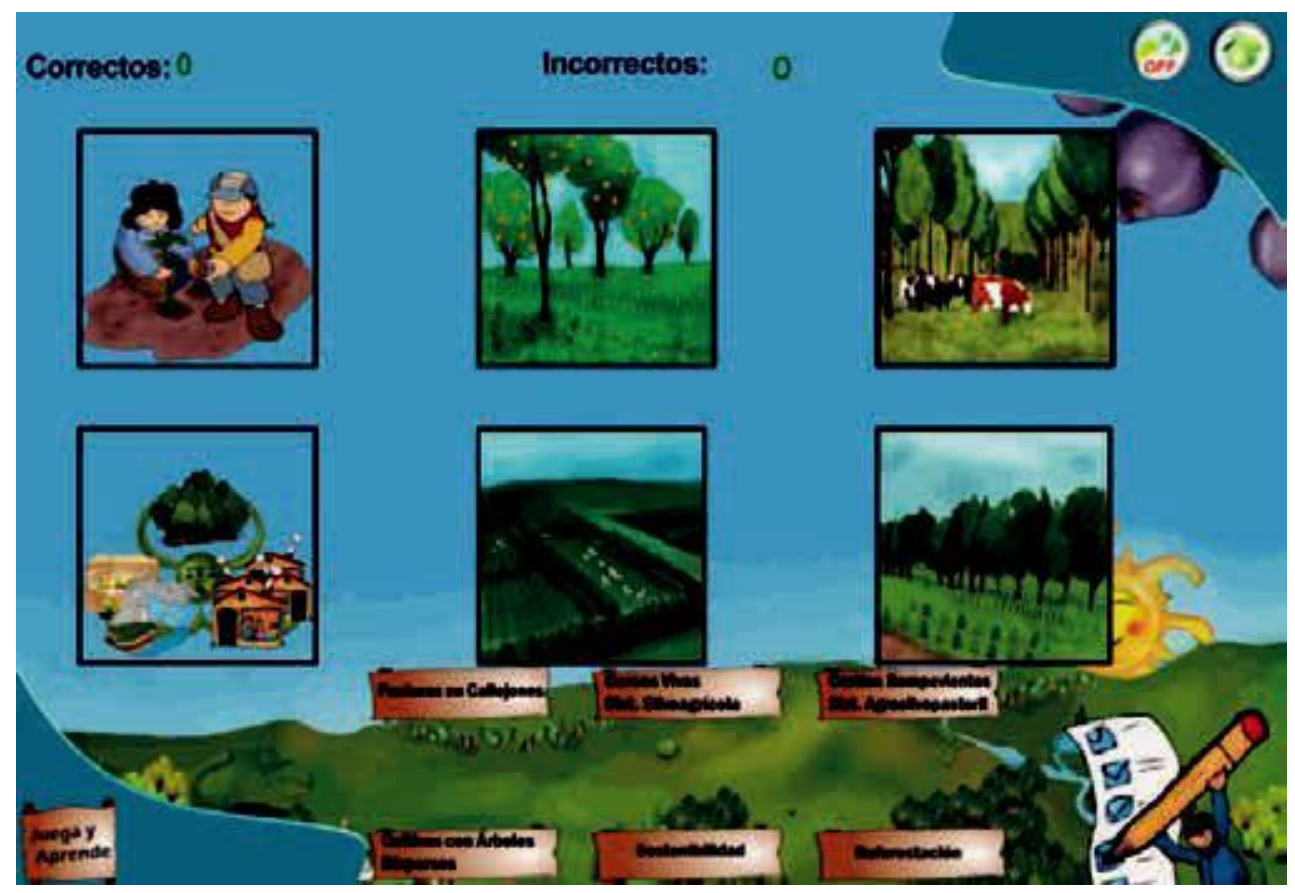

Se incluyó el juego dentro de la presente investigación, teniendo en cuenta que el desempeño de los estudiantes mejoró a medida que se los involucraba dentro de actividades lúdicas, cabe resaltar que fueron ellos quienes crearon los juegos incluidos dentro del software.

Leonel, et al., (2013), manifiesta que es necesaria la implementación de herramientas didácticas innovadoras, que permitan o faciliten la construcción de individuos reflexivos, críticos y autónomos; lo que conlleva a su vez, a la generación de un enfoque pedagógico con la lúdica, como herramienta facilitadora de los procesos de educación, en este caso en el ámbito ambiental.

Fandos, et al., (2002), afirman que una estrategia didáctica se ve representada en la lúdica a través del juego, vista como una actividad libre, placentera y voluntaria; Leonel et al. (2013b: 221), infieren que "no se puede dar una definición única del juego; sin embargo, se puede asumir como un sistema que permite el desarrollo de los individuos, que al seguir unas reglas pre-determinadas, pueden llegar a cumplir con los objetivos propuestos por el juego, en donde las acciones, estrategias y vivencias previas de los jugadores, son los elementos diferenciadores para la diversión y consolidación de habi-lidades de los seres humanos". 
En la evaluación Alfa, se evidenció el interés y la disponibilidad de trabajar con este tipo de herramientas; además, los estudiantes se apropiaron del resultado final al ver reflejado su trabajo en el software. En la evaluación Beta, se observó la aceptación del SEAf en todas las variables evaluadas (diseño, facilidad de navegación, pertinencia de colores, temáticas abordadas e ilustraciones), con un promedio de $94 \%$ de personas que calificaron cada variable como altamente adecuada y el $6 \%$ como moderadamente adecuada.

El proceso investigativo evaluado, resultó ser altamente aceptado por los usuarios, posiblemente por lo planteado por Caliva (2009), quien afirma que durante su vida el ser humano anhela alcanzar objetivos y metas que les permitan integrarse a la sociedad, esto lleva a educarse de una forma perma-nente, activa y organizada durante toda su vida, implementando diferentes estrategias de aprendizaje; para el caso agroforestal, el SEAf, se convierte en un instrumento mediador para acceder al aprendizaje.

Después de que el estudiante haya explorado espontáneamente este instrumento y encontrado una relación con el objetivo del mismo, se continúa el proceso de aprendizaje a través de la decodificación lógica del material (representación mental del concepto); para ello, es necesaria la discusión, confrontación de hipótesis, procesos de exposición de las elaboraciones que han construido los estudiantes y de argumentación en los que se confrontan hipótesis y se accede a acuerdos sustentados y a la divulgación de los resultados obtenidos, por ello, algunos estudiantes de la Institución Educativa Municipal de Cabrera participaron en el primer encuentro de aprendizajes significativos realizados en la universidad de Nariño.

Lo anterior, de acuerdo a Vigotsky (2008), se denomina "internacionalización" y se define como el momento en que el saber cultural, externo al sujeto, pasa a ser una realidad mental apropiada, como producto de la interacción con otros; es decir una representación mental construida por el sujeto de aprendizaje; en tanto, el sujeto se apropia del conocimiento.

Teniendo en cuenta las características presentes en el software educativo agroforestal y el resultado de la evaluación - altamente adecuado, se puede inferir que el software queda validado y disponible para ser utilizado por el público objetivo (estudiantes de secundaria pertenecientes a instituciones rurales), de uso libre para cualquier persona y con propiedad intelectual de los autores de éste y de la Universidad de Nariño. 



\section{LECCIONES APRENDIDAS}

Una de las características del departamento de Nariño como lo es el minifundio, que en algunos casos se sobreexplota por las actividades agropecuarias que sobrepasan su capacidad de resiliencia; es necesario profundizar en estudios que permitan conocer realmente el interés de formación para la producción del pequeño agricultor nariñense, a fin del plantear alternativas productivas sustentables pertinentes al contexto regional, de esta manera el desarrollo de las herramientas didácticas aquí descritas contribuyen a este propósito.

Mediante el uso de la tecnología y la valoración de la cultura de cada región es posible el diseño de propuestas innovadoras y coherentes con la dinámica de los medios de vida, en los cuales está inmersa una diversidad de aspectos que desde una visión integral se consideran ejes movilizadores del cambio, que urgen desencadenar como un proceso endógeno, donde cada individuo proyecte hacia la comunidad sus saberes, y en medio de dicho espacio se facilite la apropiación social del conocimiento, viabilizada entre otras, por el empleo de herramientas didácticas como las diseñadas con esta investigación "Software educativo mundo agroforestal y agroforestería material didáctico" y con la orientación adecuada de personal técnico debidamente capacitado para la acción.

Tanto el material didáctico "Agroforestería" como el software educativo "Mundo Agroforestal", se constituyen como un gran aporte para los extensionistas, quienes al contar con estas herramientas de trabajo para los procesos de formación de comunidades rurales, se les facilita su labor, al lograr mayor integración de los participantes, optimizar tiempo y esfuerzo en los procesos de acompañamiento.

El conocimiento y preferencia por juegos de mesa comunes en la región; expresado por las comunidades rurales, especialmente los juegos de cartas y parques, junto a la ilustración de la cotidianidad, fueron las variables más relevantes en el diseño del material didáctico manual; ya que generan identidad, estimulan mayor autoestima y facilitan la integración, puesto que cada experiencia al jugar con el material es nueva y mantiene un nivel de moti-vación permanente, invitando a un reto constante, induciendo al análisis y reflexión sobre su propio modelo de producción. 
El software educativo "Mundo Agroforestal”, cuyas características demuestran armonía entre interfaces, innovación en el ámbito educativo, interactividad y facilidad en la consecución de información, se considera una eficaz herramienta educativa, en la medida en que despierta interés en el usuario y de éste con su medio rural, ya que permite afianzar conocimientos agrofores-tales, siendo así pertinente para el contexto y un medio de gran impacto para generar un verdadero aprendizaje significativo.

La generación de espacios participativos para la investigación, la comunicación, el diálogo de saberes y el fomento de la creatividad, transversalizados por la lúdica; conllevan a incrementar la motivación del estudiante, quien se hace participe en la construcción de tecnologías de la información y comuni-cación, como lo es el SEAf, siendo este socialmente valorado.

Las herramientas didácticas representan un gran apoyo a la labor que debe desempeñar un profesional asistente técnico agropecuario, ya que actualmente la dinámica rural demanda de un acompañamiento diferente a lo que se presentaba hace 50 años, se requiere replantear los impactos reales de su rol en la producción, ya que se exigen resultados sin valorar el papel jugado para obtenerlos y no existe correlación entre lo que se hace y lo que se evalúa. Por consiguiente, estas herramientas didácticas, se consideran parte de las estrategias de acción adecuadas para capacitación, como un aporte significativo de la academia y la investigación para la formación integral del nuevo técnico que demanda un país competitivo. 


\section{BIBLIOGRAFÍA}

ACOSTA, P. 2014. Culturas tradicionales y cambios contemporáneos: el pueblo indígena Kokonuco y las tecnologías de la información y la comunicación. Desafíos, Vol. 26 (2), pp.153-179.

AlONSO, C., GALlEGO, D. y HONEY, P. 1999. Los estilos de aprendizaje. Procedimientos de diagnóstico y mejora. $4^{\mathrm{a}}$ ed. Bilbao, España: Ediciones Mensajero.17 p.

ANTÓN, C. 2003. Desarrollo de un Sistema de Gestión de Perfiles de Usuario para la Personalización en el Acceso a Contenidos Digitales. Universidad Politécnica de Madrid. Departamento de Ingeniería de Sistemas Telemáticos. 25 p.

ATTA-KRAH, K.1993.Agroforestry in the Highlandsof Eastern and Central Africa. Kabale, Uganda. 139 p.

AUSUBEL, N.1983. Psicología Educativa: Un punto de vista cognoscitivo. 2 ed. Trillas México. 26 p

BADIA, A., MENESES, J. \& SIGALÉS, C. 2013. Teachersperceptions of factorsaffectingtheeducational use of ICT in technology-richclassrooms. Electronic Journal of Research In Educational Psychology, Vol. 11 (3). pp. 787-807.

BEER, J., IBRAHIM, M., SOMARRIBA, E., BARRANCE, A. y LEAKEY, R. 2004. Establecimiento y manejo de árboles en sistemas agroforestales. Capítulo 6. Árboles de Centroamérica. OFICATIE. 46 p.

BEER, J., MUSCHLER, R., KASS, D. y SOMARRIBA, E. 1998. Shade management incoffee and cacao plantations. Agrofor. Syst 38: pp. 139-164.

BERNAL, T.C.A. 2000. Metodología de la investigación para administración y economía. Bogotá: Prentice Hall. pp. 40-42.

BERWAL, J. 1987. Teaching Foreign Languages with Realia and Other Au-thentic Materials. ERIC Q\&A. Office of Educational Research and Improve-ment (ED), Washington, DC. 6 p. Revisado diciembre 3 de 2014, en: http:// files.eric.ed.gov/fulltext/ED289367.pdf 
BURBANO, N. 2013. Educación para el progreso del Estudiante del sector rural en Nariño. Revista Entramado. Universidad libre de Cali. Vol. 9 (1). 112 p.

BUSSTRA, M., DE GRAAF, C. y HARTOG, R. 2007. Design Of Digital Learning material on social-psychological theories for nutrition behavior research.

Journal of Educational Multimedia \& Hypermedia, 15 (2). pp.163-182.

BUSTOS, A. y ROMÁN, M. 2011. La importancia de evaluar la incorporación y el uso de las TIC en la educación. Revista Iberoamericana de evalua-ción educativa, Vol. 4 (2). pp. 3-7.

CABERO, J. 2001. Tecnología educativa: diseño y utilización de medios de enseñanza. Paidós, Barcelona. 30 p.

CALIVA, J. 2009. Manual del capacitador para el facilitador. Centro de lide-razgo en agricultura. Instituto Interamericano de Cooperación para la Agri-cultura (IICA), San José de Costa Rica. 102 p.

CÁlIX, H. y CASTILLO, A. 2000. Soportes vivos para Pithaya (Hylocereus spp.) en sistemas agroforestales. Agroforestería de las Américas. . Desarrollo de un Sistema de Gestión de Perfiles de Usuario para la Personalización en el Acceso a Contenidos Digitales. Universidad Politécnica de Madrid. Departa-mento de Ingeniería de Sistemas Telemáticos Vol. 7 (2). pp. 21-25.

CAMACHO, E; CARDESO, F. y NUÑEZ, G. 2004. Guía de estudio Arqui-tecturas de Software. Trabajo de grado de Ingeniería de Sistemas, Facultad de ingeniería, Universidad Nacional de Colombia. 58 p.

CARVAJAL, A. 2011. Apuntes sobre el desarrollo comunitario. 1 ed. Univer-sidad de Málaga, España. Eumed.net.75 p.

CENTRO AGRONÓMICO TROPICAL DE INVESTIGACIÓN Y ENSEÑANZA, (CATIE), 1993. Curso Internacional "Desarrollo de Sistemas Agroforestales”. Documento IICA. Turrialba, CR. 210 p.

CATIE. 2001. Módulos de enseñanza agroforestal. Turrialba, C.R. 27 p. 
COLCIENCIAS. 2012. Apropiación social del conocimiento. Sistema nacional de ciencia, tecnología e innovación. En: www.colciencias.gov.co/programa_estrategia/apropiaci-n-social-del-conocimiento; Consulta: marzo, 2014.

COMBE, J. y BUDOWSKI, G. 1979. Clasification of traditional agroforestry techniques In Workshopon traditional agroforestry systems in Latin Ame-rica. Turrialba C.R. CATIE.17-47 p.

CORPORACIÓN RED PAÍS RURAL. 2010. La Investigación Acción Participativa. En: http://www.paisrural.org/molino/15/investigacion.shtml. 1 p. Consulta: junio, 2012.

CORTES, M. y GARCIA, E. 2009. La Influencia Del Contexto Sociocultural En el Desarrollo Cognitivo de Niños y Adolescentes. Tesis de especialización de sicóloga, Facultad de humanidades, Escuela Normal de Especialización, Sinaloa, México DF. 77 p.

COSTA, M. y DORRÍO, B. 2010. Actividades manipulativas como herramienta didáctica en la educación científico-tecnológica. Revista Eureka sobre Enseñanza y Divulgación de las Ciencias, 7(2). pp. 462-472

CUELLAR, J. 2011. Documento de caracterización parte alta de la microcuenca Miraflores, quebrada Piquisiqui, Nariño, Colombia. 39 p.

Datos", [en línea] 5campus.com, Estadística <http://www.5campus.com/lec-cion/aed> Consultado: Octubre 2013.

DEPARTAMENTO ADMINISTRATIVO NACIONAL DE ESTADÍSTICA, (DANE). 2010. Censo General 2005, boletín 13/09/2010, Perfil Nariño. En: https://www.dane.gov.co/files/censo2005/PERFIL_PDF_CG2005/ 52000T7T000.PDF. 6 p.; consulta: junio, 2014.

. DANE, 2012. Informe de Coyuntura Económica Regional. Convenio interadministrativo del departamento de Nariño. $N^{\circ} 111$ de abril de 2000. Colombia. 15 p.

. DANE. 2012. Plan de Desarrollo Departamental (2012-2015):

Nariño mejor. República de Colombia. Gobernación de Nariño. 230 p. 
ESCOBAR, A. 2005. Bienvenidos a Cyberia: notas para una antropología de la cibercultura. Revista Estudios Sociales, (22). pp. 15-35

FALGUERA, L. 2010.Importancia de conocer la conducta del consumidor. Revista ESHOB. Vol.11. Barcelona, España. 6 p.

FALS, B. 2008. La investigación acción participativa. Revista Espacio Abierto. Vol. 17. 4 p.

FANDOS, M., JIMÉNEZ, J. y PIO, A. 2002. Estrategias didácticas en el uso de las tecnologías de la información y la comunicación. Revista Acción Pedagógica. Vol. 11(1): pp. 28-39.

FERNÁNDEZ, A. y LÓPEZ, M. 2008. La inclusión del componente emocional en la formación inicial de maestros: Una experiencia para el desarrollo de la conciencia sensorial. Revista Iberoamericana de Educación Vol. 43

(3). Madrid/Paraguay/Buenos Aires: Centro de Altos Estudios Universitarios (CAEU) Organización de Estados Iberoamericanos para la Educación, la Ciencia y la Cultura (OEI).

FIGUERAS, S. y GARGALLO, P. 2003. Análisis exploratorio de datos. Disponible en: http://www.5campus.com/leccion/aed.;consulta: septiembre, 2015.

FREIRE, P. 1969. La educación como práctica de libertad. Madrid, editorial Siglo XXI. 152 p.

GALEANO, R. 2008. Diseño centrado en el usuario (artículo de investigación académica, científica y tecnológica). Revista Q, 2 (4). pp. 12-14. En: http://revistaq.upb.edu.co; consulta: Agosto, 2013.

GALVIS, E.; MARTINEZ B.; OLIVEROS, L. y OLIVEROS, M. 2012. Las TIC: Herramientas motivadoras para la apropiación de la lecto-escritura a través de textos. Trabajo de grado de Licenciatura en Educación Básica con énfasis en Tecnología Informática. Facultad de Educación, Universidad Coo-perativa de Colombia, sede el Bagre, Antioquia. 59 p.

GATT, S. 2003. Constructivism-Aneffective Theory of Learning. en Gatt, S. y Vella, y. (Eds.), Constructivis tteaching in Primary School Social Studies, Ma- 
thematics, Science, ICT, Design and Technology. Malta: Agenda Publishers.

GELFIUS, F. 1997. Herramientas para el Desarrollo Participativo. Salvador. EDICPSA. 80 p.

GLIESSMAN, S. R., R. GARCIA E. M., AMADOR A. 1981. The ecological basis for the application of traditional agricultural technology in the management of tropical agroecosystems.Agro-Ecosystems. pp. 7:173-185.

GOLEMAN, D. 2008. Inteligencia Emocional. Barcelona. Kairos ed. 384 p.

GOTTRET, M. V. 2011. El enfoque de medios de vida sostenibles: una estra-tegia para el diseño e implementación de iniciativas para la reducción de la pobreza. 1 ed. Turrialba, C.R: CATIE, 184 p. Serie Técnica. Manual Técnico / CATIE; No. 103.

GOUYON, A, de FORESTA, H. y LEVANG, P.1993. Does 'jungle rubber' deserveits name? An analysis of rubber agroforestry systems in Southeast Sumatra, Agrofor. Syst. 22. pp. 181-206.

GUZMÁN, G., ALONSO, A., POULIQUEN, y SEVILLA, E.1994. Las me-todologías participativas de investigación: el aporte al desarrollo local endó-geno, Instituto de Sociología y Estudios Campesinos, ETSIAM, Córdoba. Agricultura Ecológica y Desarrollo Rural, II Congreso de la Sociedad Espa-ñola de Agricultura Ecológica, Pamplona, Iruña. Revisado el 25 de octubre de 2014, en: http://www.invaf.com.mx/pdf/L102.pdf.

HERNÁNDEZ, R., FERNÁNDEZ, C. y BAPTISTA, P. 2006. Metodología de la investigación. 4 ed. México. McGraw-Hill Interamericana. 33 p.

HODSON, D. 1992. In searchfor a meaningfulrelationship: anexploration of someissuesrelating to integration in scienceeducation. International Journal of Science Education, 14. pp. 541-566.

HONORABLE CONCEJO MUNICIPAL DE PASTO. 2012. Acuerdo No. 008 de mayo 31, por el cual se aprueba el plan de desarrollo del municipio de Pasto 2012 - 2015. “Transformación productiva”. Alcaldía de Pasto, Colombia. $210 \mathrm{p}$. 
JIMÉNEZ, F., KASS, D. y JIMÉNEZ, F. 1998. El cultivo en callejones. Apuntes de Clase del Curso Corto: Sistemas Agroforestales. Turrialba, C.R. Proyecto Agroforestal CATIE/GTZ. pp. 257-277.

JIMÉNEZ, F., MUSCHLER, R. y KÖPSELL, E. 2001. Funciones y aplicaciones de sistemas agroforestales. Serie materiales de enseñanza/CATIE, no 46. Turrialba, C.R.: CATIE, Proyecto Agroforestal CATIE/GTZ. 128p.

JIMÉNEZ, F., MUSCHLER, R. y KÖPSELL, E. 2001.Introducción a la agroforestería. En: Funciones y aplicaciones de sistemas agroforestales. Serie materiales de enseñanza/CATIE, no 46. Turrialba, C.R. CATIE, Proyecto Agroforestal, CATIE/GTZ. 24 p.

JIMÉNEZ, J. 2002. Estrategias didácticas en el uso de las tecnologías de la información y la comunicación. Revista Acción pedagógica. Universidad de los Andes. Vol. 11 (1). 36 p.

KANG, P., OSTERMANN, J., SHILlinG, J., NEUPERT, W., CRAIG, E. PFANNER N. 1990. Requirement for hsp70 in the mitochondrial matrix for translocation and folding of precursor proteins. Nature 348(6297). pp.137-43.

KASS, D. 1998. Barbechos mejorados. En: Jiménez, F. y Vargas, A. Apuntes de clase del curso corto: Sistemas Agroforestales. Proyecto Agroforestal CA-TIE/GTZ. Turrialba, C.R. pp. 239-256.

KING, K.1979. Concepts of agroforestry, in: Chandler T., Spurgeon D. (eds.), International Cooperation in Agroforestry, ICRAF, Nairobi, Kenya. pp.1-13.

KOLB, D. 1976. The Learning Style Inventory: Technical Manual. Boston, Ma.: McBer. pp.

LAVADO, A. 2011. Las TIC como medio para perfeccionar la dirección del proceso de enseñanza. Revista IPLAC, publicación latinoamericana y cari-beña de educación. Vol. 4 (3). pp.2 - 5.

LEBART, L. 1974. On the Benzécri's method for finding eigenvectors by stochastic approximation.COMPSTAT, Proceedings in Computational. Statist., Physicaverlag, Vienna, pp. 202-211; disponible en: http://ses.telecom- aristech. 
fr/lebart/doc/LEBART_IFCS.Kobe.1997.pdf. Consultado en diciembre de 2013.

LEÓN, A., LUNA, C. y LEONEL, H. 2014. Software educativo "mundo agroforestal": Estudio de caso, Subcuenca Alta del río Pasto, Nariño, Colombia. Revista de Ciencias Agrícolas, Volumen 31 (1). pp. 65-77. Segundo semestre.

LEONEL, H. 2011. Gestión participativa de cuencas hidrográficas: el caso de la cuenca del rio Valles, oriente de México. Tesis doctoral en ciencias ambientales. Universidad Autónoma de San Luis Potosí. México. 390 p.

LEONEL, H., AGUILAR, M. y REYES, H. 2010. Factores sociodemográfi-cos y niveles de participación en la gestión de la cuenca del río Valles, oriente de México. En: Prospectiva, No. 15, Octubre. pp. 263293. Universidad del Valle-Colombia.

LEONEL, H., RIVAS, H. y LUNA, C. 2013 a. Uso de las tecnologías de la información y de la comunicación para la gestión social y ambiental del agua. pp. 159-170. En: Agua Para la Vida. Memoria de la IV semana Nacional de la Ciencia, la Tecnología y la Innovación. Nariño, Universidad Mariana. 478 p.

LEONEL, H., RIVAS H. y LUNA C. 2013 b. El juego como herramienta para la educación ambiental. pp. 219-231. En: Agua Para la Vida. Memoria de la IV semana Nacional de la Ciencia, la Tecnología y la Innovación. Nariño, Universidad Mariana. 478 p.

LOBERA, J. 2009. Investigación participativa: un paso adelante. Madrid España, Tecfa. 25 p.

LOK, R. 1998. Introducción a los huertos caseros tradicionales tropicales. Turrialba, C.R. CATIE. Proyecto Agroforestal CATIE/GTZ. Módulo de Enseñanza Agroforestal No 3. 157 p .

LUNDGREN, B. y RAINTREE, J. 1982. Sustained agroforestry. In: B. Nes-tred (ed.). Agricultural Research for Development: potencials and Challen-ges in Asia. The Hague, The Netherlands, ISNAR. pp. 37 - 49. 
MARÍN Y JURADO. 2010. Aplicación de Estrategias Metodológicas de En-foque Constructivista en la Motivación hacia el Aprendizaje. Tesis de pregrado de licenciado en ciencias de la Educación. Facultad de Ciencias Sociales. Universidad Técnica de Machala. Ecuador. 37 p.

MARQUÉS, P. 2001. Los procesos de enseñanza y aprendizaje. La motivación. Universidad de Oviedo. España. pp. 25-28.

MAYER, R. 2003. The promise of multimedia learning: Using the same ins-tructional design methods across different media. Learning and Instruction, 13. pp.125-139.

MAYER, R. y MORENO, R. (2002). Aids to computer-based multimedia learning. Learning and Instruction, 12. pp. 107-119.

MÉNDEZ, E., BEER, J. y FAUSTINO, J. 2000. Plantación de árboles en línea. Turrialba, C.R. CATIE. Proyecto Agroforestal CATIE/GTZ. Materiales de enseñanza No 39. Módulo de enseñanza agroforestal 1. 117 p.

MENDIETA, M. y ROCHA, L. 2007. Sistemas agroforestales. Universidad Nacional Agraria. Managua, Nc. 117 p.

MINISTERIO DE AGRICULTURA Y DESARROLLO RURAL. 2013. Estrategia de cooperación internacional del sector agropecuario 2013 2015, Colombia. En: https://www.minagricultura.gov.co/ministerio/Documents/Estrategia-de-Cooperacion-Internacional-del-Sector-Agropecuario-2013-2015.pdf. 34 p; consulta: agosto, 2014.

MINISTERIO DE AGRICULTURA Y DESARROLLO RURAL. 2013. PLAN NACIONAL DE DESARROLLO 2012-2015.Colombia. 35 p.

MINISTERIO DE EDUCACIÓN. 2010. Mecanismos de participación. Colombia. pp. 37-39.

MONTAGNINI, F. 1992. Sistemas Agroforestales. Principios y Aplicaciones en los Trópicos. San José, C.R. 622 p.

MORENO, J., ANDRADE, H., GARCÍA, J., HERNÁNDEZ, U., MAES- 
TRA, G. y LÓPEZ, G. 2014. Modelo de evaluación para valorar el cambio en las prácticas docentes con TIC. Revista UIS. Ingenierías, Vol. 13 (1). pp. 7-21.

MUÑOZ, E., NÚÑEZ, F. y OTÁLORA, C. 2007. Prototipo didáctico para la enseñanza de la Ingeniería Estructural. Revista de Ingeniería Vol. 17 (1), Enero - Julio. Universidad de Costa Rica. pp. 99-111.

MUÑOZ, J. y PORTILLA, L. 2005. Caracterización Morfológica de plantas de Chilacuán (Vasconcelle acundinamarcensis V.M. Badillo) en el municipio de Pasto, departamento de Nariño; Facultad de Ciencias Agrícolas, Universi-dad de Nariño, Colombia.

MUSÁLEM, S. 2001. Sistemas agrosilvopastoriles. Universidad Autónoma de Chapingo. División de Ciencias Forestales. 120p.

NAIR, P. 1985. Clasification of agroforestry systems. Agroforestry systems.3. pp. 97-128.

NAIR, P. 1993. An introduction to agroforestry. Kluwer Academic, Netherlands. pp. 3- 53.

NAIR, P. 1997. Agroforestería. Chapingo, México, Universidad Autónoma Chapingo. 543p.

NAIR, P; MUSCHLER, R. 1993. Agroforestry.En: Pancel, L (ed). Tropical Forestry Handbook. Heidelberg, Springer. 1097 p.

NAVIA, J. 2001. Comportamiento del maíz bajo un arreglo agroforestal en el Valle del Cauca. Revista de Ciencias Agrícolas - Universidad de Nariño. Vol. 18(1). pp.114-124.

ORGANIZACIÓN DE LAS NACIONES UNIDAS PARA LA ALIMENTACIÓN Y LA AGRICULTURA, (FAO). 2008. El Estado Mundial de la Agricultura y la Alimentación. Colección FAO: Agricultura No 27. Roma. 55 p.

- FAO. 2008. El estado mundial de la agricultura y la alimentación. Colección FAO: Agricultura No 27. Roma. 55 p. 
OSPINA, A. 2003. Agroforestería. Aportes conceptuales, metodológicos y prácticos para el estudio agroforestal. Santiago de Cali, Valle del Cauca. 238 p.

PADILLA, S. 1995. Manejo forestal andino. Proyecto FAO -Holanda "Desarrollo Forestal Participativo en los Andes”, E.P. Centro de Impresión. Ecuador. 297 p.

PAGES, J. 1994. La didáctica de las ciencias sociales, el currículum y la formación del profesorado. Signos Teoría y Práctica de la educación, año 5 -No. 13. pp. 38-51.

PALOMEQUE, F. 2009. Sistemas agroforestales. Secretaría de agricultura, desarrollo rural. Chiapas, MX. 29 p. Personalización en el Acceso a Contenidos Digitales. Universidad Politécnica de Madrid. Departamento de Ingeniería de Sistemas Telemáticos. 25 p.

PETERS, C., BALICK, M., KAHN, F. y ANDERSON, A. 1989. Oligarchic forests of economic plants in Amazonia: utilization and conservation of an important tropical resource. Conservation Biology 3. pp. 341-361.

PEZO, D. e IBRAHIM, M. 1999. Sistemas silvopastoriles. Módulo de enseñanza agroforestal no 2. 2 ed. Turrialba, CR, CATIE-GTZ. 275 p

PILATOU, V., MARINOPOULOS, D. y SOLOMONIDOU, C. 2010. Development of appropriate digital material to cope with primary School Students, conceptions about the greenhouse phenomenon and the way it affects the weather condictions of a region. International Journal of Learning. 17 (8). pp. 77-91.

PLAN DE DESARROLLO DEL MUNICIPIO DE PASTO 2012-2015. "Transformación productiva". Alcaldía de Pasto. Colombia. pp. 25 - 27.

PRESSMAN ROGER S. 2010. Ingeniería del Software. Un enfoque Práctico. University of Connecticut. $7^{\text {a }}$ edición, McGrawn-Hill, México, 773 p.

PRESSMAN, R. 2005. Ingeniería de Software. Un enfoque práctico. 6 ed. Estados Unidos. Mc Graw-Hill.110 p. 
RAINTREE, J. 1987. The state of the art of agroforestry diagnosis and desing. Agroforestry Systems (Holanda). 5. pp. 219-250.

RAMÍREZ, R. W. 2005. Manejo de Sistemas Agroforestales. 11 p.

RESTREPO, C; LONDOÑO, P; MONTOYA, O; RUBY, E. 2008. Guía para el facilitador (Serie Jornadas Educativas. La Cultura del Agua). Ministerio de Ambiente, Vivienda y Desarrollo Territorial. Vol. 6 (2). 62 p.

RIVAS, T. D. 2005. Sistemas Agroforestales 1. Uach. 8 p.

ROBEY, D. 2007. TIC y cambios organizativos. Edutecne. Oxford. 39 p.

RODRIGUEZ, Y. 2014. Interdisciplinariedad en la carrera de ingeniería agronómica: un enfoque desde la disciplina de física. Lat. am. j. phis. Educ. Vol. 8(1). pp. 218-223.

ROMERO, L., SALINAS, V. y MONTERA, F. 2010. Estilos de aprendizaje basados en el modelo de Kolb en la educación virtual. Revista Apertura; Vol 2 (1): Evaluación: Modelos y Metodología. Revisado el 8 de diciembre de 2014 en: http://www.udgvirtual.udg.mx/apertura/index.php/apertura3/article/view/21

RUIZ, D., URIBE, E. y PHILLIPS, C. 2005. Modelos estructurales: Gran in-centivo para aprender el comportamiento estructural. ACOFI, XXV Reunión de Facultades de Ingeniería. Cartagena.

SAARIKOSKI, L., SALOJÄRVI, S., DEL CORS, DANTE. y EMANUELA, O. 2001, "The 3DE: An environment for the development of learner-oriented customized educational packages". ITHET: revisado el 6 de diciembre de 2014, en: http://www.eecs.kumamoto-u.ac.jp/ITHET01/proceedings.htm

SANCHEZ, J. 1999. Construyendo y aprendiendo con el computador. Centro zonal Universidad de Chile, proyecto ENLACES/MECE. Santiago de Chile, 137 p.

SARES, O. 2010. Aplicación de estrategias metodológicas de enfoque constructivista en la motivación hacia el aprendizaje en los niños y niñas de 5 a 6 años d las escuelas Ing. Jorge Alex Serrano, Oscar Efrén Reyes, Luís Agui- 
lar Marín, CharbelBadul. Tesis de pregrado de licenciado en ciencias de la Educación. Facultad de Ciencias Sociales. Universidad Técnica de Machala. Ecuador. 158 p.

SECRETARÍA EDUCACIÓN MUNICIPAL DE PASTO. 2012. Plan de desarrollo educativo 2012-2015 "Educación con calidad y equidad para la transformación social". $127 \mathrm{p}$.

SENTANDREU, J. 2012. Adolescentes. Para la Formación Integral. Sti. Ganduxer. 1 ed. Barcelona. 36 p.

SKINNER, C. y GONZAS, M. 2007. Dimensiones espaciales de la realidad social. Eumedent. España. 86 p.

SOMARRIBA, E. 1990. ¿Qué es agroforestería? El Chasqui. Vol. 24. pp. 5-13.

SOMARRIBA, E. 1998. Diagnóstico y diseño agroforestal. Agroforestería en las Américas. Vol. 5 (17/18). pp. 68-72.

SOMARRIBA, E. 2009. Planificación agroforestal de fincas. Turrialba, Cos-ta Rica, CATIE. (Materiales de Enseñanza No. 49. Colección Módulos de Enseñanza Agroforestal No.6). 100 p.

SOMARRIBA, E. 2012. Definición de agroforestería. Producción de madera en sistemas agroforestales de Centroamérica. pp. 21-26.

TEJADA, L. 2009. Las salidas, un recurso para el aprendizaje en la educa-ción infantil. Revista digital innovación y experiencias educativas, No. 14, enero. Revisado el 4 de diciembre de 2014, en: http://www.csicsif.es/andalucia/modules/mod_ense/revista/pdf/Numero_14/LIDIA_TEJADA_1.pdf

TORQUEBIAU, E.1992. Are tropical agroforestry home gardens sustainable? Agr. Ecosyst. Environ. Vol. 41. pp. 189-207.

TRUJILLO, N. 2008. Silvopastoreo: árboles y ganado, una alternativa productiva. Forestal. Revista-MM. pp. 22-29.

VANDENBELT, R. 1990. Agroforestry in the semiarid tropics, in: Mac Dic- 
ken K.G., Vergara N.T. (eds.), Agroforestry Classification and Management, Wiley, New York.150-194 p.

VÉLEZ, G. y MORENO, F. 1993. Principios de Crónica forestal y del medio ambiente. Universidad Nacional de Colombia. Medellín.Vol.8. pp. 43-57.

VIGOTSKY, L. 2008. Pensamiento y Lenguaje (Teoría del desarrollo de las funciones psíquicas). México, Ediciones Quinto Sol. 191 p.

VILLAMIZAR, L. 2007. Estrategias de formación de profesores universitarios para el uso de las tecnologías de información y Comunicaciones (TIC) a partir del sistema de aprendizaje let me learn: dos estudios de caso. Tesis doctorado interuniversitario en tecnología educativa, Universidad Rovira I Virgili, Facultad de Ciencias de la Educación y psicología, departamento de Pedagogía. Terragona - España. 195 p

WORLD AGROFORESTRY CENTRE. 2011. Transformando vidas $y$ paisa-jes. Disclamer. CIFOR, CIAT, ICRAF. pp. 77-81. 



\section{GLOSARIO}

Agricultura minifundista: El minifundio es una pequeña extensión de terreno agrícola dedicado a la producción pero sólo para autoconsumo, con la mano de obra familiar.

Chaza: Es un juego tradicional, denominado hoy en día como deporte de raqueta, parecido al tenis, en donde se lanza una pelota, que es golpeada con la mano o una raqueta.

Сисипиbа: Es un juego tradicional que consiste en lanzar bolas a un tablero agujereado, con diferentes puntajes, siendo el de mayor valor el del centro. El tablero agujereado está soportado por dos tablas, en forma de ángulo; y se encuentra inclinado para facilitar el paso de las esferas.

Escondidas: también llamado escondecucas, escondidas, escardillas, escondidijo, escondido, esconder, escondedero, o escondiditas, es un juego popular que se juega mejor en zonas con potenciales puntos para ocultarse tales como un bosque, un parque, un jardín o una casa grande.

Juegos tradicionales: los juegos infantiles clásicos o tradicionales, que se realizan sin ayuda de juguetes tecnológicamente complejos, sino con el propio cuerpo o con recursos fácilmente disponibles en la naturaleza.

Lúdica: se refiere a todo aquello propio o relativo al juego, a la diversión, es decir, un juego de mesa, una salida con amigos a un parque de diversiones son todas actividades lúdicas.

Prueba: Las pruebas del Software son una función de la calidad, que tiene como objetivo principal detectar errores.

Sapo: es un juego de lanzamiento de precisión múltiple donde se intenta introducir un determinado número de fichas o discos de hierro en los múltiples agujeros que existen en la mesa de la rana. Algunos de ellos tienen obstáculos que dificultan la precisión del lanzamiento.

TIC: Tecnologías de la Información y la Comunicación. 
Trompo: Un trompo es un objeto que puede girar sobre una punta, sobre la que sitúa su centro gravitatorio de forma perpendicular al eje de giro, y se equilibra sobre un punto gracias a la velocidad angular, que permite el desarrollo del efecto giroscópico. 


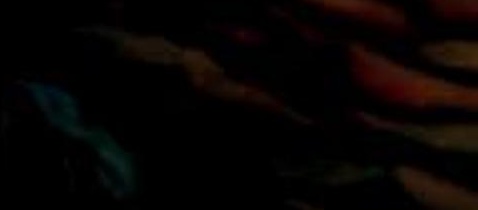

El autor - Hugo Ferney Leoncl es Ingeniero Forestal de la Universidad del Tolima con especialización en Ecologia con énfasis en Gestión Ambiental de la Universidad de Nariño: Magister en Planificación y Manejo Ambiental de Cuencas Hidrográticas de la Universidad del Tolima y Doctor en Ciencias Ambientales de la Universidad Autonoma de San Luis Potosí, México. Profesor investigador del Grupo de Investigación PIFIL, director del Departamento de Recursos Naturales y Sistemas Agroforestales de la Facultad de Ciencias Agricolas de la Universidad de Nariño, Pasto Colombia. Autor y coautor de diversas publicaciones nacionales e internacionales

La autora - Gloria Cristina Luna Cabrera es Ingeniera Agrónoma de la Universidad de Nariño con especialización en Gestión de Proyectos Ambientales; Magister en Educación Ambiental. Profesora investigadora y directora del Grupo de Investigación PIFIL del Departamento de Recursos Naturales y Sistemas Agroforestales de la Facultad de Ciencias Agricolas de la Universidad de Nariño. Autora y coautora de diversas publicaciones nacionales e internacionales.

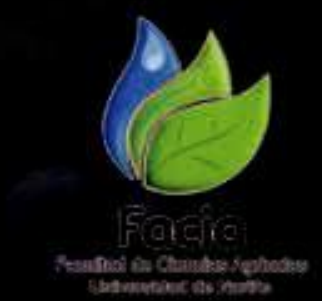

Ehanwarces ins:

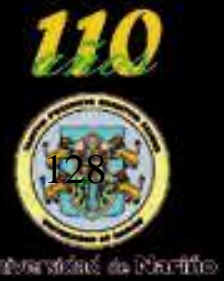

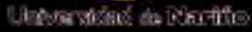

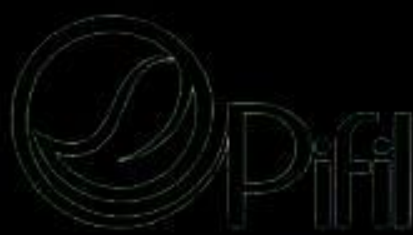

